\title{
WestVirginiaUniversity
}

THE RESEARCH REPOSITORY @ WVU

Graduate Theses, Dissertations, and Problem Reports

2018

\section{Examining the Process of Shared Use through Community-School Partnerships}

\author{
Brooke C Towner
}

Follow this and additional works at: https://researchrepository.wvu.edu/etd

\section{Recommended Citation}

Towner, Brooke C, "Examining the Process of Shared Use through Community-School Partnerships" (2018). Graduate Theses, Dissertations, and Problem Reports. 7296.

https://researchrepository.wvu.edu/etd/7296

This Dissertation is protected by copyright and/or related rights. It has been brought to you by the The Research Repository @ WVU with permission from the rights-holder(s). You are free to use this Dissertation in any way that is permitted by the copyright and related rights legislation that applies to your use. For other uses you must obtain permission from the rights-holder(s) directly, unless additional rights are indicated by a Creative Commons license in the record and/ or on the work itself. This Dissertation has been accepted for inclusion in WVU Graduate Theses, Dissertations, and Problem Reports collection by an authorized administrator of The Research Repository @ WVU.

For more information, please contact researchrepository@mail.wvu.edu. 
Examining the Process of Shared Use through Community-School Partnerships

\author{
Brooke C. Towner, M.S.
}

\author{
Dissertation submitted \\ to the College of Physical Activity and Sport Sciences \\ at West Virginia University \\ in partial fulfillment of the requirements for the degree of \\ Doctorate of Philosophy in \\ Kinesiology
}

Eloise Elliott, Ph.D., Chair

Sean Bulger, Ed.D.

Thomas Bias, Ph.D.

H. William Kohl, Ph.D.

Department of Coaching and Teaching Studies

\author{
Morgantown, West Virginia \\ 2018
}

Keywords: partnerships, physical activity, policy, public health, shared use Copyright 2018 Brooke C. Towner 


\section{ABSTRACT \\ Examining the Process of Shared Use through Community-School Partnerships}

Brooke C. Towner, MS

Background/Purpose: Research suggests physical activity policy is emerging as an avenue to target physical activity behaviors. While government and state organizations have identified shared use as a specific policy strategy to increase community access to recreational physical activity opportunities, few studies have examined the shared use process and the partnerships at the policy and environmental levels within the local context. The purpose of this study was to examine the influential factors of shared use initiatives and the role of the community-school partnership during the shared use process. In addition, this study seeks to provide recommendations for the development and implementation of shared use initiatives. Methods: A multiple case study method was utilized. Three schools served as the cases investigated. Seven interviews were conducted with a combined total of nine participants which included school administration, key partners, and a shared use expert. Data were analyzed first using thematic analysis deductively across the Contextual Interaction Theory constructs and Social Ecological Model policy and environmental levels, and then inductively to allow subthemes to emerge. Results: Cross-case analysis revealed subthemes within the theoretical constructs and levels: (1) coordinated communication, (2) partnerships, (3) personal commitment, (4) funding, (5) increased assets, (6) community ownership, and (6) opportunity. Conclusion: The findings suggest consideration should be given to policy dissemination and education for school administration as well as the school shared use community. Multifaceted partnerships are needed to implement a robust shared use initiative, enhance the physical environment, and foster a sense of community within the social environment 


\section{Dedication}

This manuscript is dedicated to my husband, Byron. We did it. Truly, we did it! You have been my ultimate support and encourager. Words cannot express my gratitude for the sacrifices you have made and the challenges you have overcome during this journey. As we have grown together throughout this process, I am sure together we can make a difference as we take our next steps. 


\section{Acknowledgements}

To the participants of my cases, whose experiences where shared passionately and served as the heart of this study, my sincere thanks. I will be forever grateful.

To Dr. Eloise Elliott, my dissertation chair, for your unwavering support, both professionally and personally, I am incredibly grateful. You have been an inspiration and I am so appreciative of this time we have been able to work together. To the members of my committee, thank you: Dr. Sean Bulger for your professional guidance and insight. Dr. Thomas Bias for your encouragement, willingness to be a sounding board, and asking those challenging questions. Dr. Harold W. Kohl for venturing over into the PETE world and your valuable advice.

I also want to acknowledge my family and friends for their support. To my son, Brennan, your smile and laugh reminded to me to live in the moment. May this document be a reminder there is a payoff for hard work and perseverance. Set your mind to and achieve it. You can do all things through God who strengthens you. To my mother, Robin Cutright, whose encouragement was endless through during this season in my life. You have taught me to live by faith. I am strong because of you! To Audra Manriquez and Kaitlyn Tisler, for the best "You Got This" speeches in the world. Your encouragement always came at exactly the right time. To my colleagues and friends at West Virginia University, Hannah Kipfer, Cory Breithoff, Adam Keath, Robert Posehn, Tyler Goad, and Karl Zang, it has truly been a pleasure. Thank you for the laughs, the distractions, and for making this time a valuable and rewarding experience. 


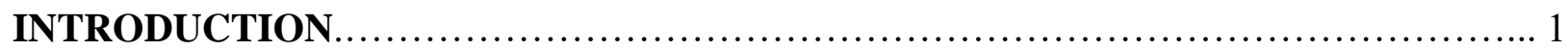

Definition of Terms....................................................... 6

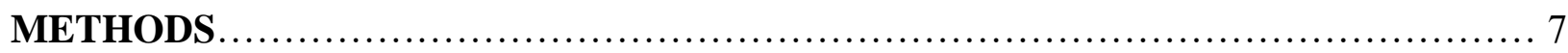

Multiple Case Study Research Design........................................ 7

Participants and Sampling.............................................. 8

Data Collection Procedures................................................ 11

Data Analysis.......................................................... 13

Basic Assumptions...................................................... 16

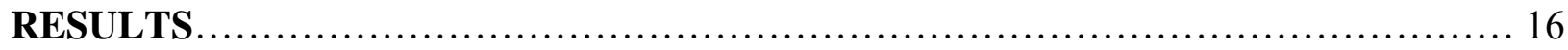

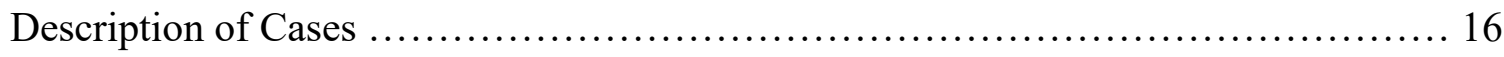

Theoretical Constructs Case by Case ....................................... 20

Cross-Case Analysis .................................................. 34

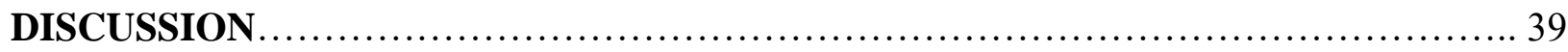

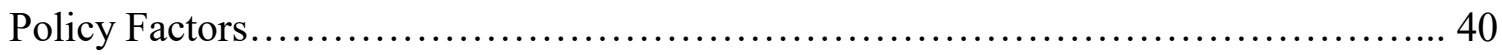

Environmental Factors................................................ 43

Contributions.............................................................. 46

RECOMMENDATIONS ................................................... 47

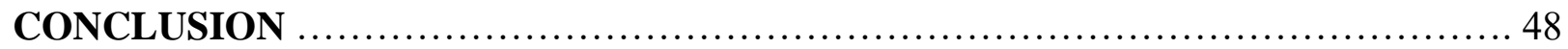

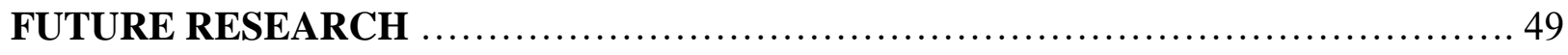

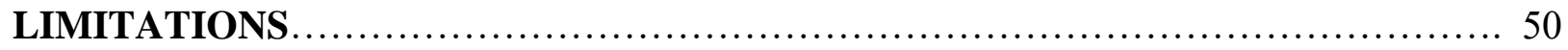

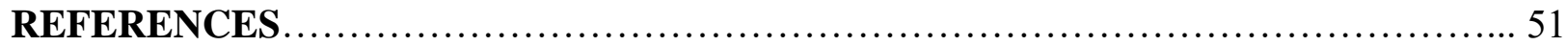




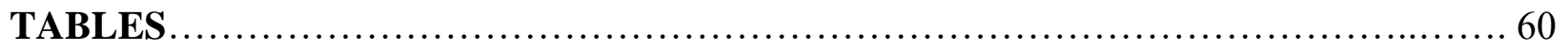

Table 1: Demographics by School.............................................. 60

Table 2: Shared Use Agreement and Facilities Audit by School...................... 61

Table 3: Partnership Information by School................................. 62

Table 4: Definition of Theoretical Constructs.................................. 63

Table 5: Summary of Emergent Sub-themes for Information...................... 64

Table 6: Summary of Emergent Sub-themes for Interaction...................... 65

Table 7: Summary of Emergent Sub-themes for Motivation...................... 66

Table 8: Summary of Emergent Sub-themes for Power.......................... 67

Table 9: Summary of Emergent Sub-themes for Environment................... 68

Table 10: Summary of Emergent Sub-themes for Policy ........................ 69

Table 11: Summary of the Cross-case Analysis................................. 70 


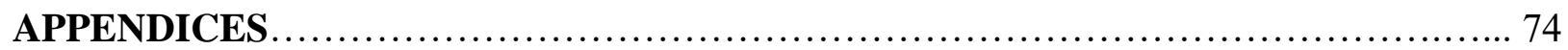

APPENDIX A: Shared Use Agreement Items and Descriptions..................... 74

APPENDIX B: Expert Panel Emails....................................... 77

APPENDIX C: Expert Panel Informed Consent............................... 79

APPENDIX D: Expert Panel Nomination Form.............................. 81

APPENDIX E: Principal Emails.......................................... 84

APPENDIX F: Principal Informed Consent.................................. 86

APPENDIX G: Principal Information Form................................ 88

APPENDIX H: Community-School Partnership Emails................................ 91

APPENDIX I: Community-School Partnership Informed Consent.................. 92

APPENDIX J: Expert Panel Interview Protocol................................... 94

APPENDIX K: Principal Interview Protocol...................................... 96

APPENDIX L: Focus Group Protocol...................................... 100

APPENDIX M: Codes to Themes Analysis from Saldana......................... 103

APPENDIX N: Case Study Procedure from Yin.............................. 104

APPENDIX O: Extended Literature Review................................. 105 


\section{Introduction}

In 2008 the U.S. Department of Health and Human Services released the Physical Activity Guidelines for Americans. The recommendations include 60 minutes of daily physical activity for children and adolescents and at least 150 minutes of moderate-intensity physical activity for adults to achieve substantial health benefits. These health benefits include decreases

in heart disease, Type II diabetes, hypertension, hyperlipidemia, weight gain and obesity, as well as increases in general well-being, and can be realized by adhering to the current guidelines (Haskell, Lee, Pate, Powell, \& Blair, 2007; Reiner, Niermann, Jekauc, \& Woll, 2013; World Health Organization [WHO], 2010).

However, the majority of Americans do not regularly participate in physical activity at a frequency high enough to achieve these health benefits (Troiano et al., 2008). When looking at state rankings concerning major health indicators like physical activity, West Virginia is found in the bottom quartile of the 50 states. In West Virginia, less than $15 \%$ of adults are meeting the current 2008 Physical Activity Guidelines for Americans (U.S. Department of Health and Human Service [USHHS], 2011). According to the State Indicator Report on Physical Activity, 13\% of West Virginia youth are reporting no physical activity, and only $31 \%$ met the PA guidelines (Center for Disease Control and Prevention [CDC], 2014). Blair (2009) addresses physical inactivity as a major public health concern of today and calls for more attention to be directed at increasing the amount of regular physical activity.

To target physical activity, consideration must be given to the interplay between the social, environmental, and political systems within the context of the local community setting (American Dietetic Association [ADA], 2006; Haggis, Sims-Gould, Winters, Gutteridge, \& McKay, 2013; Tucker et al., 2011; Woods \& Mutrie, 2012). Coupling community-based 
programs with school-based programs can provide continuity and have greater potential to increase the amount of physical activity (Bryant et al., 2010). Multi-level strategies implemented to increase physical activity include receiving continuous implementation help and supportive policies at the state, regional and local levels (Mâsse, McKay, Valente, Brant, \& Naylor, 2012). Community engagement supports the social aspect of physical activity. One way to foster community enagement to is encourage members to take advantage of opportunties to be active within the community (Haggis et al., 2013; Huberty, Balluff, O’Dell, \& Peterson, 2010; Mâsse et al., 2012). Shared use agreements (SUA) between schools and communities allow community access to school recreational facilities (i.e. a playground or track) after operating hours. Creating a SUA between the school and a community organization to increase access to physical activity opportunities for students, family, and community members has proven effective at increasing physical activity (Bassett et al., 2013; Burbage, Gonzalez, Dunning, Simon, \& Kuo, 2014; Choy, McGurk, Tamashiro, Nett, \& Maddock, 2008; Kanters, Bocarro, Filardo, Edwards, Mckenze, \& Floyd, 2014).

To impact population level change relying on individualized strategies (i.e. education and treatment programs) is not a sustainable model. Individual strategies are time intensive and cost ineffective as the purpose is to change behavior one person at a time (Brownson et al., 2008). Public health approaches focusing on the complex interactions that involve multiple sectors (i.e. business, education, public health) of a community provide a comprehensive approach to create population level change in physical activity (Kohl et al., 2012). Initiating environmental change has the potential to allow more physical activity opportunities to be available, and therefore, the possibility of a healthier population (Sacks et al., 2008). However, if policy processes supporting environmental change are not implemented appropriately the desired outcome is not attained 
(Rütten, Abu-Omar, Gelius, Dinan-Young, Frandin, Hopmen-Rock, \& Young, 2012).

Community-school partnerships show promise in aiding the development and implementation of policy processes within the local setting (Lucidarme, Marlier, Cardon, De Bourdeaudhuij, \& Willem, 2014). Establishing a SUA is a policy initiative with the potential to impact population level physical activity behavior change.

The West Virginia legislature passed the Shared Use Limited Liability Protection for Schools Bill (WV Senate Bill 238 - herein referred to as the Shared Use bill) in 2015 in efforts to increase access to more physical activity opportunities and improve population physical activity levels through a community context. The Shared Use bill removes liability from the school when the school allows organizations and the community to use their gymnasiums, playgrounds, outdoor tracks, and other recreational facilities. SUAs have the potential to impact physical activity in communities by establishing mutually beneficial partnerships (Burbage et al., 2014; Carlton et al., 2016; Haggis et al., 2013; Jones \& Wendel, 2015; Tucker et al., 2011). Creating a SUA between the school and community increases access to physical activity opportunities for community members (Choy et al., 2008; Gutin, Yin, Johnson, \& Barbeau, 2008; Kanters et al., 2014; Mâsse et al., 2012).

Opportunities available for physical activity are determined by how an environment is desgined. (Hansen, Meyer, \& Lenardson, 2015). The physical environment is associated with design and use of the specific space. The school physical environment is typically designed for multiple purposes, including recreation and physical activity. Community-based programs built on the existing public school infrastructure, like tracks and gymnasiums, have the ability, if made available, to increase access to physical activity opportunities and become a sustainable physical activity option for the surrounding community (Haggis et al., 2013; Kristjansson, Elliott, Bulger, 
Jones, Taliaferro, \& Neal, 2015; Yin et al., 2005). Spengler, Young, \& Linton (2007) also noted the cost sharing advantage of using schools' physical environment (i.e. schools' existing recreation facilities) for community use.

Multi-level involvement is required for the development and implementation of a SUA. Previous research suggests using a social ecological framework to examine multi-factorial relationships across sectors (i.e. education, community) to address the "interaction and interdependency between individuals, multiple setting (i.e. home, school) and levels (i.e. local, government, family) that influence behavior" (Haggis et al., 2013, p. 894). Focusing on the community-school partnership involved in a shared use initiative is a key piece to the process. Partnerships with stakeholders are built when forces are united to identify the problem and determine the best path of action for that particular community. How community-school partnerships are formed and work together to achieve a shared goal will drive the creation and use of a SUA.

In a community-school partnership the theoretical constructs affecting collaborative implementation are different from traditional policy implementation (Koontz \& Newig, 2014). The Social Ecological Model (SEM) as the framework represents the interdependence between the policy and environmental (i.e., physical and social) levels. Each level must offer supportive conditions to achieve the desired outcome of the initiative (Green, Richard, \& Potvin, 1996; Stokols, 1996). Layering the SEM with the Contextual Interaction Theory (CIT) offers a deductive, social process approach that considers several contextual constructs and the interaction between the implementers and the target population (O'Toole, 2004). CIT distinguishes four core constructs that jointly contribute to the implementation of policy like a SUA: motivation, information, power, and interaction (Spratt, 2009). Haggis et al. (2013) 
recommended narrowing the focus to a few levels and utilizing relationships within those levels to target a desired outcome. The use of the SEM coupled with the CIT allows for the examination of the interplay of several constructs unique to the collaborative implementation of an shared use initiative across multiple levels of policy, and the physical and social environments.

Given the importance of increasing access to physical activity opportunities within communities, there is limited research on best practices available on how to form, implement and sustain a shared use initiative through a community-school partnership. Previous research has examined shared use characteristics in U.S. school districts (Jones \& Wendel, 2015; Kanters, Bocarro, Moore, Floyd, \& Carlton, 2014; Omura, Carlson, Paul, Sliwa, Onufrak, \& Fulton, 2016). Barriers and facilitators to the shared use process have been identified (Burbage et al., 2014; Spengler, Connaughton, \& Maddock, 2011; Testa, 2000). Evaluation measures have analyzed physical activity levels as a result of shared use policy implementation (Carlton et al., 2016; Schultz, Wilhelm Stanis, Sayers, Thombs, \& Thomas, 2016). A few case studies have been conducted to examine the process of the shared use within the community context (Choy et al., 2008; Cooper \& Vincent, 2008). This study will build on the previous research by exploring the how and why of shared use implementation and the partnerships that initiate and sustain the shared use initiative.

The purpose of this study was to a) examine local-level characteristics of communityschool partnerships to develop and implement SUAs in West Virginia public schools and b) generate practical recommendations for creating formal SUAs for school administrators and community organization leaders. The research questions guiding this study are: a) How does the 
community-school partnership influence the development and implementation of a SUA? and b)

What are the influential factors of a SUA?

\section{Definition of Terms}

1. Environment - A broad term to encompass the physical and social factors that are affected by public policy.

2. Expert - is an individual who possess the knowledge and experience to participate in the selection of the shared use cases. For this study, the panel will consist of the physical education coordinators and members from public health or physical activity organizations. The experts have been in contact with shared use schools and supported shared use in West Virginia.

3. Case Study - is a research method that "investigates a contemporary phenomenon (the “case") in its real-world context" (Yin, 2014, p. 2).

4. Policy - is a statement of legislative, regulatory, or policy decision-making action that provides an organizing structure or guidance for collective and individual behavior (Schmid, Pratt, \& Witmer, 2006).

5. Shared Use - refers to the "opening of public buildings and grounds at times they are usually closed in order for community residents to exercise and engage in other recreational activities" (Downer et al., 2016, p. 2).

6. Shared Use Agreement (SUA) - is a formal "written contract that lays out the responsibilities of all the parties involved in the initiative" (Downer et al., 2016, p. 25). 


\section{Methods}

\section{Multiple Case Study Research Design}

To address the call for shared use case study research, this study utilized a qualitative multi-case study approach to examine the local-level factors involved in implementing a shared use initiative. A multi-case study research process (plan, design, prepare, collect, analyze, and share) outlined by Yin (2014) was used to guide this study. Yin's process begins with the planning phase where reviewing the relevant literature serves as a guide to construct the research line of inquiry. In the design phase the case is defined through criteria and theoretical propositions are identified. The propositions used for this study were the policy and environmental levels within the SEM and the four constructs of the CIT (information, interaction, motivation, and power). Additionally, case study tactics were identified to maintain validity and reliability. The aim of the design phase was to create a cohesive design that aligns the research questions with the CIT constructs and SEM levels. In the preparation phase the case study protocol was developed and approval granted from the Institutional Review Board. During the collection phase, a comprehensive database for the case study was created, data was triangulated from different sources, and a chain of evidence was maintained. The next phase was analysis. When analyzing the data, the researcher watched for patterns and themes that converged, addressed divergent explanations, and attempted to display the data in different ways. Written, visuals and oral materials were preliminarily drafted during data analysis Sharing the conclusions of the case study was the final phase. In the final phase, the audience was defined, and the case study report was finalized. For this study, three cases were chosen to reduce the risk of losing attributes to the individual cases (Creswell, 1998). Permission was received from West Virginia University’s Institutional Review Board (IRB) to conduct the study. 


\section{Participants and Sampling}

For this study, the participants were expert panelists, school principals, and communityschool partners. The expert panelists were representatives from state education departments, state public health organizations, and state physical activity organizations who have helped WV schools develop and implement SUAs. The three expert panelists were knowledgeable and able to identify West Virginia public schools where share use has been implemented. From a range of geographical locations, the schools selected represent the cases for this study. From the three selected schools, the principals who participated currently engaged in shared use with their community. One or two key partners from each school participated in the study representing a variety of societal sectors (i.e., education, non-profit/volunteer, and parks and recreation). Each key partner participated in or utilized the shared used process at their school.

Expert Panel. The expert panel selection process outlined by Butt (1993) and Testa (2000) was used to identify appropriate participants for the study. After approval was received from the IRB, three representatives from West Virginia organizations were asked to participate in the expert panel. Panel members were first contacted with a brief email introducing the study, describing the reason they are being contacted, and requesting a time to contact them to discuss the study further (Appendix B). Following the introductory email, a phone call was made to discuss the study goals and ask for their participation in identifying school principals who have played a central part in creating a shared use initiative for their school and community. With their verbal consent to participate, panel members were then sent a follow-up email with the nomination procedure and form, selection criteria, and a cover letter outlining participation in the research study (Appendix B and C). 
Expert panelist used criterion-based sampling to nominate principals who have collaborated within a partnership to create and implement shared use for their community. For criterion-based sampling a list of essential characteristics was used to guide the panel members in the nomination process (Merriam, 2009). The expert panelists nominated principals who matched the list so information-rich cases were identified (Merriam, 2009). The nomination form included the following criteria: a) a shared use initiative is in place at the principal's school, b) the shared use initiative is actively in use, c) key partners assisted with the shared use process or utilized shared use at the school, and d) based on the expert panel members knowledge of the nominee, the principal was a rich, knowledgeable source of information (Appendix D). Panel members were asked to complete and return the consent and nomination forms to the researcher via email within 10 days. Expert panelists were contacted for a brief, 10 - 15 minute phone interview to discuss their experience with shared use.

Principal Selection. Nominated principals were first contacted with an introductory email that provided a brief overview of the study, why they were contacted and a request for a good time to call them to discuss the study further. If the expert panelists agreed, they were copied on the introductory email to the principal they nominated. Within three days, a phone call was then made to each principal who received a nominated. During the call each principal was informed he or she had been nominated by a WV expert in shared use as playing an essential role in the development of a shared use initiative within their school and community. The principal was invited to participate in this research study to explore the shared use process and the role of community-school partnerships. The three cases were selected through convenience sampling based on principal's agreement to participate in the research study. The three principals were asked to schedule a 30-60 minute in-person interview, provide SUA documentation, and 
nominate at least one key partner in the shared use process for their school through network sampling (Krueger \& Casey, 2009). Network sampling is used when key participants matching the established criteria are asked to refer the researcher to other participants (Merriam, 2009; Testa, 2000).

A follow-up e-mail was sent to each of the three selected principals immediately after the phone conversation which included: a) a note of thanks for agreeing to participate in the study, b) the research study purpose statement, c) cover letter, d) a request for the SUA documentation, and e) a principal information form that includes the identification of at least two communityschool partnership members (Appendix E, F and G). The principals were asked to identify a day and time for a face-to-face interview with the researcher. The exact date and time of the interview was determined over the phone or e-mail with the principal or designated scheduler. The principals were asked to complete and return the principal information form and SUA documents to the researcher via email within 10 days.

Key Partner Selection: Identified key partners were first contacted with an introductory email, then by phone, and then sent a follow-up email. The introductory email informed the partnership member about their nomination by the principal, provided the purpose of the study, and asked for a time that would work for them to discuss the study over the phone. If the principals agreed, they were copied on the introductory email to their community-school partnership members. After the phone call with the key partner, a follow-up e-mail was sent that included: a) a thank you for their interest in participating in the study, b) a brief written description of the research study, and c) the cover letter (Appendix $\mathrm{H}$ and I). An interview day and time was scheduled with key partners over the phone or e-mail. An interview reminder email was sent the day prior to the scheduled date. 


\section{Data Collection Procedures}

Yin (2014) suggests case study research provides an opportunity to investigate a realworld case but must rely on the use of multiple sources of evidence to support contextual understanding. To adequately explore the impact of community-school partnerships on the shared use process and the important factors of shared use, data were collected concerning perceptions of individuals involved and relevant SUA documents. To address the research questions regarding a) how community-school partnerships influence development and implementation of shared use and b) the influential factors of shared use, data collection included interviews, school facilities audit, and shared use document analysis.

Expert Interviews. A semi-structured phone interviews was conducted with one expert from the panel. The interview lasted 30 minutes. The expert panelist received the interview questions prior to participating in the interview (Appendix J). At the start of the interview, the purpose of the study and the interview procedures were communicated. Informed consent was obtained prior to conducting the interview. The interview was audio recorded. The objectives of the interview were to a) investigate the panelists experience with shared use, b) address real and perceived barriers to implementation of shared use, and c) explore the influence of communityschool partnerships in the shared use process. During the interview, the standard guide was used, and follow-up questions were asked as needed for clarification.

Principal Interviews. Semi-structured interviews lasting 30-60 minutes were conducted with three school principals. Principals were sent the interview questions prior to the interview (Appendix K). Informed consent was obtained prior to the interview. At the beginning of the interview, the purpose and process of the interview was explained. The interviews were carried out at each school. The interviews were audio recorded. 
The objectives of the interviews were to a) explore the shared use process, b) examine how collaborative relationships between schools and the community were established and sustained, and c) investigate characteristics involved in creating a shared use initiative. Using Spickard's (2005) outline for constructing interview guides, the research questions central to the study were broken down into smaller theory-based questions (TQ). TQ connecting the SEM and the CIT were developed to inform the research questions. The TQ were then operationalized further into more easily understandable and answerable interview questions (IQ). The standard interview guide created was followed for each interview, and additional questions were asked as needed for clarification.

Key Partner Interviews. A dual or single partner interview was conducted with at least one key partner from each school. At the start of the interview, the researcher explained the purpose of the study, and addressed the use of audio recording. Key partner interviews lasted 30 - 60 minutes. A semi-structured interview protocol developed using Spickard's (2005) method was used to guide the discussion (Appendix L). Clarifying questions were asked as needed. Additional observations or thoughts were documented immediately after the interview concluded.

Documents and Facilities Audit. In addition to the interviews, the formal SUA and any other shared use documentation that would highlight the shared use process were requested from the principal. The request was made to the principals for any shared used documents to be sent to the researcher within 10 days of receiving the follow-up email. Additional documentation included but was not limited to policy statements, facility planning descriptions, promotional material, and district and school mission statements. Also, based on the principal information sheet and the facilities listed as available for shared use, a school facilities audit was performed. 


\section{Data Analysis}

After the completion of interviews, the researcher transcribed the audio recordings, and reviewed any field notes. Braun and Clarke's (2006) method for thematic analysis was used to identify, analyze and report data themes and patterns. Following Yin's (2014) case study procedure to ensure cohesiveness, the researcher moved forward and backward as the analysis developed over time across sources and methods.

Phases of Coding. The thematic analysis occurred over the six phases outlined by Braun and Clarke (2006). In the first phase, the researcher became familiar with the data through transcription, repeated readings of the data, and actively searching for meaning and patterns. Notes were taken during this phase as ideas for coding developed. In the second phase, first a deductive coding process occurred using the two levels of the SEM (policy and environment) and the four constructs of the CIT (motivation, knowledge, capacity/power, and interaction). Following the deductive theory-based coding process, a generic inductive coding method combining attribute, structural, descriptive and in vivo coding was used to allow for flexibility and development of substantive discoveries (Saldana, 2016). NVivo software was used to catalog the coding process. The third phase involved arranging full sets of codes into broader, potential categories (i.e., a code map) to begin to bring meaning, structure, and order to the data (Anfara, 2008) (Appendix M). The categories were condensed further to produce a collection of potential themes. During the fourth phase, the potential themes were reviewed to ensure themes reflect a coherent pattern, and the mapping process was extended out to include a thematic level. The accurate reflection of the data as a whole was considered by reviewing the selected themes (Braun \& Clarke, 2006). In phase five the themes were named and defined by considering the stand-alone themes and the themes in relation to one another. Lastly, a report was written that 
"provides a concise, coherent, logical, non-repetitive, and interesting account of the story the data tell - within and across themes" (Braun \& Clarke, 2006, p. 23). As suggested by Yin (2014) the phases of coding outlined occurred across the data in each case to produce individual case summaries and then the data was used as whole to produce a cross-case report (Appendix N).

Reliability and Validation Strategies. Within qualitative research, reliability and validity of the evidence must be established to provide useable insight and conclusions (Merriam, 2009). To maintain reliability and validity for this study, the researcher selected the use of various case study tactics.

Case Study Database. The main purpose of developing a case study database was that the data remains in a retrievable form. The database was organized, and consisted of field notes, case study documents, and any new narrative document the researcher created during the analysis phase. The creation of a case study database increased the reliability of a study as other persons could access the entire data set apart from the written case report (Merriam, 2009; Yin, 2014). Maintaining a case study database provided a clear record of the multiple case studies. For the purposes of this study a folder was maintained that included the raw data free of any data analysis or narratives for the case study report. The raw data in this folder was organized by source, and date obtained. The raw data folder was maintained for the examination of the data collected free of the researcher's interpretations. A separate folder contained the analysis and narrative report documents.

Triangulation. Triangulation of data sources involved using multiple sources to collect evidence. The goal of triangulation was to increase the strength of the findings of this study. Through the utilization of multiple sources, converging lines of inquiry emerged thus creating more convincing and accurate findings. Triangulation increased construct validity by analyzing 
the data sources collectively (Yin, 2014). The data sources that were used in the triangulation of evidence in this study were field notes, documents, and semi-structured interviews. Triangulation occurred within each case across all data sources to allow for consistencies and inconsistences to emerge. For the cross-case analysis, each data source was examined as a group (i.e. interviews) and collectively as a unit (i.e. single case report).

Peer Examination. Feedback was received from a knowledgeable source about coding, preliminary case summaries, memos during analysis, and the multi-case drafts to enhance the reliability of the study. The purpose of peer examination was to "assess whether the findings are plausible based on the data" (Merriam, 2009, p. 220). Meetings were set up with a second researcher (i.e., committee member) to discuss the analysis as codes form, themes emerge, and the cases began to take shape. Notes were taken during these meetings and the necessary modifications made.

Reflexivity. A characteristic true of qualitative research is that "the researcher is the primary instrument for data collection and analysis" (Merriam, 2009, p. 15). The researcher is a co-constructor of meaning within the case. As a researcher, I acknowledge my previous experience and bias through reflective and analytical memos, written before and after data collection, and during the analysis to help achieve transparency in my role. I address the experience and bias I bring into this research process as a) a general understanding of shared use, policy, and community-school based partnerships, b) a critical lens about the importance of community-school partnerships to the implementation of shared use initiatives, and 3) a desire to clarify the contribution of community-school partnerships to shared use in order to better equip school districts, schools, and communities to gain increased access to physical activity opportunities. 


\section{Basic Assumptions}

1. The use of expert panel members requires members to have some expert level knowledge of shared use in West Virginia public schools.

2. The inclusion criteria for case selection is appropriate and assures all the participants have experience with the shared use process.

3. The participants will honestly answer the interview questions.

\section{Results}

Each school selected represents a case. Participants across all cases included three school administrators, one to two key partners from each school for a total of five partners, and one shared use expert. All nine participants reported experience as an implementer or user of shared use policy. The findings are presented case by case starting with a description of each school, a depiction of theoretical constructs, levels and sub-themes, and then followed by a cross-case analysis. The data are interpreted by participant $(\mathrm{P})$ summaries to create the case and through direct quotes where the interview (I) and line number (L) of the transcription data are identified. For example. P1-I1-L15 translates to participant one, interview one, and line number 15 in the interview transcription.

\section{Description of Cases}

Case 1: School A. School A is located in a rural setting in the Northern Panhandle region of West Virginia with a city population of 931. School A is a combined middle and high school from grades seven to twelve with a modest student enrollment of 325 . The principal has been in the administrative position for 12 years (see Table 1).

School A was newly built in 2012, and the school is equipped with well-maintained recreational facilities and equipment. The facilities available for community use include two full- 
size gymnasiums, two weight room areas, an exergaming room, indoor walking track, and ball fields. The shared use initiative for unorganized activity (i.e., use of playground, track, ball fields) is staffed with a full-time position whose contract includes coverage for the shared use initiative. The recreational facilities are open during the weekdays from 4 p.m. to 7 p.m., and again on the weekends, given there are no previously scheduled school-sanctioned events (i.e., basketball games, wrestling tournament, etc.; see Table 2). With a signed user agreement, community organizations are able to use School A's recreational facilities for organized activities (i.e., supervised programming, league play).

As one of the first adopters to formalize a shared use agreement in WV, School A is one of the champion examples of shared use between the school and community (P2). However, the origins of when shared use started at School A are unclear as it happened overtime informally. In describing the start of shared use at the school, the principal commented:

"Shared use is something we have always done, we just never had a name for it before or a piece of paper that said what it was" (P1-I1-L81).

A more explicit path can be traced to how shared use became formalized at School A. Upon receiving a two-year CDC Community Transformation grant in 2011 through the Be Healthy Now Community Initiative started by the Northern West Virginia Rural Health Education Center, School A begin a school exergaming program. One of the requirements of the grant was that the exergaming program had to be open to the community.

"We started our exergaming program at our old school. We wanted to wait till we got here [to the new school], but we got a grant. The grant wouldn't wait, so we had to start the program at our old school and the people - the community just came in. We had no 
agreement with anybody. Anyways, we just let them use it because we've always had open gyms on the weekends and stuff." (P1-I1-L2).

Upon moving to the new building in 2012, School A received a state-level grant. The grant provided a grant administrator to walk the principal and critical school faculty through the process of creating a formal shared use agreement. The grant administrator also attended meetings with the superintendent and school board to explain shared use and to be an educational resource. In 2014 a formalized SUA was created between School A, West Virginia University, and the Northern West Virginia Rural Health Education Center. The community primarily learns about the shared use opportunities at the school through word of mouth (see Table 3).

Case 2: School B. School B is located in an urban cluster with a city population of 49,968 in the Metro Valley region of West Virginia. School B is a traditional high school which includes grades nine to twelve. The student enrollment is 1,700 . The assistant principal in charge of facilities has been in the administrative role for 4 years (see Table 1).

The school's outdoor recreational facilities have always been open for shared use. Outdoor facilities available for unorganized community use are the outdoor track, tennis courts, and ball fields. In 2015, a new running trail was built covering three miles around the wooded perimeter of the school campus. The trail added to the facilities available for informal shared use at School B. Additionally, the gymnasium, and outdoor ball fields are available for organized use but require a user agreement between the school and the organization and proof of insurance (see Table 2).

Since the school was built 21 years ago, shared use has always been informally in place with the outdoor recreational spaces. In 2016 at the ribbon-cutting ceremony for the newly constructed running trail, school administrators first learned their school was considered a shared 
use facility. A representative from the school board awarded the school administration a red sign that stated they were a shared use school. Additionally, at the county level, there was an attempt to formalize share use as it was a topic of discussion at a county school wellness meeting. The principal described the meeting events:

"Now, in a wellness meeting about a year ago, I remember this being discussed. And, the policies or the agreements were being done at the board office, and the point of contact for that, I heard was a guy that moved on to another county. So, it has never really been delivered to us, and it hasn't been given to me. And, it would probably be given to me, because I'm the facilities guy here. As I said, it is just very informal” (P4-I3-L89). The availability of the facilities for community use continues to be publicized through School B's social media outlets (see Table 3).

Case 3: School C. School C is in the Northern Panhandle of West Virginia with a population of 28,157 . At its current location, School C was built in 1975 . School C is one of the ten elementary schools in the county and is in an affluent area of the city. The prekindergarten to fifth grade student enrollment is 503. The principal has been in the administrative position for two years (see Table 1).

Informal shared use for unorganized physical activity has always been in place at School C. The playground gates are unlocked for community use from the end of the school day to the start of the next school day. During the evenings the community has access to the flat outdoor play area. At the beginning of the school year in 2017, the play area was resurfaced, fencing was replaced, and basketball hoops were added to encourage enhanced use (see Table 2). Shared use also takes place through organized activities. Community organization must enter into a user agreement with School C and provide proof of insurance. 
Formalization of shared use at School C started with the principal approaching the parent-teacher organization with the recently passed WV shared use bill and a call for fundraising to build a playground that would serve the children during the school day and the community outside of school hours. Newly appointed district and county administration along with the new city mayor and council members were approached by the principal and key partners at the beginning of 2017. Numerous meetings took place to build capacity and created a collective vision for shared use across all school and community spaces throughout the city and county. A key partner addresses the community-school vision for shared use during the early partnership meetings:

"We were all there together trying just to initiate that conversation, you know, that we wanted to make this a community playground. He [the parks and recreation director] had just been hired. We wanted to try and see if we could fit our self into whatever, you know, vision they had" (P8-I6-L30).

As of March 2018, a final version of a formal shared use agreement between the schools, city, and county departments to initialize shared use has been distributed and awaits the necessary signatures to put it into motion (see Table 3).

\section{Theoretical Constructs Case by Case}

The results are described case by case using the theoretical constructs as themes from the Contextual Interaction Theory (CIT) which include: (1) Information, (2) Interaction, (3) Motivation, (4) Power and the Social Ecological Model (SEM) levels which include: (5) Environment and (6) Policy (see Table 4). Emergent sub-themes revealed from the theoretical constructs within each case are presented. 
Construct One: Information. Information is one of four theoretical constructs within the CIT. For this study, information refers to the knowledge the key partners possess to carry out tasks and implementation efforts specific to shared use as well as the knowledge the intended users have to take advantage of the share use opportunities. The findings for construct one: information is presented through the sub-themes within each case. Sample data has been pulled to embody the emergent sub-themes for each school (see Table 5).

\section{School A.}

Culture. At School A the school culture has always been to maintain open facilities for shared use with the community. While the principal makes all the administrative decisions regarding shared use, the superintendent, school board, faculty and community support for the initiative has been widespread (P2 and P3). This can be attributed to the progressive nature to be inclusive of all users with their equipment selection as they continue to implement the shared use initiative. While the shared use initiative began over ten years ago from their old building to their new facilities, the process was gradual (P1). The principal was entrusted with the ability to carry out the necessary tasks to open his school to the community. The community had been able to utilize school grounds for recreational purposes, but as School A received grant funding and a new school building, they emerged as a shared use facility leader in the area for the last eight to ten years $(\mathrm{P} 2)$.

Information sharing. One critical piece of implementation is how the information is shared with the intended users. School A has utilized faculty training as an avenue for sharing information. Groups of interested faculty and staff get personal training advice from one of the shared use faculty (P3). Parent demo days at the end of the semester are another way School A disseminates knowledge about shared use and availability to users. Parents are invited into the 
school building to explore the facility and its physical activity offerings. School A serves as the hub for its community. The community learned mostly about shared use through word of mouth. Sporting and community events are another way the community is exposed to the recreational opportunities the school has to offer. For some events, the attendance is over 1,000 people in one weekend. The sheer number of people in attendance at events at School A allows many people in the community to view and experience the available school recreational facilities and spread the word to others (P1, P2, and P3).

Technical knowledge. Much of the success of the shared use initiative is attributed to the combined years of clinical and field experiences of the two key faculty members running the program (P1, P2, and P3). The two faculty members at School A served on the State Education Advisory Board. The experience on the board allowed them to gain sufficient knowledge to aid in the shared use process. Also, the faculty at School A had the opportunity to work with grant officers trained in the development and delivery of shared use initiatives. The grant officer's involvement resulted in the creation of a formal shared use agreement. However, key partners at the school felt the grant administrators did not have the technical understanding needed to create an inclusive shared use initiative for all users because they did not have a background in exercise physiology, physical education or similar area (P2 and P3).

\section{School B.}

Culture. Since School B was built in 1996, the outdoor recreational facilities have been open to the community outside of school hours. Shared use of the outdoor space is viewed as a requiring limited maintenance and oversight as compared to indoor spaces that required a supervisor and custodial staff to be on site during the event. At School B, shared use has not been 
formalized in a written document or "given much thought" as it was a part of the inherent culture of the school and accepted as the norm (P4).

Information sharing. The topic of shared use was once discussed in an administration wellness team meeting, but no action was taken to involve the county schools in conversations about shared use. At School B there has been no formal shared use training or educational materials distributed to the administration (P4). While shared use has been implemented informally for two decades due to the lack of community members taking advantage of the opportunity, the principal feels there may be a need to rethink how the community is made aware of the shared use facilities as the school.

\section{School C.}

Awareness. In the beginning, the principal took the idea of shared use and the vision for a new community-school playground to the Parent Teacher Organization (PTO). The PTO began to fundraise for a playground to expand the offerings for children during the school day and the community after school hours. Awareness was raised in the community about School C's efforts. Other schools began to reach out to School C and their partners for guidance on the shared use process (P7). The principal recommended that efforts to raise awareness come from the statelevel through reaching out to schools, park and recreation departments, and community associations (P8).

Education. To be able to implement shared use, partners must be knowledgeable about the process. Starting informally with Google searches, extending out to the literature, and then finding other shared use schools, the principal and the two primary community partners at School C educated themselves on shared use (P6, P7, and P8). The education was a major component of building capacity, understanding the benefits, and recognizing what informal 
shared use initiatives were already in place at the school, city and county levels (P8). Having a partner who can speak to and knows what is happening at all levels, school, city, and county, is recommended (P8) to increase knowledge for shared use implementation.

Construct Two: Interaction. Interaction is another theoretical construct within the CIT. Interaction addresses the level of collaboration and cooperation which influenced the quality of shared use implementation for the cases in this study. The findings for the interaction construct are presented as sub-themes for each case. Sample data is displayed to illustrate the emergent sub-themes for each school (see Table 6).

\section{School A.}

Barriers. The limiting factor in the implementation of shared use in School A was staffing of the indoor recreational facilities. There is a dedicated faculty member to monitor the shared use areas during open hours. However, the staff member also serves as the varsity sport athletic trainer. Due to the dual assignment in his contract, the facilities remain closed during home and away varsity games and other conflicting events. The variance in the shared use schedule is a barrier to consistent community use, especially during the varsity sports seasons. While there is a consensus about the need for a dedicated position to monitor the facilities during open shared use hours, the barriers that must be overcome to staff a shared use supervisor are the cost and the lack of interest in the position (P1, P2, and P3).

Support. The shared use process is not straightforward (P2). The type of people involved is key to quality implementation. The success of it is getting the right people in the right position (P3). At School A there was a snowball effect of hiring the right people at the right time that led to obtaining two grants back to back and the creation of a dual assignment position split across teaching, athletic training, and shared use supervision (P1). Because School A received grants, 
the administration and faculty could collaborate with various grant officers to expand the shared use offerings and policy at the school. However, building a lasting partnership is difficult to sustain as the support the grant personnel provided ended with the grant term (P2).

\section{School B.}

Partnerships. At School B, collaboration happens to various degrees depending on the partner. Through a user agreement, community organizations utilizing the space experience a good relationship with an open dialogue between the school and organization to voice concerns and share successes (P4 and P5). Partnerships require a lead person to help coordinate the development and implementation of an initiative. To this point at School B, the main administrative contact for shared use at the county education office took a job in another county. When this key contact person moved on, shared use collaboration efforts ceased and the movement for implementation on a larger scale was dropped. (P4).

\section{School C.}

Barriers. Change was one barrier influencing the quality of shared use implementation. While informal shared use was being implemented all over the county, School C initializing a formalized SUA to include the schools, city, and county was a significantly different direction from the norm. "It is difficult, because everyone is scared. Change is scary. And, I think that's what we're sitting at right now and all the different fronts of that. You know, when you forge a new path, it is tough" (P7-I6-L464).

Building capacity. Building capacity for shared use at School C occurred gradually over time. It first started with the PTO and then at the city level when new leadership changes happened in 2017. A new mayor and council members were appointed, and a city parks and recreation director position was created. The principal and a key community member saw the 
newly created parks and recreation director position as an opportunity to form a new partnership and move their vision for shared use forward (P6 and P8).

Responsibilities. After fostering a common vision for shared use within the partnership, the SUA component that took the longest to facilitate was the delegation of responsibilities. The SUA was written to include language that allowed to the greatest extent possible that the schools could use the city and county facilities and vice versa (P8). Items discussed included funding provisions for equipment purchases through a shared fund, providing city personnel to staff unorganized activity for indoor use of school recreational spaces, shared personnel for equipment maintenance and safety checks, and procedures for maintaining lines of open communication between all partners (P6, P7, and P8).

Construct Three: Motivation. The CIT construct of motivation refers to the level of importance placed on shared use and the alignment of shared use with personal or community beliefs, goals, and interests. Sub-themes across the motivation construct are presented for each case (see Table 7).

\section{School A.}

Personal commitment. There is a strong personal commitment to shared use among the administration and faculty at School A. It requires evening hours and a dedicated administration, faculty, and staff who believe in the mission of shared use (P2). The principal believes their shared use program is excellent and it will continue because the school is the center of the community. The community member valued the opportunity for shared use. If the program were to stop, the community members would run the administration "out on a rail" (P1-I1-L149).

Community Resource. School A is viewed as a community resource (P1, P2, and P3). The community pays taxes, so the community should have access. The community has adopted a 
sense of ownership and pride in the quality of the facility and felt as the though the school is a community base (P2). Additionally, the school is the closest facility with recreational offerings in miles for many families. Maintaining the goal of always being open aligns with the primary objective of shared use for School A.

\section{School B.}

Community-owned. The school is a building supported by taxpayer dollars. Community organizations view the ability to utilize School B's recreational spaces as a great deal and different way to make use of their dollars. By allowing the organized activities to take place after school and on the weekends, there is a higher level of importance placed on shared use (P5).

Priority. Shared use at School B is not a primary priority. This may be due to the nature of the school culture. School B has always participated in shared use as an informal initiative (P4).

\section{School C.}

Community goal. Working together to create a formal SUA, the city and county are placing value on increasing community-wide physical activity, reducing barriers to physical activity opportunities and combating the obesity issues within the state (P6). A high level of importance has been placed on reducing barriers to physical activity through shared use. Before one of the key contributing community members would agree to be on the school fundraising board, it had to be agreed upon School C's playground would be a shared use facility outside of school hours (P8). Between School C's partners' interests, strong alignment exists for the implementation of share use to be able to positively change physical activity levels. The goal with a formalized SUA is to create more physical activity programming, increase the number of 
available facilities that are in a walkable or bikeable distance, and generate schools that are community physical activity hubs (P6, P7, and P8).

Construct Four: Power. For this study, power indicates the factors that empower shared use implementation and the formal and informal resources involved. For each case within the power construct, sub-themes are described, and sample data reported (see Table 8).

\section{School A.}

Funding. One primary source of informal power (i.e., funding, time, skills, and consensus) for School A was the ability to receive funding from the county level and grants. The county was able to provide the funds to support building updates, new equipment purchases, and a dedicated shared use staff position (P1 and P2). Grant funding allowed the shared use program to expand the offerings to include a renovated space solely for exergaming and new exergaming equipment. The challenge School A faces now is connecting with another funding source as the grant terms have ended (P3). While the mission of shared use is alive and well in School A, the bills still need to be paid and funding shared use is linked to the ability to implement the program.

Consensus. The support for shared use was built several years ago at a number of county board meetings. As the gatekeeper to the school is the administrator, this administration has taken a position to be pro-fitness, physical activity, and wellness for the community. Through changes in county-level administration, there is still consent to maintain the formal shared use agreement (P1). The ability to advocate for shared use is a continual process as the key faculty, and staff members attend board meetings to present new ideas and gain support (P2 and P3). 


\section{School B.}

Funding. Securing funding was one way School B was empowered to expand their implementation of informal shared use. Grant money obtained by the local state Senator was funneled to the County Board Office and matched to aid in the development of the running trail. After obtaining the funding, the school district administration was hands off which enabled School B to make decisions about the trail and trail use. However, because the funds received were attached to a political campaign, there was hype surrounding the opening of the trail, and School B was then officially labeled a shared use school (P4).

\section{School C.}

Funding. Through fundraising School C obtained the entire amount of funding needed to construct the new playground. Having the necessary funding during the initial partnership meetings empowered the key stakeholders to ask for a cooperative and collaborative SUA between the schools, city, and county. To aid in the continued implementation of the SUA, School $\mathrm{C}$ will continue to fundraise at their $5 \mathrm{~K}$ event. Shared use partners at the school, city, and county levels are working to establish a pooled maintenance fund for repairs to shared use playgrounds and community recreational spaces (P6, P7, and P8).

Consensus. Having a completely new administration from the school board down presented an opportunity at School $\mathrm{C}$ to build consensus about shared use. The change in city officials also helped to leverage support for the initiative (P6). During meetings with the partners, a clear message was communicated about the benefits not only for School C but all the city schools and community physical activity spaces. The partners were able to reach a collective agreement about the importance of opening many recreational spaces for the community and have created a final SUA awaiting partnership signatures (P7). 
Construct Five: Environment. The SEM construct of environment is used for this study to describe the physical and social factors that are affected by shared use policy. The sub-themes for environment are reported for each case (see Table 9).

\section{School A.}

Location. Remotely located School A offers physical activity opportunities that community members would have to drive over 15 miles through the winding roads and pay to use. The closest fitness facility in the town closed, so the best-equipped place and least expensive option for the students, faculty, staff, and community members is the school. The shared use initiative provides the community a place to go to be physically active in the winter months and offers students the opportunities before and after school to engage with each other and recreate. The shared use program will continue to thrive at School A as they are the number one option for recreation in the area $(\mathrm{P} 1, \mathrm{P} 2$, and $\mathrm{P} 3)$.

Offerings. School A is well-equipped and offers physical activity options for all ages. Providing a safe environment is critical, so equipment is selected for a wide range of users, the student-athlete to the 80-year-old (P3). A poster highlighting numerous options available to a person on the weekend at School A was designed and displayed at the state capital during a shared use advocacy campaign. During events held at School A, many of the visitors commented on the state of the facility, physical activity opportunities available, and hours the school was open to the community (P1 and P2).

\section{School B.}

Type of space. The type of space at School B dictates how the space is shared, informally or formally. Outdoor spaces are more accessible to share as there is little planning and clean up 
involved in opening those recreational areas to the community. In contrast, sharing indoor spaces requires scheduling, custodial staff to be on site, a user agreement, and fee (P4).

Familiarity. Implementing an informal shared use initiative at School B allows the community to take advantage of familiar physical activity opportunities after school hours and on weekends. The principal feels having an environment that the community is familiar with makes it easier for the community to use. The principal commented not only on the number of people but the same people he sees taking advantage of the trail and ball fields (P4). For formal shared use of organized events, the school serves as a familiar location within the community, and there is an ease of use for the students, parents and community members participating (P5).

\section{School C.}

Assets. The parks and recreation director mapped out the current state of shared use by conducting a city-wide physical activity asset audit. The asset audit allowed all partners to understand the spaces being used by who and when. As shared use was already in place in many areas around the city, the asset map created an avenue for discussion about extending the implementation of shared use. Consensus was then able to be reached to move forward in the shared use process (P7 and P8).

Safety. The safety of the playground area at School C was a critical component to jumpstart the shared use process. Bollards were put in place to prevent someone from driving through the fencing onto the playground area. The school principal and partners used the buy-in and momentum from the safety improvements made to gain support from the Board of Education. Additional safety features like cameras and visibility of the school grounds to businesses and community housing make the school an attractive resource to the city. Also, because of School 
C's safety features, community members who take advantage of shared use feel safe letting their children walk or ride their bikes to play on the school grounds (P8).

Accessibility. There is also the social environment link of shared use to the connectivity of the neighborhoods. When school recreational facilities are accessible after hours, the community takes advantage and has now had a location to meet and foster new relationship and maintain existing ones. The principal commented on driving by the playground in the evenings and seeing children rollerblading, playing kickball or basketball, or riding their bikes. The playground is serving as a great place for the parents to gather and the community to connect (P6).

Construct Six: Policy. A statement of action to be carried out by the government, an agency or organization which provides structure and organization for collective action to achieve an intended goal is the definition of the CIT policy construct. Policy sub-themes within each case are presented (see Table 10).

\section{School A.}

Liability concerns. Prior to the WV Shared Use Bill being passed in 2015, the administration at School A had taken precautions to protect against liability. A dedicated position was created to monitor the shared use program and facilities to avoid legal situations (P2). However, when School A received the New You grant through the American Heart Association shared use campaign, the administration, faculty, and staff learned about the limited liability protection enacted with the Shared Use Bill. This piece of legislation was critical in gaining continued county-level administrative support (P1).

Implementation. Shared use was not a novel idea at School A. Prior to learning about the Shared Use Bill and understanding the legislation, School A had been implementing their shared 
use initiative before moving into the new school building in 2012 (P1, P2, and P3). As familiarity with the WV shared use legislation increased, School A gained administrative support for the creation of a formal shared use agreement in 2015 (P1).

\section{School B.}

Liability concerns. With a signed formal user agreement and proof of insurance, community organizations are able to hold organized events in School B (P4 and P5). The concern arises when the liability could potentially fall back to the school. The principal commented on the benefit of formalizing a shared used agreement for the unorganized activities taking place on the school grounds. Having a formal policy on file would ease liability concerns and allow the principal to feel better about letting more people in to use the facilities, which is the intended goal of shared use (P5).

Dissemination. Administration at School B was not aware of the recently passed Shared Use Bill. There is a disconnect between the levels of administration as School B was only informed about being a shared use school at the opening event for the running trail. No further information was communicated to the school administration. The principal sees a need for the formalization of shared use for unorganized activities and the trickle down of the information concerning shared use from higher levels of the county and state education administration (P4).

\section{School C.}

Dissemination. The key partners at School C were aware of the Shared Use Bill because they had done their own research. School C was not provided with structure or guidance for carrying out shared use. At the start of the shared use process, the key partners had to look to states other than WV to find any information on how to develop and implement a SUA. Eventually, the partners became aware of shared use schools in other WV counties and reached 
out to those schools for information. Shared use at School C was a bottom-up process; there was not a trickle-down of information from the county school board or state department of education (P6, P7, and P8).

Opportunity. Coupling new school administration and city officials with learning about the Shared Use Bill, the principal and key partners at School C were provided with an opportunity to develop and implement a tailored shared use policy. The Shared Use Bill afforded the key partners with legislation to combat the previous thought that school playgrounds could not be open after hours due to the liability risk (P6). Since the bill granted schools limited liability protection, dialogue opened between the partners on how to put shared use into action to offer more physical activity opportunities for the school children and community members (P8).

\section{Cross-Case Analysis}

The cross-case analysis is built upon the salient emergent sub-themes as categorized by the theoretical constructs of the CIT and levels of the SEM found in the specific case analysis of the three schools (see Table 11). The shared use expert's experiences were used to emphasize the findings throughout the cross-case analysis.

Information. Examining the information construct across all schools, participants indicated the need for coordinated communication to deliver information about shared use at all levels. While all schools have heard of the Shared Use Bill or taken steps to become knowledgeable about the bill, communication specifically related to increasing partners' technical knowledge to be able to facilitate the development and implementation of shared use initiatives is essential. School principals and key partners approached the superintendent and the school board to begin the shared use process. The shared use expert commented: 
"I think that is absolutely essential that the department of education understand this benefit and be proactive with the principals and connect with - the superintendents have a monthly meeting; the principals have meetings in their counties every month to talk about things at their schools. And, obviously should be having that - that conversation should be had at that level, and then it should be happening at the community level as well" (P9I7-L258).

Concerning the community level, only one school, School C, started the shared use development process with numerous partners within the community (P6, P7, and P8). However, regarding the implementation of shared use initiatives, all schools communicated shared use offerings in a way specific to their school context and dynamic. While the use of Twitter and Facebook social media outlets were utilized, so was extending invitations to parents and community members to visit the school during the school day to check out the recreational offerings and allowing word of mouth to spread.

Interaction. Across all participants, collaboration and cooperation are cited within the interaction construct. Facilitators and barriers also play a significant role in exploring interaction (Spratt, 2009). Schools that engaged multiple partners had a more robust development and implementation of shared use. A primary facilitator in the robustness of shared use at a school was the use of the sector approach. By recruiting more sectors (i.e., land use and community development, parks and recreation, education, media, etc.), there was a greater extent of community involvement in the shared use process and implementation.

"When it works well, it works because the local community becomes involved with the school - the parents become involved, the students are intimately involved in the process. And, they are then - they become the caretakers, not only of the shared use contract but 
the physical playground and building themselves. And, it looks different for each individual community, and that is what it is supposed to be" (P9-I7-L55).

By involving multiple partners, sectors, and community members, the school principals and partners could work in collaboration, not isolation, to achieve their goals and receive the benefit of assistance (i.e., funding, maintenance, safety improvements).

While all participants experienced barriers during the shared use process, there was a difference in barriers expressed dependent on the robustness of collaboration. In the cases where high levels of collaboration with the community were expressed, barriers described focused on all partners developing the same philosophical beliefs about shared use as the key partners. Cases with lower levels of collaboration, the barriers mentioned dealt more with the process based challenges of securing funding for staffing positions or scheduling the facilities for organized use.

Motivation. Many of the participants cited the importance of shared use for their communities in analyzing the motivation construct. Specifically, the participants recognized the value of reducing obstacles to participating in physical activity. Findings suggest that adopting shared use as a personal priority contributed to being able to build capacity with potential partners. Participants also highlighted the value of shared use as reflected in the mention of increased access to physical activity opportunities for the community and the potential to increase positive physical activity behaviors. The expert commented on the personal commitment of school administration,

"I was having a conversation with the principal from School A. He is so, so, so emotionally and personally connected to his community that he was telling that he works up at the school on various days on purpose so he can open it on the weekend when 
somebody might not think it is available per say, he is there with them. So, I was just blown away by the commitment to it" (P9-I7-L229)

Power. Across the power construct, participants discussed primarily informal sources of power that they had to obtain. The most dominant source of informal power discussed was funding. In all cases, funding played a primary role in facilitating shared use initiatives. Specifically, participants mentioned how securing funds made it possible for the principal and key partners to begin programming and to enhance and expand shared use for unorganized activity. In helping schools begin the shared use process, the expert stated,

"even as we could not get additional money to offer communities, we had conversations with them about how to become self-sufficient to a certain degree and even move forward with projects that include the playgrounds and open them up to the local community and the public, um - through their own means, whether it would be fundraising through local business, pairing up with a park association and it really had to be a lesson, because a lot of people were not familiar that" (P9-I7-L81).

Collectively, another source of power mentioned was the ability to gain support. The participants indicated without the support of higher level school administration or influential city and county officials, these shared use initiatives may not have been implemented. Gaining consensus required the dedication of the principals and key partners. Partners were required to leverage their knowledge and political capital, and commit their time to be empowered to move the shared use initiatives forward.

Environment. Examining the environment construct, the participants commented on how the school facilities are a physical asset to their communities. However, there were differences in how the physical school environment was viewed. Schools with higher enrollment 
put a value on the school adding to the assets within the school district and community area, while schools with lower enrollment placed value on being the only physical place for recreation and physical activity within reasonable proximity.

From a social ecological perspective, participants cited the importance of community support and ownership. Opening up school recreation facilities not only increased access but increased the opportunity at the social level for community members to begin meaningful conversations.

“what I noticed was people were having conversations about a whole lot of stuff when they were meeting on the playgrounds to watch their kids play, exercise themselves or utilizing the building for something fun that they just didn't have access normally. People were starting to band to together over issues of community economic development, of racial justice, of social justice. They were starting to fight other fights because they were actually meeting each other and talking to each other. So, there were so many benefits" (P9-I7-L182).

Policy. Many participants cited the importance of the shared use legislation. Broadly the Share Use Bill is viewed as one of the solutions to developing the school and surrounding neighborhoods as community hubs. The policy is the kindling that can ignite the conversations and begin to mobilize the policy for collective action.

"The legislation is a conversation starter. It definitely is a benefit because it means `something it that um - the state was overwhelmingly approving that schools should be able to open their doors. It showed that they were important to communities and that should be able to function in that capacity without being worried about financial burdens of issues that could arise if something happens... But it really functions as a conversation 
starter, because you can go in there and say, listen, your state delegation, you state elected officials believed in this. They believed so much that they are telling you, we will protect you financially. They are now encouraging you to do this" (P9-I7-L237).

At the school level, the importance of the policy is about the permanence of the policy. Creating a formalized shared use agreement provides a statement that recognizes the liability provided through state legislation. The formalized agreement also establishes a school-wide or district-wide policy that cannot be shut down with the changing of a new administration. However, due to lack of awareness, not all school administrators have taken full advantage of the shared use policy.

\section{Discussion}

School districts who are able to engage in the shared use process alongside community partners (i.e., parents, parks and recreation departments, community organizations) are in a position to not only provide physical activity resources for the community but gain benefits from collaborative partnerships. Understanding the factors and the partners that contribute to the shared use process can provide recommendations for best practices related to shared use policy and successful implementation. This qualitative multiple case study explored the influential factors of shared use and the role community-school partnerships have in the shared use process. Recommended by WV shared-use experts, this study examined current shared use initiatives in three WV public schools that allow community use of the schools' recreational facilities after school hours. A cross-case analysis was performed on the three individual school cases. The CIT and SEM frameworks were used for this study to examine the following constructs that have an influence on decisions related to sharing the school facilities with the community: (1) information, (2) interaction, (3) motivation, (4) power, (5) environment, and (6) policy. By 
integrating the CIT constructs into the SEM constructs, new implications for practice and policy are discussed centered around the research questions: a) How does the community-school partnership influence the development and implementation of a SUA? and b) What are the influential factors of a successful SUA? The evidence gathered from these three cases, and the cross-case analysis reveals issues that have not been exposed in prior case study research. The most significant issue revealed was the lack of coordinated communication from the top level down to the schools about the Share Use Bill. Another important finding was the low number of key partner involvement. To frame the discussion, this section contains key findings and implications related to policy factors and to environmental factors, and provides recommendations for practice, policy, and future research.

\section{Policy Factors}

Building off the cross case analysis, a policy factor affecting shared use was the need for increased technical knowledge. Similar research suggests there is an overall lack of knowing where to start the shared use process (Carlton et al., 2016). Other scholars have suggested that increasing technical information through clarification of the policy to school administration affects the maximum use of the school recreational spaces outside of school hours for physical activity (Stein et al., 2015). Results of this study illustrated that even though state legislation enacted a policy to provide limited liability for shared use in schools and communities, without a plan for dissemination to ground level implementers (i.e., principals, key partners), the policy will not be utilized to the fullest extent. School and community leaders need to be aware and educated on the policy, the benefits, and how to take collective action to develop and implement shared use. All participants, even those who before the interview had no information about the 
Shared Use Bill, expressed the need for clear lines of communication from the top down to increase awareness, acceptance, and implementation of shared use.

Addressing the perceived lack of information received from higher level administration through the information construct illustrates this critical aspect of policy. This study expands on previous findings by calling for top-down communication. Having planned top-down dissemination of policy efforts can affect policy implementation by increasing understanding and potentially utilization. Evidence suggested two types of information, technical and relational, are critical to robust policy implementation (Boer \& Bressers, 2011). Increased technical information about shared use, understanding the shared use policy, knowing how to integrate the policy in one's community-school context, and being aware of whom the policy is supposed to benefit are desired outcomes and can influence the implementation of shared use. However, information alone doesn't move policy into action. This study also took into account the partnerships as interaction played a role as a policy factor.

Support of administration has been established in previous research as a critical factor in physical activity initiatives (Cooper \& Vincent, 2008; Geraghty et al., 2009; Testa, 2000). Gaining the support of higher level education administration and city officials was an essential facilitator of policy implementation. Many participants cited the importance of getting district, city, or county level administration on board as a critical enabler to the shared use process. In shared use efforts, having administrative leadership serves as the bridge between city officials, partners, parents, and community members.

Previous physical activity policy research recommends involving multiple sectors to increase the depth and breadth in the development and implementation of shared use policy (Bull, Bellew, Schöppe, \& Bauman, 2004; Downer et al., 2016; Filardo, Vincent, Allen, \& 
Franklin, 2010). By involving other sectors outside of education, the community-school partnership becomes multi-dimensional, and the partners work to integrate and sustain shared use strategies. Contrary to the suggestions in the shared use guide and toolkits on using a sector approach to build shared use partnership teams (Downer et al., 2016; Filardo et al., 2010), an interesting and unexpected finding was limited number of diverse partnerships. Schools included in this study were utilizing informal shared use without the assistance of community partners for years. Even when partnerships were present, there were a low number of sectors represented within the partnerships across cases in the shared use process. These finding suggest that partnerships outside of the school are not essential in the shared use process.

Community-school partnerships should be considered when the benefit to the school is worth the time investment. While various community groups used each of the schools for organized activities, only one case pursued community partners to engage in the development and implementation of a formal shared use agreement. All participants from School C cited the importance of collaboration, consensus building, and various partners involved throughout the school, city and county levels. This is consistent with CIT; implementers of an initiative must have high level of relational knowledge to create advantageous partnerships (Spratt, 2009). Thus, the findings suggest the diversity and depth of the key partners involved can enhance the robust implementation of shared use in specific community-school contexts.

Addressing the broader scope of shared use, policy alone was a minimal factor in shared use initiatives within this study. Across all cases, the Shared Use Bill had limited impact in the decision to open the schools' recreational spaces. Prior to the Shared Use Bill passing in 2015, all schools were informally sharing their recreational spaces. While the Shared Use Bill provides 
limited liability protection, there are no restrictions within legislation defining the type of shared use, informal or formal, that must occur on school grounds to be covered.

There may not be a need to formalize SUAs as all schools within this study were participating in shared use informally. While previous recommendations highlight the benefit to creating a formalized agreement as a permanent policy (Downer et al., 2016), a policy can be revised and change with new leadership. Engaging in the formalization process of shared use may raise more questions than provide solutions, and potentially affect the shared use culture inherent to the school and community. Depending on the school culture creating a formalized agreement may be unnecessary as the Shared Use Bill provides limited liability for schools with or without a formal SUA. A potential way to decide between formalizing an SUA or not would be to conduct a needs assessment.

Previous shared use literature recommends performing a needs assessment and evaluation (Downer et al., 2016; Filardo et al., 2010). However, no school in this case study conducted a needs assessment to determine the interests and needs of the people they would serve and the best approaches to implementing shared use before opening school recreational facilities for community use, and no evaluation plan was in place.. Additionally, there was a lack of monitoring usage across all cases. The use of physical activity systematic observation tools could provide usage data (i.e. number of users, type of users, intensity of physical activity and type of physical activity) for principals and key partners to assess the viability of continued utilization of shared use.

\section{Environmental Factors}

In addition to the policy level, shared use initiatives work to grant access to or enhance the physical environment and create change within social networks. 
Physical. Previous findings reported budget constraints as a barrier to shared use efforts (Burbage et al., 2014; Carlton et al., 2016; Omura et al., 2016). A key enabler for each case was the ability to obtain some source of funding to improve their recreational spaces. Shared use implementation successes were partly due to the improvements made to the physical environments. The improvements made it possible to enhance or expand the shared use offerings and attracted media attention. Media coverage of the funding, fundraising efforts, and improvements to the physical environment promoted the schools' shared use efforts.

Another factor influencing the physical environment was the power to grant access to the facility. While the school administration has the power to allow access to their school grounds, without a mutually beneficial partnership, shared use is viewed as cost inhibitive (Filardo et al., 2010). The challenge is to allow access to school facilities but at the same time create a benefit for all partners, not just consent to use school facilities and all responsibilities be taken on by the school. Similarly, the importance of the cost-benefit analysis has been identified by Kanters (2014). To ensure a mutually beneficial partnership in sharing recreational spaces, strategies utilized included shared maintenance of the recreational facilities, an established equipment fund, and staffing provided to monitor indoor facilities use.

Social. Previous research has emphasized the importance of building social capital (i.e., community buy-in, involvement) as a critical factor in the implementation of shared use (Bauch, 2001; Cardon et al., 2012). The results of this study showed varying levels of community involvement. However, in conjuction with the findings of McKenzie (2016), the more involved the community was at the beginning of the shared use process, the development and implementation of shared use activities were more robust in those schools. Involving the community in the process (i.e., planning, data collection, and fundraising) from the beginning 
can lead to increased awareness and understanding of physical activity needs and aid in the assessment of the environmental and policy changes. Similarly, in alignment with SEM, individuals within the community must support the initiative in order for change within the social environment to occur (McLeroy, Bibeau, Steckler, \& Glanz, 1988). A factor inhibiting implementation of shared use initiatives may be that school culture of shared use is not the same as the community culture of shared use. In regard to school culture, all principals mentioned how the outdoor recreational facilities have always been open for community use after school hours. However, the community may not have adopted the shared use culture as was displayed in the schools either report of low facility usage or there was no system in place to monitor usage. Therefore, shared use partners should not disregard the importance of harnessing social capital as a shared use initiative catalyst.

Using shared use to create an opportunity for physical activity for the community does not mean the community will take advantage of the opportunity (Carlton et al., 2016). The availability of information becomes critical at the social environment level during implementation. An influential factor within the social environment may be a clear promotional strategy for a shared use initiative. Findings from this study illustrate that while the media and social media outlets (i.e., Facebook, Twitter) were used, no pre-planned strategy for dissemination of the shared use policy or initiative to the community was utilized. Geraghty et al. (2009) emphasized the need for a well-developed communication plan that can reach a wide range of targeted users while remaining focused on the message of shared use. Therefore, partners involved in the shared use process should incorporate a strategic communication plan into the development process. 


\section{Contributions}

This study makes substantive contributions to shared use research, theoretically and methodologically, as well as provides implications for policy. Filling a gap identified in the literature (Young et al., 2014), this research sought to address the influential factors of shared use and role of the key partners. Substantively, an enhanced understanding of the influential factors was gained through thematic analysis. Participants were able to describe the shared use process, how partnerships were formed, the impact of policy on shared use efforts, and the strategies, barriers, and facilitators involved. The advice shared (i.e., top-level education administration overseeing the dissemination of policy information, shared use training at principals meetings) could be used by other principals, parents, and involved community members to begin the shared use process. Specifically, this is one of the first studies in shared use research to identify the need for top-level education administration (i.e., State Department of Education) to create a coordination communication plan, so policy and shared use implementation information reaches the county and school level across the state. Overall, one of the main findings was the shared use process is dependent on invested individuals (i.e., principals and key partners), the amount of shared use information they have, and their interaction and motivation to move the initiative forward. The findings reveal that while all schools have the ability to implement shared use policy, the local context and social environment influences the extent to which shared use is implemented, and partnerships are utilized.

While previous shared use research is primarily quantitative, this study fills a methodological gap by using a qualitative, multiple case study approach to examine the shared use process and the partnerships involved. The use of case study methods allowed for the 
interaction between significant factors of shared use to be discovered and an in-depth description of shared use cases to surface.

Theoretically, this study provides an example of how the CIT and SEM can be integrated to examine a physical activity policy initiative. Using this theoretical approach allowed for the identification of CIT sub-themes to emerge within the policy and environmental levels of the SEM.

Lastly, this study provided insight into shared use from the school-level implementers leading to policy implications. While findings suggest a majority of the participants have a personal commitment to shared use, it may not be enough for robust implementation across all SEM levels. The findings suggest that shared use may not be implemented to the fullest potential, be beneficial to all partners, and may not lead to the anticipated community buy-in to enhance the social level.

\section{Recommendations}

Given that lack of experience and resources limit shared use implementation (Jones \& Wendel, 2015), a top-down strategy for dissemination of shared use policy and educational materials should be developed. Policy information could be disseminated from the administration responsible for health and wellness within the Department of Education. Dissemination could occur at the superintendent meetings and county-wide principal meetings through a brief training about the policy and an overview of shared use and shared use agreements.

The creation of a resource space for the centralization of shared use information for all school administration is crucial. The centralized resource could house published SUAs, suggested templates, ideas for funding sources, how-to information on development, implementation, dissemination, and highlight shared use champion schools. Having access to 
centralized information could aid in answering the question of where to start the shared use process.

The promotion of the shared use at the school level should be considered. First through the development of stranded and targeted shared use messaging throughout the year across multiple sources (i.e., newsletter, media outlets, and social media outlets) is needed. Also, implementing shared use programming for unorganized activities (i.e., bike night or walk-n-talk nights) is advised, especially in the early stages, to help form a community-school culture that takes advantages of shared use opportunities. Taking the time to create a well-designed promotional strategy and programming could assist in revitalizing an existing shared use initiative or jumpstarting a new one.

Broadly, the utility of shared use within the context of the community-school setting must be considered. Before entering into a SUA, the implementation of shared use must make sense for the entities involved. Given the time and resources that are invested in a shared use initiative, a needs assessment should be conducted to evaluate the need or worth of a shared use initiative for the school and community. If a need is found, getting the pieces in place that set up shared use for potential success is recommended. The pieces that are critical in the shared use process are technical knowledge, funding, and community investment, and evaluation of outcomes. Key stakeholders involved must be aware when an opportunity presents itself to form mutually beneficial partnerships. If these pieces are not put into place, then it is unlikely that a school's shared use initiative will have long-term success and sustainability

\section{Conclusion}

Public schools are recognized as a community resource equipped with recreational facilities that can be shared with the community (Young et al., 2014). Recognizing the school as 
a resource, national and state-level physical activity planning efforts have included shared use as a viable strategy (Bulger et al., 2015; National Physical Activity Plan Alliance, 2016). As a physical activity policy, shared used has the potential to positively enhance the communityschool social environment and increase population-level changes in behavior. Given the potential positive impact of implementing shared use, there are many questions regarding the influential factors of shared use and the role partnerships can play during the shared use process. Significant findings from this study revealed the importance of coordinated communication efforts about shared use from the top down as well as between the school and community, and need for diversity and depth within the key partners involved in the shared use process to create a mutually beneficial partnership. Results from this study offered insights for shared use partners to consider when planning shared use initiatives that aim to open school recreational facilities to the community. This study further highlights the need for more considerable attention to be devoted to research and dissemination of physical activity policies, specifically shared use. In WV, an effort to increase awareness and education about shared use needs to be prioritized. With top-down prioritization, the state should realize an improved quantity and quality of shared use initiatives through community-school partnerships across WV.

\section{Future Research}

Future studies investigating shared use practices and partnerships are encouraged. Continued research is needed to investigate long-term shared use initiatives. Examining shared use characteristics specific to various demographic settings should be considered. Research may investigate state, county and school administration's awareness and knowledge of shared use policy and implementation. Finally, insights into the social reinforcements to enhance the community of use of shared use facilities are needed. 


\section{Limitations}

1. The use of an expert panel may potentially limit the data collected due to the familiarity of the panel members to those nominated.

2. The use of convenience sampling for the cases limits the homogeneity of the selected schools.

3. The results of a multiple case study may be suggestive but are limited to generalization due to the exploration of only a small number of community-school partnerships involved in the shared use process (Simon \& Goes, 2013). 


\section{References}

American Dietetic Association. (2006). Position of the American Dietetic Association:

Individual-, Family-, School-, and Community-Based Interventions for Pediatric

Overweight. Journal of the American Dietetic Association, 106(6), 925-945.

http://doi.org/10.1016/j.jada.2006.03.001

Anfara, V. A., J. (2008). Visual data displays. In L. M. Given (Ed.), The Sage encyclopedia of qualitative research methods (p. Vol. 2, pp. 930-934). Thousand Oaks, CA: SAGE.

Bassett, D. R., Fitzhugh, E. C., Heath, G. W., Erwin, P. C., Frederick, G. M., Wolff, D. L., ... Stout, A. B. (2013). Estimated energy expenditures for school-based policies and active living. American Journal of Preventive Medicine, 44(2), 108-113.

http://doi.org/10.1016/j.amepre.2012.10.017

Bauch, P. A. (2001). School-community partnerships in rural schools: Leadership, renewal and a sense of place. Peabody Journal of Education, 76(2), 204-221.

http://doi.org/10.1207/S15327930pje7602

Blair, S. N. (2009). Physical inactivity: The biggest public health problem of the $21^{\text {st }}$ century. British Journal of Sports Medicine, 43, 1-2.

Boer, C. De, \& Bressers, H. (2011). Contextual interaction theory as a conceptual lens on complex and dynamic implementation processes. Challenges of Making Public Administration and Complexity Theory Work, (2009), 1-39.

Braun, V., \& Clarke, V. (2006). Using thematic analysis in psychology. Qualitative Research in Psychology, 3(2), 77-101. http://doi.org/10.1191/1478088706qp063oa

Brownson, R. C., Kelly, C. M., Eyler, A. a, Carnoske, C., Grost, L., Handy, S. L., ... Schmid, T. L. (2008). Environmental and policy approaches for promoting physical activity in the 
United States: a research agenda. Journal of Physical Activity $\{\&\}$ Health, 5(4), 488-503.

Bryant, C. A., Courtney, A. H., McDermott, R. J., Alfonso, M. L., Baldwin, J. A., Nickelson, J., ... Zhu, Y. (2010). Promoting physical activity among youth through community-based prevention marketing. Journal of School Health, 80(5), 214-224.

Bulger, S. M., Elliott, E., Jones, E., Fitzpatrick, S., Jones, D., O’Hara Tompkins, N., \& Olfert, M. (2015). ActiveWV 2015 West Virginia Physical Activity Plan, 1-44.

Bull, F. C., Bellew, B., Schöppe, S., \& Bauman, A. E. (2004). Developments in National Physical Activity Policy: an international review and recommendations towards better practice. Journal of Science and Medicine in Sport, 7(1), 93-104. http://doi.org/10.1016/S1440-2440(04)80283-4

Burbage, L., Gonzalez, E., Dunning, L., Simon, P., \& Kuo, T. (2014). Building mutually beneficial partnerships to improve physical activity opportunities through shared-use efforts in under-resourced communities in Los Angeles County. Preventive Medicine, 67(S1), S4S9. http://doi.org/10.1016/j.ypmed.2014.01.001

Butt, M. (1993). What do superintendents do to turn vision inot action? A biography of pragmatic visionaries. University of La Verne, La Verne, CA.

Cardon, G. M., Van Acker, R., Seghers, J., De Martelaer, K., Haerens, L. L., \& De Bourdeaudhuij, I. M. M. (2012). Physical activity promotion in schools: Which strategies do schools (not) implement and which socioecological factors are associated with implementation? Health Education Research, 27(3), 470-483. http://doi.org/10.1093/her/cys043

Carlton, T. A., Kanters, M. A., Bocarro, J. N., Floyd, M. F., Edwards, M. B., \& Suau, L. J. (2016). Shared use agreements and leisure time physical activity in North Carolina public 
schools. Preventive Medicine. http://doi.org/10.1016/j.ypmed.2016.08.037

Centers for Disease Control and Prevention. (2014). State Indicator Report on Physical Activity.

Choy, L. B., McGurk, M. D., Tamashiro, R., Nett, B., \& Maddock, J. (2008). Increasing access to places for physical activity through a joint use agreement: a case study in urban Honolulu. Preventing Chronic Disease, 5(3), A91. http://doi.org/A91 [pii]

Cooper, T., \& Vincent, J. M. (2008). Joint Use School Partnerships in California: Public Health Law and Policy ( PHLP ). Retrieved from http://citiesandschools.berkeley.edu/reports/CCS_PHLP_2008_joint_use.pdf

Creswell, J. W. (1998). Qualitatiave inquiry and research design: A practical quide through qualitative analysis. Thousand Oaks, CA: Sage.

Downer, S., Fields, J., Rothman, Z., Lopinsky, T., Strochlic, B., Fishwick, L., \& Broad Leib, E. (2016). The Massachusetts Community Use Toolkit.

Filardo, M., Vincent, J. M., Allen, M., \& Franklin, J. (2010). Joint use of public schools: A framework for a new social contract. Washington, DC.

Geraghty, A., Seifert, W, Preston, T., Holm, C. V. Duarte, T. H., \& Farrar, S. M. (2009).

Partnership moves to community toward complete streets. American Jouranl of Preventative Medicine, 37 (6S2), S420-S427.

Green, L. W., Richard, L., \& Potvin, L. (1996). Ecological Foundations of Health Promotion. American Journal of Health Promotion, 10(4), 270-281.

Gutin, B., Yin, Z., Johnson, M., \& Barbeau, P. (2008). Preliminary findings of the effect of a 3year after-school physical activity intervention on fitness and body fat: the Medical College of Georgia Fitkid Project. International Journal of Pediatric Obesity : IJPO : An Official Journal of the International Association for the Study of Obesity, 3 Suppl 1, 3-9. 
http://doi.org/10.1080/17477160801896457

Haggis, C., Sims-Gould, J., Winters, M., Gutteridge, K., \& McKay, H. A. (2013). Sustained impact of community-based physical activity interventions: key elements for success. BMC Public Health, 13(1), 892. http://doi.org/10.1186/1471-2458-13-892

Hansen, A. Y., Meyer, M. R., \& Lenardson, J. D. (2015). Built environments and active living in rural and remote areas: A review of the literature. Current Obesity Reports, 4(4), 484-493. http://doi.org/10.1007/s13679-015-0180-9

Haskell, W. L., Lee, I. M., Pate, R. R., Powell, K. E., \& Blair, S. N. (2007). Physical activity and public health: Updated recommendation for adults from the American college of sports medicine and the American heart association. Retrieved November 20, 2015, from http://scholarcommons.sc.edu/cgi/viewcontent.cgi?article=1117\&context=sph_physical_act ivity_public_health_facpub

Huberty, J. L., Balluff, M., O’Dell, M., \& Peterson, K. (2010). From good ideas to actions: A model-driven community collaborative to prevent childhood obesity. Preventive Medicine, 50(SUPPL.), S36-S43. http://doi.org/10.1016/j.ypmed.2009.08.013

Jones, S. E., \& Wendel, A. M. (2015). Characteristics of joint use agreements in school districts in the United States: findings from the School Health Policies and Practices Study, 2012. Preventing Chronic Disease, 12, E50. http://doi.org/10.5888/pcd12.140560

Kanters, M. A., Bocarro, J. N., Filardo, M., Edwards, M. B., Mckenzie, T. L., \& Floyd, M. F. (2014). Shared use of school facilities with community organizations and afterschool physical activity program participation: A cost-benefit assessment. Journal of School Health, 84(5), 302-309. http://doi.org/10.1111/josh.12148

Kohl, H. W., Craig, C. L., Lambert, E. V., Inoue, S., Alkandari, J. R., Leetongin, G., \& 
Kahlmeier, S. (2012). The pandemic of physical inactivity: global action for public health. The Lancet, 380(9838), 294-305. http://doi.org/10.1016/S0140-6736(12)60898-8

Koontz, T. M., \& Newig, J. (2014). From Planning to Implementation: Top-Down and BottomUp Approaches for Collaborative Watershed Management. Policy Studies Journal, 42(3), 416-442. http://doi.org/10.1111/psj.12067

Kristjansson, A. L., Elliott, E., Bulger, S., Jones, E., Taliaferro, A. R., \& Neal, W. (2015). Needs assessment of school and community physical activity opportunities in rural West Virginia: the McDowell CHOICES planning effort. BMC Public Health, 15(315), 1-10. http://doi.org/10.1186/s12889-015-1702-9

Krueger, R. A., \& Casey, M. A. (2009). Participants in a Focus Group. Focus Groups: A Practical Guide for Applied Research, 63-84.

Lucidarme, S., Marlier, M., Cardon, G., De Bourdeaudhuij, I., \& Willem, A. (2014). Critical success factors for physical activity promotion through community partnerships. International Journal of Public Health, 59(1), 51-60. http://doi.org/10.1007/s00038-013$0527-5$

Mâsse, L. C., McKay, H., Valente, M., Brant, R., \& Naylor, P. J. (2012). Physical activity implementation in schools: A 4-year follow-up. American Journal of Preventive Medicine, 43(4), 369-377. http://doi.org/10.1016/j.amepre.2012.06.010

McKenzie, T. L. (2016). Context Matters: Systematic Observation of Place-Based Physical Activity. Research Quarterly for Exercise and Sport, 1367(October), 1-8. http://doi.org/10.1080/02701367.2016.1234302

McLeroy, K. R., Bibeau, D., Steckler, A., \& Glanz, K. (1988). Ecological Perspective on Promotion Programs. Health Education Quarterly, 15(4), 351-377. 
http://doi.org/10.1177/109019818801500401

Merriam, S. B. (2009). Qualitative Research A Guide to Design and Implementation (1st ed.). San Francisco: CA: Jossey-Bass.

National Physical Activity Plan Alliance. (2016). U.S. National Physical Activity Plan. Columbia, SC.

Omura, J. D., Carlson, S. A., Paul, P., Sliwa, S., Onufrak, S. J., \& Fulton, J. E. (2016). Shared use agreements between municipalities and public schools in the United States, 2014. Preventive Medicine. http://doi.org/10.1016/j.ypmed.2016.09.026

O'Toole, L. (2004). The theory-practice issue in policy implementation research. Public Administration, 82(2), 309-329.

Reiner, M., Niermann, C., Jekauc, D., \& Woll, A. (2013). Long-term health benefits of physical activity - a systematic review of longitudinal studies, 1-9. http://doi.org/10.1186/1471$2458-13-813$

Rütten, A., Abu-Omar, K., Gelius, P., Dinan-Young, S., Frandin, K., Hopman-Rock, M., \& Young, A. (2012). Policy assessment and policy development for physical activity promotion: results of an exploratory intervention study in 15 European Nations. Retrieved November 19, 2015, from http://www.health-policy-systems.com/content/pdf/1478-450510-14.pdf

S238. (2015). Assemb. Reg. Sess. (W.V. 2015).

Sacks, G., Swinburn, B. A., Lawrence, M. A., Seidell, J., Swinburn, B., Egger, G., ... Owen, N. (2008). A systematic policy approach to changing the food system and physical activity environments to prevent obesity. Australia and New Zealand Health Policy, 5(1), 13. http://doi.org/10.1186/1743-8462-5-13 
Saldana, J. (2016). The coding manual for qualitative researchers. (J. Seaman, Ed.) (Third). Thousand Oaks, CA: SAGE Publications, Inc.

Schmid, T. L., Pratt, M., \& Witmer, L. (2006). A Framework for Physical Activity Policy Research. Journal of Physical Activity and Health, 3, 20-29.

Schultz, C. L., Wilhelm Stanis, S. A., Sayers, S. P., Thombs, L. A., \& Thomas, I. M. (2016). A longitudinal examination of improved access on park use and physical activity in a lowincome and majority African American neighborhood park. Preventive Medicine, 6-11. http://doi.org/10.1016/j.ypmed.2016.08.036

Simon, M. K., \& Goes, J. (2013). Scope of the study. Dissertation and Scholarly Research: Recipes for Success. http://doi.org/10.1080/02681309009414645

Spengler, J. O., Connaughton, D. P., \& Maddock, J. E. (2011). Liability concerns and shared use of school recreational facilities in underserved communities. American Journal of Preventive Medicine, 41(4), 415-420. http://doi.org/10.1016/j.amepre.2011.06.031

Spengler, J. O., Young, S. J., \& Linton, L. S. (2007). Schools as a community resource for physical activity: Legal considerations for decision makers. American Journal of Health Promotion, 21(4 SUPPL.), 390-396. http://doi.org/10.4278/0890-1171-21.4s.390

Spickard, J. (2005). How to construct an interview protocol. Creative Commons.

Spratt, K. (2009). Policy Implementation Barriers Analysis : Conceptual Framework and Pilot Test in Three Countries. Health Policy Initiative Task Order I, (October), 48.

Stein, A., Baldyga, W., Hilgendorf, A., Walker, J. G., Hewson, D., Rhew, L., \& Uskali, A. (2015). Challenges in promoting joint use agreements: Experiences from community transformation grant awardees in North Carolina, Illinois, and Wisconsin, 2011-2014. Preventing Chronic Disease Public Health Research, Practice and Policy, 12, 140457. 
http://dx.doi.org/10.5888/ped12.140457.

Testa, K. C. (2000). Development of joint-use educational facility agreements between California public school districts and community entities: A cross-case analysis of strategic practices, barriers and supportive elements. University of La Verne.

Troiano, R. P., Berrigan, D., Dodd, K. W., Mâsse, L. C., Tilert, T., \& Mcdowell, M. (2008). Physical activity in the United States measured by accelerometer. Medicine and Science in Sports and Exercise, 40(1), 181-188. http://doi.org/10.1249/mss.0b013e31815a51b3

Tucker, S., Lanningham-Foster, L., Murphy, J., Olsen, G., Orth, K., Voss, J., ... Lohse, C. (2011). A school based community partnership for promoting healthy habits for life. Journal of Community Health, 36(3), 414-422. http://doi.org/10.1007/s10900-010-9323-9 United States Department of Health and Human Services. (2008). 2008 Physical Activity. Health (San Francisco).

Woods, C. B., \& Mutrie, N. (2012). Putting Physical Activity on the Policy Agenda. Quest, 64(2). http://doi.org/10.1080/00336297.2012.669318

World Health Organization. (2010). Global recommendation on physical activity for health. Geneva, Switzerland: WHO Press. Retrieved from http://medcontent.metapress.com/index/A65RM03P4874243N.pdf\%5Cnhttp://scholar.goog1 e.com/scholar?hl=en\&btnG=Search\&q=intitle:Global+Recomendations+on+physical+activ ity+for+health\#0

Yin, R. K. (2014). Case Study Research Design and Methods (5th ed.). Thousand Oaks, CA: SAGE Publications, Inc.

Yin, Z., Gutin, B., Johnson, M. H., Hanes, J., Moore, J. B., Cavnar, M., ... Barbeau, P. (2005). An environmental approach to obesity prevention in children: Medical College of Georgia 
FitKid Project year 1 results. Obesity Research, 13(12), 2153-2161.

http://doi.org/10.1038/oby.2005.267

Young, D. R., Spengler, J. O., Frost, N., Evenson, K. R., Vincent, J. M., \& Whitsel, L. (2014).

Promoting physical activity through the shared use of school recreational spaces: A policy statement from the American heart association. American Journal of Public Health, 104(9), 1583-1588. http://doi.org/10.2105/AJPH.2013.301461 


\section{Tables}

Table 1

Demographics by School

\begin{tabular}{llll}
\hline Categories & School A & School B & School C \\
\hline City Classification & Rural & Urban Cluster & Urban Cluster \\
City Population & 931 & 49,968 & 28,157 \\
Grade Levels & $7-12$ & $9-12$ & PK-5 \\
Student & 325 & 1,700 & 503 \\
Enrollment & & & \\
Student & 99.1\% White & $80.1 \%$ White & $88.6 \%$ White \\
Demographics & 0.6\% African- & 16.5\% African- & $8.5 \%$ African- \\
& American & American & American \\
& 0.3\% Asian & $1.4 \%$ Asian & $1.3 \%$ Asian \\
& & $1.1 \%$ Hispanic & $1.1 \%$ Indian \\
& & Two or More 0.5\% & $0.5 \%$ Hispanic \\
& & Ethnicities & \\
Administrator's & 12 & $0.3 \%$ Indian & \\
Years at School & & 4 & 2 \\
\hline
\end{tabular}


Table 2

Shared Use Agreement and Facilities Audit by School

\begin{tabular}{|c|c|c|c|}
\hline Categories & School A & School B & School C \\
\hline $\begin{array}{l}\text { Type of Shared Use } \\
\text { Agreement signed }\end{array}$ & Formal & Informal; none & $\begin{array}{l}\text { Informal; Formal } \\
\text { proposed }\end{array}$ \\
\hline Level of Shared Use & School & School & $\begin{array}{l}\text { School; City; } \\
\text { County }\end{array}$ \\
\hline $\begin{array}{l}\text { Year Formal Shared } \\
\text { Use Enacted }\end{array}$ & 2014 & -- & 2018 \\
\hline $\begin{array}{l}\text { Indoor Facilities } \\
\text { (organized use with } \\
\text { approved contract) }\end{array}$ & $\begin{array}{l}\text { Full-size gymnasium } \\
\text { (2); indoor walking } \\
\text { track; weight room } \\
\text { (2); exergaming room }\end{array}$ & $\begin{array}{l}\text { Gymnasium; } \\
\text { multipurpose spaces }\end{array}$ & $\begin{array}{l}\text { Gymnasium; } \\
\text { multipurpose } \\
\text { spaces }\end{array}$ \\
\hline $\begin{array}{l}\text { Outdoor Facilities } \\
\text { (organized use with } \\
\text { approved contract) }\end{array}$ & $\begin{array}{l}\text { Football fields; ball } \\
\text { fields }\end{array}$ & $\begin{array}{l}\text { Track; greenspace; } \\
\text { running trail; ball } \\
\text { fields; tennis courts }\end{array}$ & Basketball courts \\
\hline $\begin{array}{l}\text { Indoor Facilities } \\
\text { (unorganized use) }\end{array}$ & $\begin{array}{l}\text { Full-size gymnasium } \\
\text { (2); indoor walking } \\
\text { track; weight room } \\
\text { (2); exergaming room }\end{array}$ & -- & -- \\
\hline $\begin{array}{l}\text { Outdoor Facilities } \\
\text { (unorganized use) }\end{array}$ & $\begin{array}{l}\text { Football fields; ball } \\
\text { fields }\end{array}$ & $\begin{array}{l}\text { Track; greenspace; } \\
\text { running trail; ball } \\
\text { fields; tennis courts }\end{array}$ & $\begin{array}{l}\text { Playground; play } \\
\text { area; basketball } \\
\text { courts }\end{array}$ \\
\hline Times Available & $\begin{array}{l}4 \text { p.m. }-7 \text { p.m. on } \\
\text { most weekdays and } \\
\text { weekends }\end{array}$ & $\begin{array}{l}\text { After school on } \\
\text { weekdays and } \\
\text { weekends }\end{array}$ & $\begin{array}{l}\text { After school on } \\
\text { weekdays and } \\
\text { weekends }\end{array}$ \\
\hline
\end{tabular}


Table 3

Partnership Information by School

\begin{tabular}{llll}
\hline Categories & School A & School B & School C \\
\hline Partners & $\begin{array}{l}\text { School } \\
\text { administrators and } \\
\text { faculty; Grant } \\
\text { officers; Community } \\
\text { organizations for } \\
\text { organized use }\end{array}$ & $\begin{array}{l}\text { School } \\
\text { administrators; } \\
\text { Community } \\
\text { organizations for } \\
\text { organized use }\end{array}$ & $\begin{array}{l}\text { School } \\
\text { administrators; } \\
\text { School Board; City } \\
\text { Council, City } \\
\text { department officials; }\end{array}$ \\
$\begin{array}{llll}\text { Positive Relationship } \\
\text { with Partners } \\
\begin{array}{l}\text { Partnership Scope } \\
\text { Yes }\end{array}\end{array}$ & School-specific & School-specific & $\begin{array}{l}\text { Parents; Community } \\
\text { members }\end{array}$ \\
& & $\begin{array}{l}\text { Yes } \\
\text { School-specific and } \\
\text { County-wide }\end{array}$ \\
\hline
\end{tabular}

Table 4

Definition of Theoretical Constructs

\begin{tabular}{ll}
\hline Constructs & Summary of Construct \\
\hline Information & $\begin{array}{l}\text { Possessing sufficient knowledge to carry out tasks and implementation } \\
\text { specific to shared use and for the intended users to take advantage of } \\
\text { shared use opportunities. } \\
\text { The level of collaboration and cooperation which influences the } \\
\text { quality of shared use implementation. } \\
\text { Thteraction }\end{array}$ \\
The level of importance placed on shared use and the alignment of \\
shared use with one's own personal and community beliefs, goals, and \\
interests. \\
The factors that empower shared up implementation and the formal \\
and informal resources involved \\
Power
\end{tabular}


Table 5

Summary of Emergent Sub-themes for Information

\begin{tabular}{lll}
\hline School & Emergent Sub-theme & Sample Data \\
\hline A & Culture & "Shared use is something we always have done, we just \\
never had a name for it before or a piece of paper that said \\
what it was" (P1-I1-L81) \\
"Mostly word of mouth. I mean, this is the hub of the \\
county. I mean, everyone knows about the school in our \\
community" (P1-I1 -L101)
\end{tabular}

Note. P-Refers to Participant, I-Refers to Interview, L-Refers to placement in raw data 
Table 6

Summary of Emergent Sub-themes for Interaction

\begin{tabular}{|c|c|c|}
\hline School & Emergent Sub-theme & Sample Data \\
\hline \multirow[t]{2}{*}{ A } & Barriers & $\begin{array}{l}\text { "It seems trivial. But that is one of the hot - biggest things. } \\
\text { You get all the stuff there in here, but you need someone to } \\
\text { work it. You know" (P3-I2-L55) }\end{array}$ \\
\hline & Support & $\begin{array}{l}\text { "You know we presented this stuff to the board several } \\
\text { years ago. They voted to let us have it and have been } \\
\text { supporters all along" (P1-I1-L29) }\end{array}$ \\
\hline B & Partnerships & $\begin{array}{l}\text { "The policies or the agreements were being done at the } \\
\text { board office, and the point of contact for that, I heard was a } \\
\text { guy that moved on to another county. So, it has never really } \\
\text { been delivered to us, and it has been it hasn't been given to } \\
\text { me" (P4-I3-L90) }\end{array}$ \\
\hline \multirow[t]{3}{*}{$\mathrm{C}$} & Barriers & $\begin{array}{l}\text { "And, when you're paving a new path, it is difficult, because } \\
\text { everyone is scared. Change is scary. And, I think that's what } \\
\text { we're sitting at right now and all the different fronts of that. } \\
\text { You know, when you forge a new path, it is tough, and that's } \\
\text { what we're doing" (P7-I6-L464) }\end{array}$ \\
\hline & Building capacity & $\begin{array}{l}\text { "We were all there together trying just to initiate that } \\
\text { conversation, you know, that we wanted to make this a } \\
\text { community playground. The city parks and recreation } \\
\text { director had just been hired. We wanted to try and see if we } \\
\text { could fit our self into whatever, you know, vision they had } \\
\text { (P8-I6-L30) }\end{array}$ \\
\hline & Responsibilities & $\begin{array}{l}\text { "And so, we each will have our own separate things. And } \\
\text { our maintenance department with the county, if something } \\
\text { would break we are going to be the ones who service it. } \\
\text { Which also is kind of like our buy-in and the city will be } \\
\text { happy to have that of course. It kind of takes a little bit off } \\
\text { them - a little bit of pressure off us financially if we can all } \\
\text { contribute together" (P6-I5-L165) }\end{array}$ \\
\hline
\end{tabular}


Table 7

Summary of Emergent Sub-themes for Motivation

\begin{tabular}{|c|c|c|}
\hline School & Emergent Sub-theme & Sample Data \\
\hline \multirow[t]{2}{*}{ A } & Personal commitment & $\begin{array}{l}\text { "We put in a lot of hours, and that's what it takes. You're } \\
\text { going to have to have a dedicated staff that wants to do it } \\
\text { and believes in it number one" (P2-I2-L366) }\end{array}$ \\
\hline & Community Resource & $\begin{array}{l}\text { "Our goal has always been to be open and so, that's how it } \\
\text { got started" (P1-I1-L6) "We have a lot of community } \\
\text { members come in and walk and stuff. So, you don't to lock } \\
\text { up a facility that they feel they have paid their taxes. It's } \\
\text { part - it's a community base" (P2-I2-L29) }\end{array}$ \\
\hline \multirow[t]{2}{*}{ B } & Community-owned & $\begin{array}{l}\text { "It's a great deal. We are using our tax dollars in a different } \\
\text { way. And, I appreciate that because we would hate to see } \\
\text { that school stay empty on the weekend, and now it is being } \\
\text { utilized in the community which is a good thing" (P5-I4- } \\
\text { L146) }\end{array}$ \\
\hline & Priority & $\begin{array}{l}\text { "I don't think I could say it's a priority because it just has } \\
\text { kind of been in place all along" (P4-I3-L26) }\end{array}$ \\
\hline $\mathrm{C}$ & Community goal & $\begin{array}{l}\text { "I think publicly it shows that the city and county, the } \\
\text { schools are working together to combat our huge obesity } \\
\text { issues. I think it is good to show that we believe in healthy } \\
\text { fitness levels and we believe in getting out and doing things } \\
\text { about it" (P6-I5-L220) }\end{array}$ \\
\hline
\end{tabular}


Table 8

Summary of Emergent Sub-themes for Power

\begin{tabular}{lll}
\hline School & Emergent Sub-theme & Sample Data \\
\hline A & Funding & "Our county has been very good at providing us funds to \\
do it. And, that's the key to a lot of it" (P2-I2-L4) \\
"We've always been able to back up why we want to do \\
something, and it makes perfect, logical sense. And, \\
people are like yep, let's do it" (P3-I2-L247) \\
"The board office really didn't do anything as far as \\
shared use other than the big part, steering the funds that \\
way. And, it was great. We are very pleased that he did \\
that" (P4-I3-L182) \\
"So, I think by combining funding you have the most \\
efficient use of our limited resources too. If we got $\$ 5,000$ \\
to build this playground, and every school got $\$ 5,000$ they \\
can maybe build a slide. But, if we got more money from \\
what we raised and the city and the county all putting \\
something in then, maybe we could have a really amazing \\
space. So, I think it is smarter too. Smarter use of \\
development" (P8-I6-L210) \\
"Pros would be just to have that dialogue with your local \\
officials, to know that they are supporting you and what \\
you do. To be able to tell people when you are talking \\
about this project, you're able to tell them the mayor is on \\
board and he loves this idea" (P6-I5-L341)
\end{tabular}


Table 9

Summary of Emergent Sub-themes for Environment

\begin{tabular}{|c|c|c|}
\hline School & Emergent Sub-theme & Sample Data \\
\hline \multirow[t]{2}{*}{ A } & Location & $\begin{array}{l}\text { "Especially where we are at. There's nothing } \\
\text { around here. People got to drive } 12 \text { - } 15 \text { miles } \\
\text { through the hills to get to a wellness center or a } \\
\text { facility. And we have one right here" (P3-I2-L31) }\end{array}$ \\
\hline & Offerings & $\begin{array}{l}\text { "All of us brainstormed what person could do here } \\
\text { on a Saturday? You know, if a family wants to } \\
\text { come in, and it is the weekend. You know, you } \\
\text { could do stuff in the big gym then you come up to } \\
\text { the sky track and workout, and then you could go } \\
\text { down to exergaming and play different kinds of } \\
\text { games, you know. Anything from ping pong to corn } \\
\text { hole to video games. You know, so it's almost like } \\
\text { a recreational park in a way. This is a heck of } \\
\text { facility here. Single-A, you know, school. We } \\
\text { really got it good" (P3-I2-L162) }\end{array}$ \\
\hline \multirow[t]{2}{*}{ B } & Type of Space & $\begin{array}{l}\text { "Being outside it is easier because there really is no } \\
\text { cleanup. It's not like a group coming in to use the } \\
\text { gym. You really have to plan for that" (P4-I3-L20) }\end{array}$ \\
\hline & Familiarity & $\begin{array}{l}\text { "I was just talking with one of the girls, and you } \\
\text { know they have Special Olympics there too and } \\
\text { that's kind of - it's nice that kids that have the } \\
\text { Special Olympics know where the facility is also" } \\
\text { (P5-I4-L132) }\end{array}$ \\
\hline \multirow[t]{3}{*}{$\mathrm{C}$} & Assets & $\begin{array}{l}\text { "And, the parks and recreation director and I, } \\
\text { mostly the director, did a really good job in the } \\
\text { summer of - we just started to make a list of what } \\
\text { we knew to be happening already without us doing } \\
\text { anything. You know - this group is using this field } \\
\text { and this time and this group is using the gym and } \\
\text { the classroom spaces. So, we tried to spell that all } \\
\text { out when we went to this meeting to say this is } \\
\text { already happening" (P8-I6-L88) }\end{array}$ \\
\hline & Safety & $\begin{array}{l}\text { "So, they started with safety and the importance of } \\
\text { safety. You know of our children and the safety of } \\
\text { our children playing in that space. So, you got a lot } \\
\text { of support from even the board of education with } \\
\text { the additional funding for that (P7-I6-L292) }\end{array}$ \\
\hline & Accessibility & $\begin{array}{l}\text { "I will drive by here in the evening and see - you } \\
\text { know, kids learning to ride their bikes here. It is a } \\
\text { great place for parents to come. (P6-I5-L135). }\end{array}$ \\
\hline
\end{tabular}


Table 10

Summary of Emergent Sub-themes for Policy

\begin{tabular}{|c|c|c|}
\hline School & Emergent Sub-theme & Sample Data \\
\hline \multirow[t]{2}{*}{ A } & Liability concerns & $\begin{array}{l}\text { "Yes, but our grant officer kind of took that problem off } \\
\text { because we didn't know that state provided insurance if } \\
\text { you open up your school for shared use for stuff like that, } \\
\text { so we were covered that way too. That made it a lot easier } \\
\text { for the county" (P1-I1-L31) }\end{array}$ \\
\hline & Implementation & $\begin{array}{l}\text { "We were doing it years before they gave it a name. We } \\
\text { were on top of the game way before it became a game" } \\
\text { (P2-I2-L210) }\end{array}$ \\
\hline \multirow[t]{2}{*}{ B } & Liability concerns & $\begin{array}{l}\text { "I have to go and get insured for the time we are there, and } \\
\text { I have to pay for it myself" (P5-I4-L94) }\end{array}$ \\
\hline & Dissemination & $\begin{array}{l}\text { "That means they [shared use agreements] really need to } \\
\text { be formalized at the school level and they need to let us } \\
\text { know" (P4-I3-L107) }\end{array}$ \\
\hline \multirow[t]{2}{*}{$\mathrm{C}$} & Dissemination & $\begin{array}{l}\text { "There was no trickle of how this got to our board and our } \\
\text { board gives it to us. There was none of that. So, it was } \\
\text { more of us finding this information out on our own and us } \\
\text { going up the ladder and showing them what is in place in } \\
\text { the state of West Virginia and what we can do with this } \\
\text { agreement" (P6-T5-L207) }\end{array}$ \\
\hline & Opportunity & $\begin{array}{l}\text { "I saw the bill as a really great opportunity. I thought, oh, } \\
\text { yes! Now, I don't have that as an excuse from the school } \\
\text { board not to build - to not have these spaces. They were } \\
\text { using it as - I don't in if an excuse is the right word - I } \\
\text { think they didn't felt like they had a choice that they } \\
\text { couldn't have these facilities open. So, when that law was } \\
\text { passed, I saw it as a starting point for some dialogue about } \\
\text { more facilities, better facilities, opening up facilities that } \\
\text { kind of things" (P8-T6-L259) }\end{array}$ \\
\hline
\end{tabular}


Table 11

Summary of the Cross-case Analysis

\begin{tabular}{|c|c|c|}
\hline $\begin{array}{l}\text { Theoretical } \\
\text { construct or level }\end{array}$ & Emergent Sub-theme & Sample Data \\
\hline \multirow[t]{4}{*}{ Interaction } & Partnerships & $\begin{array}{l}\text { "We have to educate land and development. You know, how do we develop our } \\
\text { neighborhoods and make them so that we have these community hubs? And then, we } \\
\text { have to talk about, you know, education and so, I think that all those different sectors } \\
\text { can play a part in also that vision of how do we make our communities more } \\
\text { physically active and healthy" (P8-I6-L296). }\end{array}$ \\
\hline & & $\begin{array}{l}\text { "And actually, some of the vendors that come to our event are actually from the } \\
\text { county school. Um - it's uh - you know - their special needs program is part of the fair } \\
\text { also. So, that just kind of made sense" (P5-I4-L54). }\end{array}$ \\
\hline & & $\begin{array}{l}\text { "I mean, it's getting the right people in the right position. That is the success of it. It } \\
\text { just is" (P2-I2-L333). }\end{array}$ \\
\hline & & $\begin{array}{l}\text { "It's not a simple process. You need to have people. I mean if you had you know a } \\
\text { fitness club. It isn't just open the door, and it runs itself" (P3-I2-L313). }\end{array}$ \\
\hline
\end{tabular}

Information Coordinated communication
"So, when I say our county previously thought it was a liability, it was prior to this current administration, but they had no knowledge of this stuff either because it was something that was never discussed. And so, nobody around knew this was a thing" (P6-I5-L184).

"When the grant administrator came aboard with the second state grant that really was the first time that I really heard about shared use because we've been doing it all along. We just haven't been calling it that" (P1-I1-L17).

"And, who can build those connections? Whose job is it to facilitate those connections? And, almost have their hand in all of these areas, in the county, in the 
city, in the school, at the practical level, at the implementation, at the vision, at the funding source. I think somebody has to be in charge of building that and facilitating or else it will just go back to their three separate places and in which they have always done business. So, whether it is a group of people, whether it is one person who is in charge, but I think that shared vision needs to be communicated and revisited over and over again otherwise it will just go back to the way it had been. Or, institutionalize the procedures well enough to get to the - well, that's my part of this role" (P8-I6-L450).

"I think, schools are central to their leadership. I saw quite a few principals that were not comfortable opening their schools if they hadn't already until they got the okay from their superintendent. So, what happened, is I would then have a talk with the superintendent we'd go over this. And, in some cases they were, they were like, oh, sure - we don't mind. And then, I would say, well, your principals don't know you are. And so, can you - I literally had to then say - can you write an e-mail or can our team write a letter and then you spread that word out to your principals to let them know you're good with this. That they don't have to worry about having your approval. That you approve of this" (P9-I7-L269).

We wanted the community to use it, to know about it, and encourage them to use it outside of school hours. Weekends, evenings, and people do use it. It [the opening of the trail] was advertised that way from the beginning" (P4-I3-L10).

"When one school decided to refurbish the playground and was able to do so, and they opened it to the neighborhood, they said they had a meeting, and they explained what was happening which is an absolutely essential piece of shared use. You have got to have a conversation. You have got to ask the community to some degree if they want it. And, if they say yes - what do they want? Because, when the community can share their needs and their wants, it is bound to be a successful project. But, also you have to let the community know" (P9-I7-L123).

Motivation Personal commitment "I think we both agree that it is definitely a priority. We have these elementary schools, middle schools, and even our high school spread throughout the community. 
Those areas can be - according to shared use they can be community centers they can be the heart of the community in all aspects, especially in recreation" (P7-I6-L47).

"I think we all collectively agree that's a way that we can try and tackle that and open these areas for the community" (P7-I6-L51).

"You know - what's the outcome going to be? Is it worth it? And, do all the people who have to play a role in it, is it worth it to them or not? So, it is worth to our principal. It is worth it to us. I don't know if it is worth it to our superintendent right now. It's not like first on her priority list, but it could be. I don't know. So, we have to try and - that's the education and awareness too, just making them see the benefit of more physical activity and opening these spaces to get them on that philosophical path" (P8-I6-L463).

Power Funding

"We are basically raising the entire amount of money needed to put it up. And so, initially when we said this - we don't want any money, but you know - in ten years down the road if it [the playground] needs something - the maintenance fund of it. Can that be what the city chips in at that point" (P6-I5-L149)?

"That's why all the politicians showed up [at the ribbon cutting for the trail]. Hey, you took my money. Now let me shake hands and get the big pair of scissors and cut the ribbon for the newspaper kind of thing" (P4-I3-L241).

"So, when we got the new school they gave us extra money for the room up there that I showed you this morning. So, that room was allotted to us just for the exergaming program" (P1-I1-L16).

"There's no equity, necessarily in the benefits. Uh - because the playgrounds and the school buildings that were the best off particularly coming from your middle-class, upper-middle-class neighborhood. But, the people that actually needed it the most were in low-income, rural neighborhoods, and they also were suffering because they didn't have financial resources to maintain their playgrounds" (P9-I8-L68). 
Environment Increased assets

Community ownership
"In this process, and that was the second piece. And, in all honesty, that was something if I had known, I would have done a lot more, and a lot faster, and a lot better um - getting communities more self-sufficient in thinking about their fundraising possibilities before waiting for us to get money from the state to help them. Um - I think they would have been served better" (P9-I8-L89).

"Looking at the assets at each location as opposed to just putting like - you know, like a couple of the lower income areas have new, you know, new playground equipment, and that's great, but when you're talking about something so close to each other, let's not duplicate each other. Let's make them two really great spaces for two different kinds of kids. Like older kids want to play basketball and whatever. Maybe your 60year-old wants to play tennis and doesn't have a place to go. You know, think outside the box of what we've always done and try to make them spaces that can be utilized that are not duplicate spaces" (P6-I5-L396).

"It [the trail] kind of goes along with what we have already. I mean, people come up and use the track. People come up and use the tennis courts, and the trail runs all around all of those things" (P4-I3-L16).

Yea. It is going to change ultimately when we get this building done next year. I mean it's going to really open up when we get the exergaming and all the equipment set back up in there. We'll set it back up next week in here anyhow after we get wrestling moved out. But it is a nuisance having to tear it all down and set it back up and all that, so then it will be permanent. [Getting out blueprints for the ball field and field house expansion]. Over here we have 65 acres and uh we are building a sports complex up there. A football field and a baseball field" (P1-I1-L158).

"I think it is excellent. I really do. I think it will continue. I mean this is the hub. If we would try and get rid of it and say hey you can't come do this at the school. They would run us out on a rail" (P1-I1-L148).

"I think that depends on where you're at. Here this is a community-based school, so it's open any time whether we have an agreement or not" (P1-I1-L55). 
Policy Opportunity

"We could say that this is a community playground. This isn't just for our school. This is an effort on our part to get the community for active and more fit and want to be healthier, especially with our kids and that it is in such a prime location to be bikable and walkable and things like that" (P6-I5-L91).

"Funding is one piece of it, but that ownership and investment that the community has is, I think, more vital. It is one of the first things that I would always suggest now that I'm well-experienced myself in working with the schools and the community. In some cases, they didn't even need funding right off; they just needed that community investment" (P9-I7-L158).

"I saw the bill as a really great opportunity. I thought, oh, yes! Now, I don't have that as an excuse from the school board not to build - to not have these spaces. They were using it as - I don't know if excuse is the right word - I think they didn't feel like they had a choice that they couldn't have these facilities open. So, when that law was passed, I saw it as a starting point for some dialogue about more facilities, better facilities, opening up facilities that kind of thing. Without the legal ramification that they were afraid of" (P8-I6-L259).

"Yes. Yes. I think we should [have a formal shared use agreement]. And, honestly, I think that in that document that should elevate from liability if someone came up here on their own" (P4-I3-L97).

"We were moving along with just building awareness and encouraging people to utilize the limited liability policy and to open up their schools and then to kind of follow-up with them and say, hey, how is it working for you? You know - what are you finding? And, understanding in the campaign that we were telling each local community, each local school district, don't believe that this is a cookie cutter outfit. Your shared use policy is how you open your building, your playground, it can be completely unique to you and your community. It fits you" (P9-I7-L46).

"But for me, I think others too, it allowed us to go into the superintendents' offices; it allowed us to walk into a principal's office and say, did you know that you're protected? And, they're like, no. I can tell you without a doubt no one knew that we had that piece of legislation" (P9-I7-L250 


\section{Appendices}

\section{Appendix A: Shared Use Agreement Items and Descriptions from Downer et al., 2016, p.} 27-28

\begin{tabular}{ll} 
Item & Description \\
\hline $\begin{array}{l}\text { Statement of purpose } \\
\begin{array}{l}\text { Identify who will sign } \\
\text { the Agreement }\end{array}\end{array}$ & $\begin{array}{l}\text { Describes the reason(s) for entering into the Community Use } \\
\text { Agreement. }\end{array}$ \\
$\begin{array}{l}\text { Find out who has the authority to make decisions on behalf of the } \\
\text { community use site and the city, town, or other organization that } \\
\text { wants to share the space. }\end{array}$ \\
$\begin{array}{l}\text { terms } \\
\text { If you are going to use abbreviations in your Agreement, define all } \\
\text { the terms at the beginning of the document so readers can easily } \\
\text { refer to it as they continue to read. }\end{array}$
\end{tabular}

Define the term of the Agreement

Describe the facility or space that will be shared

Describe the public access hours

Describe the parties' obligations

Designate a representative

Specify how users will gain access
Set a beginning and end date for the Agreement, or specify that the Agreement will renew automatically.

Include the facility's address and list the equipment in the space that will be used. Include a description of the specific rooms or areas within a larger building, if applicable. Specify that the parties can add additional spaces or exclude them if both agree.

Set out the times that the space will be used for the expanded purpose, and specify that it is controlled by the primary user at all other times.

This section will lay out the responsibilities and expectations of everyone involved in detail. It may include many of the topics that appear below. All the parties involved in the community use initiative should walk through the community use site together before the space is opened to the community. Each party should confirm that the space is ready for use by the public.

Identify the person that can make decisions about how to carry out the Agreement and can confer with others if there is an issue to address. Describe how the representatives will communicate with one another.

Describe how the community users will obtain access to the space (i.e. keys or access cards). 
Describe security

procedures

Designate someone to inspect the space

Supervision

Equipment and storage

Cleaning and maintenance

Bathrooms, drinking water, etc.

Repairs

Disagreements and conflict resolution

Operational costs

Manage risk

Termination

Amendments
This includes locking the area after use as well as the necessary steps to prepare it for additional users.

To avoid disagreements and keep the space safe, the parties will designate someone who inspects the space after each use and is responsible for notifying others of any damage and/or needed repairs.

Identify the person or entity who will be responsible for providing supervision for the activities that take place in the community use space.

Specify which equipment at the community use site can be utilized by the community users. Require the community user to supply and remove all additional necessary equipment for use of the site, or designate a secure place at the site where equipment can be stored.

Describe how the space will be kept clean and safe for all users. This section can specify that additional custodial staff should be engaged to perform new tasks associated with expanded use of the space.

Identify whether the community users will have access to restroom facilities and drinking water. Assign someone to be responsible for maintaining restrooms.

Describe how the parties will be made aware of needed repairs and assign responsibility for the cost of repairs. Explain how the parties will review the potential costs of repairs and agree to pay or share expenses.

Describe how conflicts will be handled, including how everyone will be notified of issues or problems.

Set out the costs associated with putting the Agreement into action.

Choose a way to manage risk.

Describe the terms under which the Agreement can be terminated and what kind of prior notice of termination the parties must give one another.

Specify that amendments to the Agreement must be written and approved by everyone who signs the Agreement. 
Include attachments $\quad$ Be sure to include all documents the Agreement refers to, such as other policies, insurance certificates, photos of the space, and inventory lists. 


\section{Appendix B: Expert Panel Emails}

\section{Introduction Email}

\section{Dear Expert Panel Member,}

My name is Brooke Towner. I am a doctoral student at West Virginia University. I am interested in studying how schools are working with communities to share their facilities to provide more physical activity opportunities. Would you be willing to talk briefly ( 5 minutes) over the phone with me about your knowledge of and connection to the shared use movement in West Virginia public schools? Please let me know a time and day that would fit into your schedule to briefly discuss shared use. I look forward to talking with you.

Best, Brooke C. Towner, M.S.

West Virginia University

College of Physical Activity and Sport Science

\section{Follow-up Email}

\section{Dear Expert Panel Member,}

Thank you for taking the time to speak with me over the phone. As a recap to our recent conversation, I am researching how school-community partnerships aid in the shared use agreement process. Because of your knowledge about shared-use and WV public schools, you were identified as an expert panel member to participate in this research study.

The study has been reviewed and acknowledged by the Institutional Review Board at West Virginia University. Your participation in this research study is completely voluntary. There are no known risks to participation. Your responses will be confidential.

Below are the details outlining how your expertise can contribute to my research relative to examining successful shared use agreements.

Your efforts are needed to identify West Virginia public school principals who played a key role in the shared use process for their school and community. I will be contacting selected principals to participate in an interview.

Use the attached form to nominate any number of West Virginia public school principals that fits the following criteria:

1. The school has a formal written shared used agreement in place.

2. The shared use agreement is actively being implemented.

3. A school-community partnership (i.e., people outside the school) helped to create and put the shared used agreement into place.

4. The nominees will be able to provide in-depth knowledge of the shared-use process. 
If you are willingly to participate in this research study, please complete and return the attached consent form and principal nomination form within 10 days of receiving it.

If you have any questions, please contact me at (304) 293-3295 or by email bct0001@mix.wvu.edu or Dr. Eloise Elliott at (304) 293-0869 or by email Eloise.Elliott@mail.wvu.edu

Best,

Brooke C. Towner, M.S.

West Virginia University

College of Physical Activity and Sport Sciences 


\section{Appendix C: Expert Panel Informed Consent}

\section{Consent to Participate in Research}

\section{Examining the Process of Shared Use Agreements through Community-School Partnerships}

\section{Introduction and Purpose}

My name is Brooke Towner. I am a graduate student at West Virginia University working with my faculty advisor, Dr. Eloise Elliott in the College of Physical Activity and Sport Sciences. I would like to invite you to take part in my research study, examining the shared use process and the community-school partnership that help to implement the shared use agreement in K-12 schools in West Virginia.

\section{Procedures}

If you agree to participate in this research study, you will provide school shared use nominations and participate in a phone interview about your experience with shared use. Your responsibilities will include completing and returning the principal nomination form, and consenting to participate in a phone interview to discuss your involvement with shared use and your perceptions of characteristics that contribute to successful and unsuccessful implementation of shared use. Interviews will last approximately 15 minutes. With your permission, I will record our phone interview session and take notes during the interview. The purpose of audiotaping is to accurately record the information you provide. The audio recording will be used for transcription purposes only. If you choose not to be audiotaped, I will take notes instead. If you agree to being audiotaped but feel uncomfortable at any time during the interview, I can turn off the recorder at your request. WVU IRB has acknowledgement of this protocol on file.

\section{Benefits}

There is no direct benefit to you from taking part in this study. The aim is that the research will provide an understanding of how a community-school partnership implements a shared use agreement, and hopefully gain insight into characteristics that have made the shared use process successful. The results of this research could provide practical recommendations for school shared use initiatives.

\section{Risks/Discomforts}

If any of the research questions make you feel uncomfortable, you are free to decline to answer any questions you do not wish to, or to stop the interview at any time. As with all research, there is a chance that confidentiality could be compromised; however, we are taking precautions to minimize this risk.

\section{Confidentiality}

Your study data will be handled as confidentially as possible. If results of this study are published or presented, individual names and other personally identifiable information will not be used. To minimize the risks to confidentiality, we will keep your interview data in a secure location on a password protected computer. Only the investigators 
involved in the study will have access to data collected for this study. Pseudonyms will be used to replace identifiable information. When the research is completed, I may save the nominations and transcribed interview notes for use in future research done by myself or others. I will retain these records for up to 3 years after the study is over. The same measures described above will be taken to protect confidentiality of this study data.

\section{Compensation}

You will not be paid for taking part in this study.

\section{Rights}

Participation in research is completely voluntary. You are free to decline to take part in the project. You can decide not to participate in the additional interview. If participating in the interview, you can decline to answer any questions and are free to stop taking part in the project at any time. Whether or not you choose to participate in the research and whether or not you choose to answer a question or continue participating in the project, there will be no penalty to you or loss of benefits to which you are otherwise entitled.

\section{Questions}

If you have any questions about this research, please feel free to contact me. I can be reached at 304-293-3295 or bct0001@ mix.wvu.edu or Dr. Eloise Elliott at 304-293-0869 or Eloise.Elliott@mail.wvu.edu.

If you have any questions about your rights or treatment as a research participant in this study, please contact the West Virginia University Office of Research Integrity \& Compliance at 304-293-7073, or e-mail ORIC@ mail.wvu.edu.

$* * * * * * * * * * * * * * * * * * * * * * * * * * * * * * * * * * * * * * * * * * * * * * * * * * * * * * * * * * * * *$

\section{CONSENT}

Please keep a copy of this consent form to keep for your own records. If you wish to participate in this study, please sign and date below.

Participant's Name (please print)

Participant's Signature

Date 


\section{Appendix D: Expert Panel Nomination Form}

Directions: Please nominate principals that have an effective shared used agreement in place at their school.

The selection criteria are:

1. The school has a formal written shared used agreement in place.

2. The shared use agreement is actively being implemented.

3. Key community-school partners assisted with the shared use process or utilized shared use at the school.

4. The nominees will be able to provide in-depth knowledge of the shared-use process.

If applicable, please include any additional information about the school or principal nominated.

Expert Panel Member Name:

Date:

\begin{tabular}{|l|l|l|l|}
\hline 1 & Principal's Name & School Name & County \\
\hline \multicolumn{2}{|l|}{} & & \\
\hline \multicolumn{2}{|l|}{ Principal's contact information (phone and e-mail) } & \\
\hline
\end{tabular}

Type of Shared Use Activity (if known mark an X in the open left column by the type)

\begin{tabular}{|l|l|l|l} 
Organized (i.e. afterschool program, & Unorganized (i.e. open track & Both
\end{tabular}

basketball league) or playground)

Any additional comments about this nominee:

\begin{tabular}{|l|l|l|l|}
\hline 2 & Principal's Name & School Name & County \\
\hline \multicolumn{2}{|l|}{} & & \\
\hline \multicolumn{2}{|c|}{ Principal's contact information (phone and e-mail) } \\
\hline
\end{tabular}

\section{Principal's contact information (phone and e-mail)}

Type of Shared Use Activity (if known mark an X in the open left column by the type)

\begin{tabular}{|l|l|l|l|}
\hline & $\begin{array}{l}\text { Organized (i.e. afterschool program, } \\
\text { basketball league) }\end{array}$ & $\begin{array}{l}\text { Unorganized (i.e. open track } \\
\text { or playground) }\end{array}$ & Both \\
\hline
\end{tabular}

Any additional comments about this nominee: 


\begin{tabular}{|l|l|l|l|}
\hline 3 & Principal's Name & School Name & County \\
\hline \multicolumn{2}{|l|}{} & \\
\hline \multicolumn{2}{|c|}{ Principal's contact information (phone and e-mail) } \\
\hline
\end{tabular}

Type of Shared Use Activity (if known mark an X in the open left column by the type)

\begin{tabular}{|l|l|l|l|l|}
\hline Organized (i.e. afterschool program, & & Unorganized (i.e. open track & & Both
\end{tabular} \begin{tabular}{l|l} 
basketball league) & or playground)
\end{tabular}

Any additional comments about this nominee:

\begin{tabular}{|l|l|l|l|}
\hline 4 & Principal's Name & School Name & County \\
\hline & & \\
& & & \\
\hline
\end{tabular}

Principal's contact information (phone and e-mail)

Type of Shared Use Activity (if known mark an X in the open left column by the type)

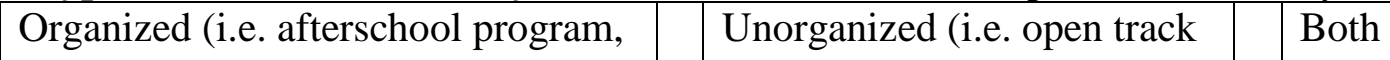
\begin{tabular}{l|l} 
basketball league) & or playground)
\end{tabular}

Any additional comments about this nominee:

\begin{tabular}{|l|l|l|l|}
\hline 5 & Principal's Name & School Name & County \\
\hline \multicolumn{2}{|l|}{} & \\
\hline \multicolumn{2}{|c|}{ Principal's contact information (phone and e-mail) } & \\
\hline
\end{tabular}

Principal's contact information (phone and e-mail)

Type of Shared Use Activity (if known mark an X in the open left column by the type)

\begin{tabular}{|l|l|l|l|l}
\hline Organized (i.e. afterschool program, & & Unorganized (i.e. open track & & Both
\end{tabular} \begin{tabular}{|l|l} 
basketball league) & or playground)
\end{tabular}

Any additional comments about this nominee: 


\begin{tabular}{|l|l|l|l|}
\hline 6 & Principal's Name & School Name & County \\
\hline \multicolumn{3}{|c|}{ Principal's contact information (phone and e-mail) } \\
\hline \multicolumn{3}{|l|}{ Type of Shared Use Activity (if known mark an X in the open left column by the type) } \\
\hline $\begin{array}{l}\text { Organized (i.e. afterschool program, } \\
\text { basketball league) }\end{array}$ & $\begin{array}{l}\text { Unorganized (i.e. open track } \\
\text { or playground) }\end{array}$ & Both \\
\hline \begin{tabular}{l} 
Any additional comments about this nominee: \\
\hline
\end{tabular}
\end{tabular}

\section{Contacting the Principal}

Do I have your permission to copy you on the introductory email to the principals you have nominated?

\begin{tabular}{l|l} 
YES & NO \\
\hline
\end{tabular}

\section{Follow-up Interview}

Would you be willing to participate in a brief 15 minute interview about your experience with shared use?

\begin{tabular}{l|l} 
YES NO & NO \\
\hline
\end{tabular}

Please e-mail this form to bct0001@ mix.wvu.edu within 10 days of receiving it.

If you have any questions, please contact Brooke Towner by phone at (419)789-2119 or e-mail at bct0001@mix.wvu.edu or Dr. Eloise Elliott at (304) 293-0869 or by email

Eloise.Elliott@mail.wvu.edu 


\section{Appendix E: Principal Emails}

\section{Introductory Email}

Dear Principal,

My name is Brooke Towner. I am a doctoral student at West Virginia University. I am contacting your because you have been nominated by (insert expert panel member) as a school with a successful shared use program. I am interested in exemplary school shared use initiatives and studying how schools are working with communities to share their facilities to provide more physical activity opportunities. Would you be willing to talk briefly ( 5 minutes) over the phone with me about your involvement with shared use in your school? Please let me know a time and day that would fit into your schedule to discuss shared use. I look forward to talking with you.

Best, Brooke C. Towner, M.S.

West Virginia University

College of Physical Activity and Sport Sciences

\section{Follow-up Email \\ Dear Principal,}

I appreciate your interest in my research study. As mentioned in our phone conversation, the purpose of this study is to examine the characteristics of successful school shared use initiatives and the role of the community-school partnership during the shared use process. For this study, I am asking that you submit a) an Informed Consent form to participate in this research study, b) your shared use agreement, c) any additional shared use documentation, and d) the Principal Information form where you will identify key community partners who worked closely with you throughout the shared use process. I am also asking you to agree to participate in a $30-60$ minute interview with me.

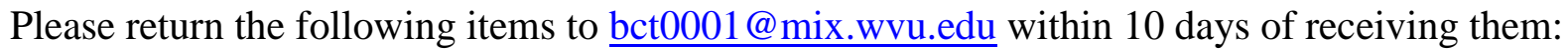

1. The attached Informed Consent form

2. The attached Principal Information form

3. The school shared use agreement document

4. Any additional documents (i.e., action plan, promotional materials)

I will use (insert method agreed upon during the phone call to schedule the interview) to set up an interview time. The interview is being conducted to examine the shared use agreement process and identify the contributions of community partners and characteristics that have made the shared use initiative successful at your school and is expected to last $30-60$ minutes.

The study has been reviewed and acknowledged by the Institutional Review Board at West Virginia University. Your participation in this research study is completely voluntary. There are no known risks to participation. Your responses will be confidential. 
If you have any questions or concerns about the nature of this study, please contact Brooke Towner at 304-293-0848 or bct0001@ mix.wvu.edu or Dr. Eloise Elliott 304-293-0869 or Eloise.Elliott@mail.wvu.edu .

Your valuable input about the shared use process will help to contribute to practical shared use recommendations. Thank you in advance for your assistance in this important endeavor!

Best,

Brooke C. Towner, M.S.

West Virginia University

College of Physical Activity and Sport Sciences 


\section{Appendix F: Principal Informed Consent}

\section{Consent to Participate in Research}

\section{Examining the Process of Shared Use Agreements through Community-School Partnerships}

\section{Introduction and Purpose}

My name is Brooke Towner. I am a graduate student at West Virginia University working with my faculty advisor, Dr. Eloise Elliott in the College of Physical Activity and Sport Sciences. I would like to invite you to take part in my research study, examining the shared use process and the community-school partnership that help to implement the shared use agreement in schools in West Virginia.

\section{Procedures}

If you agree to participate in my research, you will: 1) submit your shared use agreement document and any additional shared use documentation to me through email, 2) complete a community partner representative nomination form and submit it through email, and 3) participate in an interview about your experience with shared use. The interview will involve questions about your role as it pertains to shared use, implementation of the shared use agreement, and working within the community-school partnership. It should last 30 - 60 minutes. With your permission, I will record our interview session and take notes during the interview. The purpose of audiotaping is to accurately record the information you provide. The audio recording will be used for transcription purposes only. If you choose not to be audiotaped, I will take notes instead. If you agree to being audiotaped but feel uncomfortable at any time during the interview, I can turn off the recorder at your request. WVU IRB has acknowledgement of this protocol on file.

\section{Benefits}

There is no direct benefit to you from taking part in this study. The aim is that the research will provide an understanding of how a community-school partnership implements a shared use agreement, and hopefully gain insight into characteristics that have made the shared use process successful for your school. The results of this research could provide practical recommendations for school shared use initiatives.

\section{Risks/Discomforts}

If any of the research questions make you feel uncomfortable, you are free to decline to answer any questions you do not wish to, or to stop the interview at any time. As with all research, there is a chance that confidentiality could be compromised; however, we are taking precautions to minimize this risk.

\section{Confidentiality}

Your study data will be handled as confidentially as possible. If results of this study are published or presented, individual names and other personally identifiable information will not be used. To minimize the risks to confidentiality, we will keep your interview data in a secure location on a password protected computer. Only the investigators involved in the study will 
have access to data collected for this study. Pseudonyms will be used to replace identifiable information. When the research is completed, I may save the transcribed note and field notes for use in future research done by myself or others. I will retain these records for up to 3 years after the study is over. The same measures described above will be taken to protect confidentiality of this study data.

\section{Compensation}

You will not be paid for taking part in this study.

\section{Rights}

Participation in research is completely voluntary. You are free to decline to take part in the project. You can decline to answer any questions and are free to stop taking part in the project at any time. Whether or not you choose to participate in the research and whether or not you choose to answer a question or continue participating in the project, there will be no penalty to you or loss of benefits to which you are otherwise entitled.

\section{Questions}

If you have any questions about this research, please feel free to contact me. I can be reached at 304-293-3295 or bct0001@ mix.wvu.edu or Dr. Eloise Elliott at 304-293-0869 or Eloise.Elliott@mail.wvu.edu.

If you have any questions about your rights or treatment as a research participant in this study, please contact the West Virginia University Office of Research Integrity \& Compliance at 304293-7073, or e-mail ORIC@mail.wvu.edu.

$* * * * * * * * * * * * * * * * * * * * * * * * * * * * * * * * * * * * * * * * * * * * * * * * * * * * * * * * * * * * * * * * * * *$

\section{CONSENT}

You will be given a copy of this consent form to keep for your own records. If you wish to participate in this study, please sign and date below.

Participant's Name (please print) 


\section{Appendix G: Principal Information Form}

\section{Principal Information Form}

\section{Demographics}

Name:

Numbers of Years in Educational Administration:

Number of Years in Current Position:

Educational Background, Specialized Training, and Credentials:

\section{School Demographics}

Name of School:

Grades:

Number of students:

\section{Shared Use Agreement}

Share Use Agreement Definition: For this study shared use agreements are defined as specific, written documents that define the shared use of the space, maintenance, staffing, financing, liability and other pertinent operational items for the use of public school recreational facilities by the community.

Please list the types of recreational facilities you have available. 
Directions: Mark an " $\mathrm{X}$ " to identify the type(s) of shared used agreement you have developed with community partners that are currently in place.

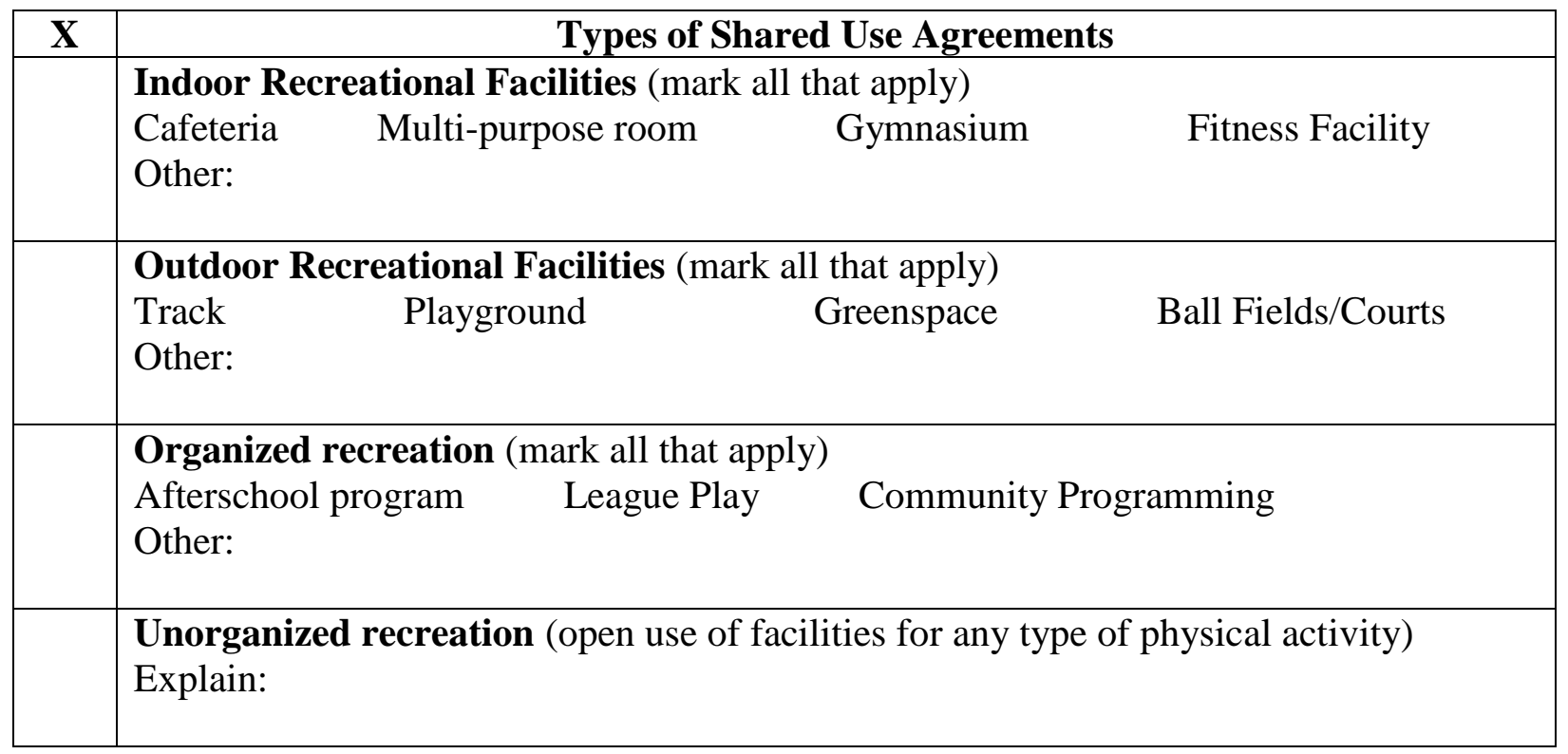

\section{Community-School Partnerships - Societal Sectors}

Directions: Mark an "X" to identify the sectors represented within the community-school partnership that aided in the shared use agreement process.

\begin{tabular}{|l|l|c|l|}
\hline $\mathbf{X}$ & Type of Community Partner & $\mathbf{X}$ & \multicolumn{1}{c|}{ Type of Community Partner } \\
\hline & Business/Industry & & Parks \& Recreation (City/County) \\
\hline & Health Care & & Non-profit, Volunteer \& Faith-based \\
\hline & Public Health & & Transportation, Land Use, \& Community Design \\
\hline & Media & & Other: \\
\hline
\end{tabular}

\section{Community Partner Representatives}

Directions: Recommend at least five representatives from the community-school partnership whom you have worked closely with in developing the shared use agreement. Representatives who are recommended will be asked to participate in a focus-group session to discuss the shared use agreement process and the role of the community-school partnership.

\begin{tabular}{|c|c|c|c|c|}
\hline $\begin{array}{c}\text { Representative's } \\
\text { Name }\end{array}$ & Title & Organization & $\begin{array}{c}\text { Contact } \\
\text { Information } \\
\text { Phone }\end{array}$ & $\begin{array}{c}\text { Contact } \\
\text { Information } \\
\text { email }\end{array}$ \\
\hline & & & & \\
\hline
\end{tabular}




\begin{tabular}{|l|l|l|l|l|}
\hline $\begin{array}{l}\text { Representative's } \\
\text { Name }\end{array}$ & Title & Organization & \multicolumn{1}{c|}{$\begin{array}{c}\text { Contact } \\
\text { Information } \\
\text { Phone }\end{array}$} & $\begin{array}{c}\text { Contact } \\
\text { Information } \\
\text { email }\end{array}$ \\
\hline & & & & \\
\hline & & & & \\
\hline & & & & \\
\hline & & & & \\
\hline \\
\end{tabular}

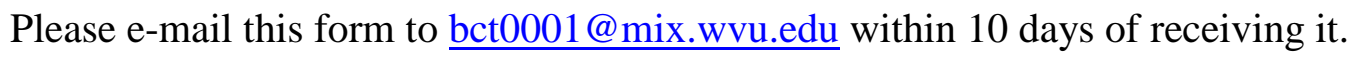

If you have any questions, please contact Brooke Towner by phone at (419)789-2119 or e-mail at bct0001@mix.wvu.edu or Dr. Eloise Elliott at (304) 293-0869 or by email Eloise.Elliott@mail.wvu.edu 


\section{Appendix H: Community-School Partnership Emails}

\section{Introductory Email}

Dear Community Partner Representative,

My name is Brooke Towner. I am a doctoral student at West Virginia University. I am contacting your because you have been nominated by (insert principal) as an integral part to the shared use initiative at (insert name of school). I am interested in conducting a research study about exemplary school shared use initiatives and studying how schools are working with communities to share their facilities to provide more physical activity opportunities. I would like to talk to you about participating in focus group about your involvement with shared use in your school. Would you be willing to set up a time we could talk briefly ( 5 minutes) over the phone? Please let me know a time and day that would fit into your schedule to discuss shared use. I look forward to talking with you.

Best, Brooke C. Towner, MS

West Virginia University

College of Physical Activity and Sport Sciences

\section{Follow-up Email}

Hello insert Community Partner Representative, I thank you for your interest in my research study. As mentioned in our phone conversation, the purpose of this study is to examine the shared use agreement process and identify the contributions of community partners and characteristics that have made the shared use initiative successful at your school. For this study I am asking you to participate in a $45-60$ minute focus group with other community partners that contributed to your school's shared use agreement. To set up a focus group time, please respond to the Doodle Poll using the following link: (attach link).

The study has been reviewed and acknowledged by the Institutional Review Board at West Virginia University. Your participation in this research study is completely voluntary. There are no known risks to participation. Your responses will be confidential. An informed consent is attached and will be collected at the time of our scheduled interview.

If you have any questions or concerns about the nature of this study, please contact Brooke Towner at 304-293-0848 or bct0001@ mix.wvu.edu or Dr. Eloise Elliott 304-293-0869 or Eloise.Elliott@mail.wvu.edu .

Your valuable input about the shared use process will help to contribute to practical shared use recommendations. Thank you in advance for your assistance in this important endeavor.

Best,

Brooke C. Towner, MS

West Virginia University

College of Physical Activity and Sport Sciences 


\title{
Appendix I: Community-School Partnership Informed Consent
}

\author{
Consent to Participate in Research \\ Examining the Process of Shared Use Agreements through \\ Community-School Partnerships
}

\section{Introduction and Purpose}

My name is Brooke Towner. I am a graduate student at West Virginia University working with my faculty advisor, Dr. Eloise Elliott in the College of Physical Activity and Sport Sciences. I would like to invite you to take part in my research study, examining the shared use process and the community-school partnership that help to implement the shared use agreement in your local school.

\section{Procedures}

If you agree to participate in my research, you will participate in a focus group about your experience with shared use. The focus group will involve questions about your role as it pertains to shared use, implementation of the shared use agreement, and working within the community-school partnership. It should last $45-60$ minutes. With your permission, I will record our focus group session and take notes during the focus group. The purpose of audiotaping is to accurately record the information you provide. The audio recording will be used for transcription purposes only. If you choose not to be audiotaped, I will take notes instead. If you agree to being audiotaped but feel uncomfortable at any time during the focus group, I can turn off the recorder at your request. WVU IRB has acknowledgement of this protocol on file.

\section{Benefits}

There is no direct benefit to you from taking part in this study. The aim is that the research will provide an understanding of how a community-school partnership implements a shared use agreement, and hopefully gain insight into characteristics that have made the shared use process successful for your school. The results of this research could provide practical recommendations for school shared use initiatives.

\section{Risks/Discomforts}

If any of the research questions make you feel uncomfortable, you are free to decline to answer any questions you do not wish to, or to stop the focus group at any time. As with all research, there is a chance that confidentiality could be compromised; however, we are taking precautions to minimize this risk.

\section{Confidentiality}

Your study data will be handled as confidentially as possible. If results of this study are published or presented, individual names and other personally identifiable information will not be used. To minimize the risks to confidentiality, we will keep your focus group data in a secure location on a password protected computer. Only the investigators involved in the study will have access to data collected for this study. Pseudonyms will be used to replace identifiable information. When the research is completed, I may save 
the transcribed note and field notes for use in future research done by myself or others. I will retain these records for up to 3 years after the study is over. The same measures described above will be taken to protect confidentiality of this study data.

\section{Compensation}

You will not be paid for taking part in this study.

\section{Rights}

Participation in research is completely voluntary. You are free to decline to take part in the project. You can decline to answer any questions and are free to stop taking part in the project at any time. Whether or not you choose to participate in the research and whether or not you choose to answer a question or continue participating in the project, there will be no penalty to you or loss of benefits to which you are otherwise entitled.

\section{Questions}

If you have any questions about this research, please feel free to contact me. I can be reached at 304-293-3295 or bct0001@ mix.wvu.edu or Dr. Eloise Elliott at 304-293-0869 or Eloise.Elliott@mail.wvu.edu. If you have any questions about your rights or treatment as a research participant in this study, please contact the West Virginia University Office of Research Integrity \& Compliance at 304-293-7073, or e-mail ORIC@ mail.wvu.edu.

$* * * * * * * * * * * * * * * * * * * * * * * * * * * * * * * * * * * * * * * * * * * * * * * * * * * * * * * * * * * * * *$

\section{CONSENT}

You will be given a copy of this consent form to keep for your own records. If you wish to participate in this study, please sign and date below.

Participant's Name (please print)

Participant's Signature

Date 


\section{Appendix J: Expert Panel Interview Protocol}

Participant Name:

Date:

Location and Time:

\section{Introductory Protocol}

To facilitate note-taking, I would like to audio tape our conversation today. I can stop recording at any time if you make the request. Only researchers on the project will have access to the recording. After the recording has been transcribed, the file will be destroyed. As reminder about your participation in this research study: (1) all information will be held confidential, (2) your participation is voluntary, and you may stop at any time if you feel uncomfortable, and (3) we do not intend to inflict any harm. Again, thank you for agreeing to participate.

I have planned this interview to last $15-20$ minutes. During this time, I have several questions that I would like to cover with you.

\section{Introduction}

Thank you for taking the time to sit down and talk with me about the shared use initiatives in the state of WV.

You have been identified a person knowledgeable about the shared use process in West Virginia public schools.

Today I will ask you a number of questions about your experiences with shared use. I will honor any request for confidentiality.

This study will identify characteristics that make the SUAs successful, and how communityschool partnerships play a central role in the shared use process. Findings will be reported as themes and patterns within individual school's shared use initiative and across the combined shared use cases. It is my hope that this study will produce practical guidelines for initiating and sustaining SUAs and a better understanding of the formation and integral role community-school partnerships play in shared use initiatives. Before we begin, what questions can I answer for you?

\section{Research Question: What are influential factors of a SUA?}

A SUA may incorporate key features, move through certain steps, or incorporate specific actions. This section of the questioning is geared toward gaining insight into how you got the SUA up and running.

1. What has been your experience working with shared use initiatives in WV public schools?

2. Based on your experiences: 
a. Please tell me about how school or county administrators have responded to utilizing share use? (Probe: Any hesitations about the shared use process? Willingness to participant in shared use?)

b. What has made shared use initiatives possible within a school/community? (Probe: What factors make a SUA work?)

\section{Research Question: How does the community-school partnership influence the development and implementation of a SUA?}

3. Think back to the schools you nominated for this study. Can you tell me about the role community-school partnership played in shared use process?

\section{Conclusion}

4. What do you think needs to happen to development and implement more SUAs in the state?

5. Is there anything else you think may be important for me to know about your experience relative to the SUA process?

That concludes the interview. Again, thank you very much for your time. I will be conducting a focus group with the community partners you recommended on (enter date).

Once I have completed the all the interviews and focus groups, I will transcribe the recordings and code for themes. For each case, I will create a summary and then compile all the cases into a final write-up. I will send out the final write-up of this study to you in May/June 2018.

Thank you. 


\section{Appendix K: Principal Interview Protocol}

Participant Name:

Date:

Location and Time:

\section{Introductory Protocol}

To facilitate note-taking, I would like to audio tape our conversation today. I can stop recording at any time if you make the request. Only researchers on the project will have access to the recording. As reminder about your participation in this research study: (1) all information will be held confidential, (2) your participation is voluntary, and you may stop at any time if you feel uncomfortable, and (3) we do not intend to inflict any harm. Again, thank you for agreeing to participate.

I have planned this interview to last 30 - 60 minutes. During this time, I have several questions that I would like to cover with you.

\section{Introduction}

Thank you for taking the time to sit down and talk with me about the shared use initiative between your school and community.

You have been identified by your peers as a key stakeholder in the shared use process in West Virginia public schools.

Today I will ask you a number of questions about your experiences throughout the shared use process. The questions posed will fall under two broad categories: 1) Questions about the development and setup of the shared use initiative and 2) Questions specific to the design and implementation of shared use at this specific site. I will honor any request for confidentiality.

This study will identify characteristics that make the shared use successful, and how communityschool partnerships play a central role in the shared use process. Findings will be reported as themes and patterns within your school's shared use initiative and across the combined shared use cases. It is my hope that this study will produce practical guidelines for initiating and sustaining shared use initiatives and a better understanding of the formation and integral role community-school partnerships play in shared use initiatives. Before we begin, what questions can I answer for you?

\section{Research Question: What are influential factors of shared use?}

School shared use initiatives may incorporate key features, move through certain steps, or incorporate specific actions. This section of the questioning is geared toward gaining insight into how you started and continue to implement shared use.

1. How did you first learn about shared use?

2. Is shared use a priority for you? IF yes, please explain. 
3. Tell me how the shared use imitative started at your school.

a. Can you talk some about the process that has gotten you to where you are today

4. No two communities are alike.

a. What originally made you consider shared use?

b. Who were the key people involved in the process?

c. Was there a specific group (seniors, children, etc.) who you thought would most benefit from shared use?

d. What areas or space do you share formally (with a shared use agreement or contract) or informally? How did you determine those would be the best use of resources?

e.

5. Did you address responsibilities (i.e., risk, liability, maintenance) of parties (i.e., the school or community partner/organization) involved in the shared use of your facilities? IF yes, please explain how those responsibilities were delegated.

6. Did you receive any technical assistance from outside the school about shared use or shared use agreements? IF yes, from whom?

Probe: Any guidance from county- or state-level administration, legal team?

7. Do you have a formal shared use agreement in place?

a. If no:

i. Have you considered creating a formal shared use document? Why or Why not?

ii. What do you see as the benefits to a formal shared use agreement?

iii. What do you see as the drawbacks to a formal shared use agreement?

iv. Have you had the opportunity to view a shared use agreement template or an agreement from another school or organization?

b. If yes:

i. Why did you choose to create a formal shared use document?

ii. What do you see as the benefits to a formal shared use agreement?

iii. What do you see as the drawbacks to a formal shared use agreement?

iv. Now that your shared use is in place, is there anything you would change (add, modify) about your written shared use agreement for the future?

8. Are you familiar with the West Virginia Shared Use Bill passed in 2015?

a. IF yes, how did you learn about the Bill?

i. Did the bill have any impact on your decision to facilitate a shared use initiative in your school?

9. Think about the support if any you received throughout the shared use development and implementation. 
a. Did you leverage political capital (i.e. the trust, goodwill, influence built up with the public through well-liked policies) during the shared use process? Please explain.

b. Did you have any educational training or material that informed you on how to develop and implement shared use initiatives? Please explain.

c. Did you feel you had adequate resources (money, time, skill etc.) to facilitate the shared use initiative? Please explain. What resources were needed?

10. Tell me about getting the word out about shared use in your community. (Probe: How did you publicize shared use of your facility with the intended users?)

11. Your shared use initiative is active, and the intended users have opportunity to use school space. How many people (students, family members, communtiy members) overall would you say take advantage of the shared use opportunity?

\section{Research Question: How does the community-school partnership influence the} development and implementation of shared use?

12. How did your community partnerships form?

13. Who were the key stakeholders involved in the shared use imitative at your school?

a. Tell me about the skills and strategies of the partners you worked with to accomplish developing the SUA.

14. Tell me about collaborating with community partners to implement shared use. Probe (Has collaboration been a plus or minus?)

15. Did any conflicts come up over the course of the shared use initiative? If yes, how did you resolve those conflicts?

16. How have you continued to maintain the community-school partnership?

\section{Conclusion}

17. How well do you think shared use "works" in your school?

18. What is the likelihood that you will continue to facilitate shared use in your school?

a. If yes, what do you think needs to change to make the process better?

b. If yes, do you think you will expand the opportunities? If so, how do you see this happening?

c. If no, why will you choose not to have shared use in the future?

19. Is there anything else you think may be important for me to know about your experience relative to the shared use process? 
That concludes the interview. Again, thank you very much for your time. I will be contacting the key stakeholders you mentioned to ask for their participation in a focus group.

Once I have completed the all the interviews and focus groups, I will transcribe the recordings and code for themes. For each case, I will create a summary and then compile all the cases into a final write-up. I will send out the final write-up of this study to you in May/June 2018.

Thank you. 


\section{Appendix L: Focus Group Protocol}

Participants' Names:

Location and Time: Date:

\section{Introductory Protocol}

To facilitate note-taking, I would like to audio tape our conversation today. I can stop recording at any time if you make the request. Only researchers on the project will have access to the recording. After the recording has been transcribed, the file will be destroyed. As a reminder about your participation in this research study: (1) all information will be held confidential, (2) your participation is voluntary, and you may stop at any time if you feel uncomfortable, and (3) we do not intend to inflict any harm. Again, thank you for agreeing to participate.

I have planned this focus group to last 45 - 60 minutes. During this time, I have several questions that I would like to cover.

\section{Introduction}

Thank you for taking the time to sit down and talk with me about the shared use initiative between your school and community.

You have been identified by your peers as a key stakeholder in the shared use process in West Virginia public schools.

Today I will ask you a number of questions about your experiences throughout the shared use process. The questions posed will fall under two broad categories: 1) Questions about the development and setup of the shared use initiative and 2) Questions specific to the design and implementation of shared use at this specific site. I will honor any request for confidentiality.

This study will identify characteristics that make the shared use successful, and how communityschool partnerships play a central role in the shared use process. Findings will be reported as themes and patterns within your school's shared use initiative and across the combined shared use cases. It is my hope that this study will produce practical guidelines for initiating and sustaining shared use initiatives and a better understanding of the formation and integral role community-school partnerships play in shared use initiatives. Before we begin, what questions can I answer for you? 


\section{Research Question: What are the influential factors of shared use?}

School shared use initiatives may incorporate key features, move through certain steps, or incorporate specific actions. This section of the questioning is geared toward gaining insight into how you started and continue to implement shared use.

1. Using the timeline you created as a guide, tell me about how the shared use imitative started at your school.

2. Is shared use a priority for you? IF yes, please explain.

3. No two communities are alike.

a. What originally made you consider shared use?

b. Who were the key people involved in the process?

c. Was there a specific group (seniors, children, etc.) who you thought would most benefit from shared use?

What areas or space do you share formally (with a shared use agreement or contract) or informally? How did you determine those would be the best use of resources?

4. Did you address responsibilities (i.e., risk, liability, maintenance) of parties (i.e., the school or community partner/organization) involved in the shared use of your facilities? IF yes, please explain how those responsibilities were delegated.

5. Do you have a formal shared use agreement or contract in place?

a. If no:

i. Have you considered creating a formal shared use document? Why or Why not?

ii. What do you see as the benefits to a formal shared use agreement?

iii. What do you see as the drawbacks to a formal shared use agreement?

b. If yes:

i. Why did you choose to create a formal shared use document?

ii. What do you see as the benefits to a formal shared use agreement?

iii. What do you see as the drawbacks to a formal shared use agreement?

6. Did you have knowledge of the intention of the Shared Use Bill passed in 2015? IF yes, what impact did it have on your decision to facilitate a shared use initiative in your school?

7. Tell me about getting the word out about shared use in your community. (Probe: How did you publicize shared use of your facility with the intended users?)

8. Your shared use initiative is active, and the intended users have opportunity to use school space. How many people take advantage of the shared use opportunity? 


\section{Research Question: How does the community-school partnership influence the development and implementation of share use?}

9. How did your community partnership form?

10. Tell me about collaborating as a community-school partnership team to implement a shared use initiative. Probes (Positives and negative to collaboration? What type of skills and strategies did your partners bring to the table)

11. Did any conflicts come up over the course of the shared use initiative? If yes, how did you resolve those conflicts?

12. How have you continued to maintain the community-school partnership?

\section{Conclusion}

13. Is there anything else you think may be important for me to know about your experience relative the shared use agreement process?

That concludes the focus group. Again, thank you very much for your time.

Once I have completed the all the interviews and focus groups, I will transcribe the recordings and code for themes. For each case, I will create a summary and then compile the all cases into a final write-up. I will send out the final write-up of this study to you in May/June 2018.

Thank you. 
Appendix M: Codes to Themes Analysis from Saldana, 2016, p. 14

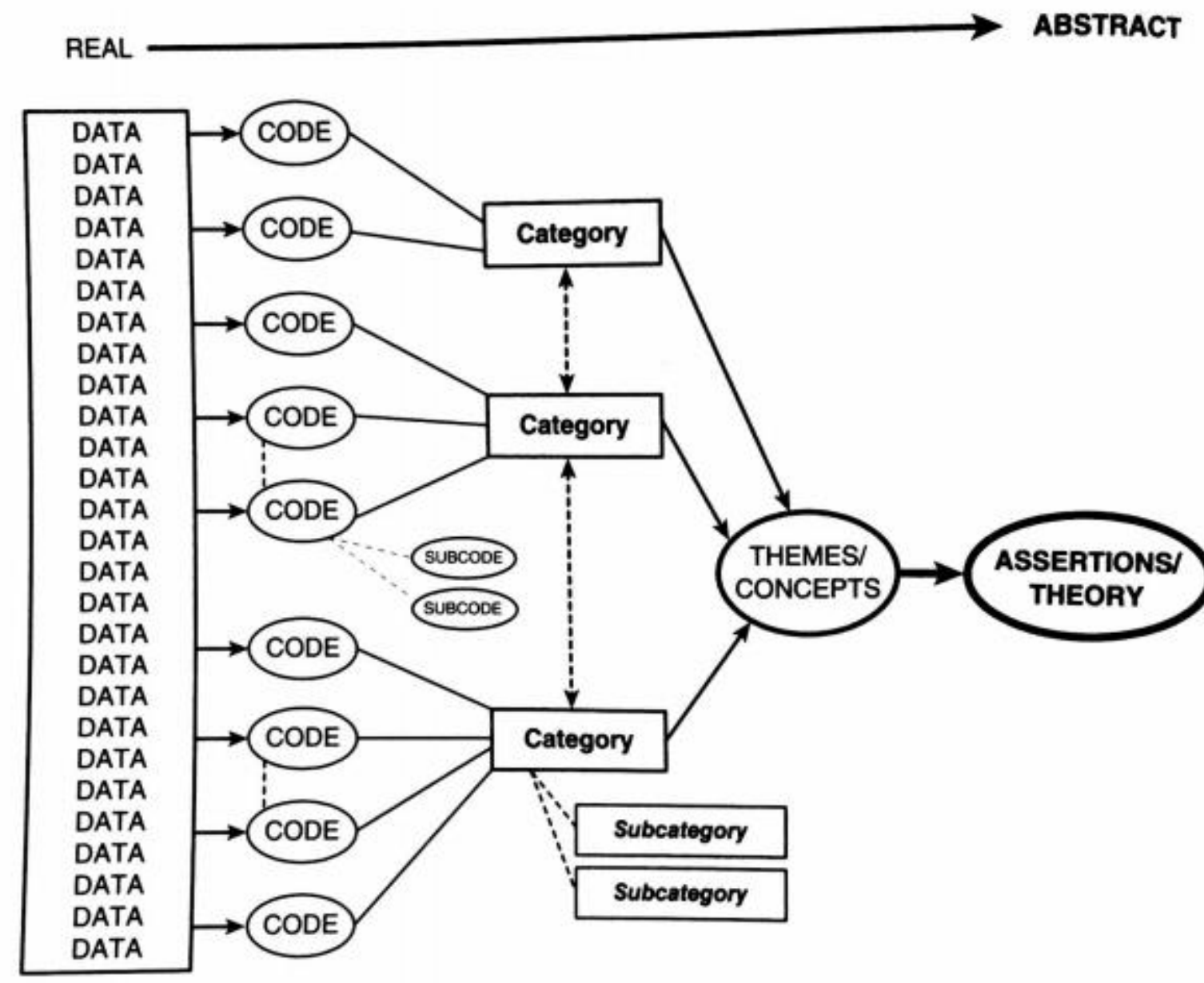

PARTICULAR 
Appendix N: Case Study Procedure from Yin, 2014, p. 60

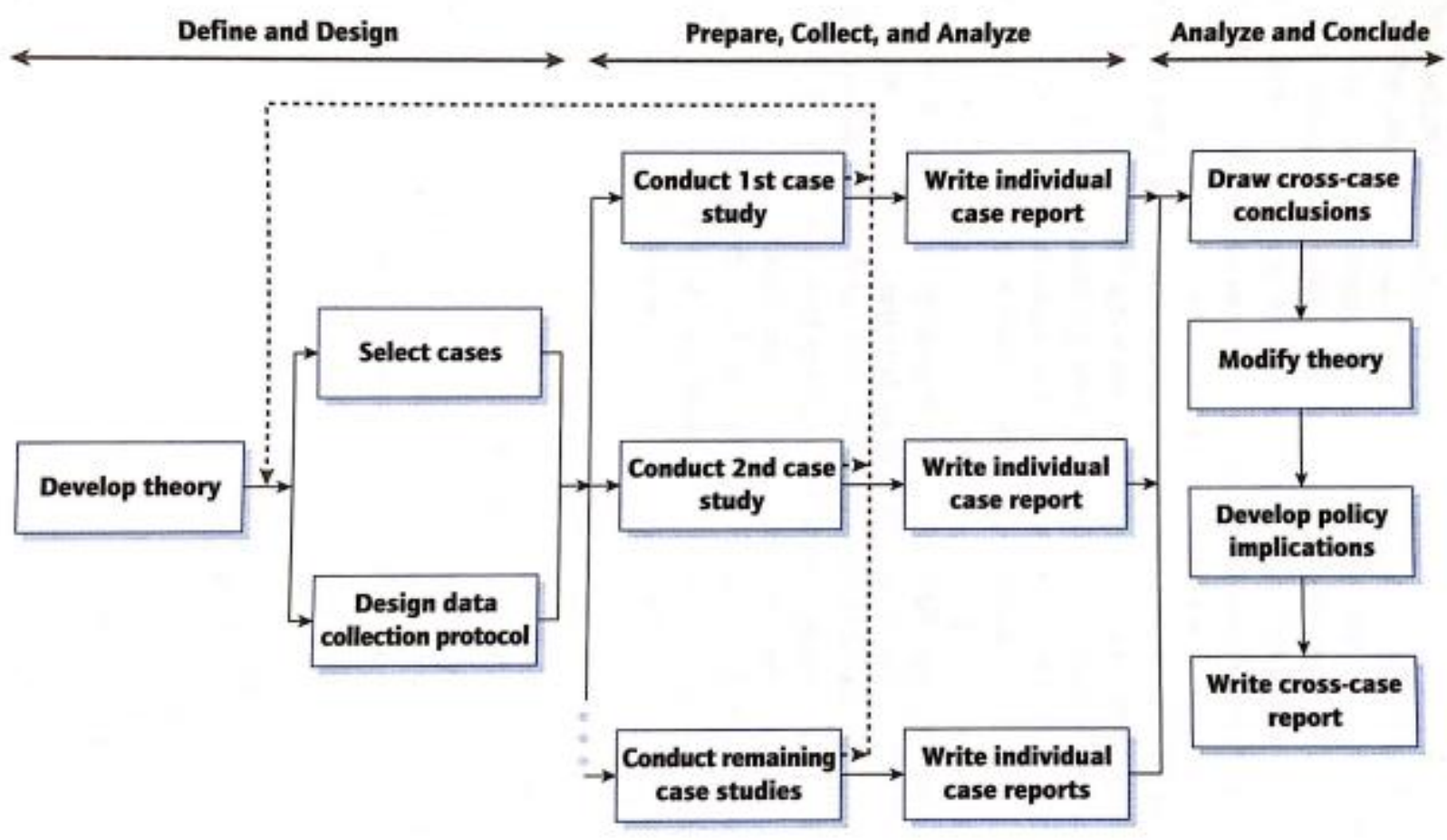




\section{Appendix M: Extended Review of Literature}

The goal of a SUA is to increase access to community opportunities for physical activity. Considering the features of the shared use process, the primary purpose of this study was to investigate and define the key characteristics of successful SUAs through the lens of communityschool partnerships to contribute to the existing literature and offer practical guidelines. The literature reviewed will provide a rationale for this study. The review presents relevant topics organized into five sections: a) health and physical activity, b) health-related public policy, c) shared use agreements, d) community-school partnerships, and e) theoretical frameworks.

\section{Health and Physical Activity}

Benefits of Physical Activity. Physical inactivity is now the fourth leading modifiable risk factor for mortality (WHO, 2010). As a nation, there is a need to focus on increasing physical activity behavior as increases in physical activity lead to improvements in overall health (Warburton, Nicol, \& Bredin, 2006). Participating in regular physical activity has numerous health, fitness, and well-being benefits. Health benefits include a lower risk of heart disease, diabetes, hypertension, and cancers (CDC, 2014; Kohl, 2001; Sothern, Loftin, Suskind, \& Udall, 1999; Warburton et al., 2006). Individuals who are physically activity have higher energy expenditure and lower mortality rates than their sedentary counterparts (Lee, Hsieh, \& Paffenbarger, 1995; Lee \& Paffenbarger, 2000; Oguma \& Sesso, 2002). Additionally, a physically active lifestyle has been shown to have positive effects on brain function and cognition in youth and adults (Hillman, Erickson, \& Kramer, 2008; Hillman, Motl, \& Pontifex, 2006; Kramer, Hahn, \& McAuley, 2001). Increasing participation in physical activity has also been shown to decrease depression and anxiety while increasing mental well-being (Fox, 1999; Paluska \& Schwenk, 2000). As physical activity is a key factor in maintaining a healthy body 
weight, links have been made between physical activity levels and body fatness (Moore et al., 2003; USHHS, 2008; Wofford, 2008).

Within the academic setting, the relationship between physical activity, cognitive functioning and academic performance is presenting promising results. Positive associations were found between physical activity, cognition, and academic performance in a systematic review of the literature (Donnelly et al., 2016). Bezold et al. (2014) in a longitudinal study found youth participants who increased their fitness levels by greater than $20^{\text {th }}$ percentile points improved their academic ranking the following year compared to students who had no change in fitness levels. In a cross-sectional study to examine the individual components of physical activity, cardiovascular fitness and motor ability (i.e. agility) were both found to positively influence academic performance (Esteban-Cornejo et al., 2014). Additionally, attention and ontask behavior are improved with physical activity in the classroom (Howie, Beets, \& Pate, 2014; Janssen et al., 2014). A study assessing the relationships between attention capacity and physical activity in 273 youth found moderate physical activity bouts have a positive effect on attention capacity (Vanhelst et al., 2016). To support academic performance and attention capacity, increasing opportunities available for physical activity should be considered.

Physical Activity Levels. The majority of Americans do not regularly participate in physical activity at a frequency high enough to achieve these health benefits (i.e. lower risk of chronic disease) (Troiano et al., 2008). According to the State Indicator Report on Physical Activity, 25.4\% of Americans are reporting no leisure-time physical activity (CDC, 2014). Nationally, $51.6 \%$ of adults are meeting the guidelines for 150 minutes of weekly aerobic activity, and $31.8 \%$ are achieving the 300 minutes of weekly aerobic activity. Fourteen percent 
$(14.3 \%)$ of the nation's youth reported no physical activity while only $27.1 \%$ met the minimum recommended aerobic activity guidelines (CDC, 2015b).

WV trends. In WV, $43 \%$ of adults are meeting the minimum recommendation for aerobic physical activity, while $26.1 \%$ are meeting the 300 minutes of aerobic activity and receiving additional health benefits. However, WV adults exceed the nationally reported value for no leisure-time activity at $35.1 \%$. West Virginia youth are holding steady with or exceeding the national percentages, where $31 \%$ are reporting meeting the aerobic activity guidelines, and $15 \%$ reported no leisure-time physical activity (CDC, 2014).

\section{Physical Activity Recommendations}

Children and adolescents. The Physical Activity Guidelines for Americans recommend 60 minutes or more of daily physical activity for children and adolescents. According to these guidelines, physical activity should be aerobic, age-appropriate, and performed at moderate- or vigorous-intensity (USHHS, 2008). To promote a healthy body weight children and adolescents should engage in aerobic activities that utilize large muscle groups like running, swimming, and jumping rope. Additionally, muscle-strengthening and bone-strengthening activities should be added to the recommended 60 minutes of physical activity at least three days a week. Musclestrengthening activities require the body to be stressed more than normal to strengthen the muscles. Unstructured activities, like playing on the monkey bars, or structured activities, like body weight exercises or resistance bands, are examples of muscle-strengthening activities. Bone-strengthening activities are higher impact activities, such as running or jumping, that promote bone growth. Providing many ways for children and adolescents to be physically active in their schools and communities will help them meet these physical activity guidelines. 
Adults. For adults, the current national recommendation is to achieve at least 150 minutes of moderate-intensity, or 75 minutes of vigorous-intensity aerobic physical activity each week for substantial health benefits (USHHS, 2008). As adults increase the amount of physical activity additional health benefits are attained by accumulating 300 minutes of moderate-intensity, 150 minutes of vigorous-intensity, or a combination of the two a week. Muscle-strengthening activities performed at a moderate to high level of intensity should also be included two days out of the week. Providing more accessibility to physical activity opportunities in the communities in which they interact will help adults meet these national recommendations.

Physical Activity Opportunities. Many factors can contribute to the lack of physical activity in a population. One factor that plays a role is access to physical activity opportunities. According to the 2017 County Health Rankings, only 58\% of West Virginians have adequate access to a location for physical activity. The lowest-ranking WV County, McDowell, reports only $47 \%$ of its population has access to physical activity opportunities while Jefferson, the highest-ranking WV County, reports $67 \%$ of the county population has adequate exercise opportunities. The top 10\% of ranked U.S. counties (approx. 300 counties) report an average of $91 \%$ of their population has access to adequate physical activity locations (University of Wisconsin Population Health Institute, 2017).

The geographical location of West Virginia in the Appalachian mountain region and the built environment (i.e. roads, community design) contribute to the lack of access to physical activity opportunities (O'Hara Tompkins, Zizzi, Zedosky, Wright, \& Vitullo, 2004). A strategy to overcome the lack of accessibility is to approach access from a local context and utilize the assets available within a community. One community asset is the school. In fact, the Society of Health and Physical Educators of America (SHAPE) takes the position that all schools should 
implement a Comprehensive School Physical Activity Program (CSPAP). Two of the five main components of CSPAP are physical activity before and after school and family and community engagement (CDC, 2015).

Before and After School. Making use of school facilities before and after school for physical activity is one way to increase access to physical activity opportunities. In an evaluation of a ten-month after-school physical activity program, participants showed a significant change in body composition (Barbeau et al., 2007). Similarly, when examining a three-year afterschool physical activity intervention, Gutin et al. (2008) found the effect of participation resulted in significant improvements in participants' fitness and body fatness. These after-school programs not only have direct fitness effects for participants but when the program is coordinated by a community organization, there is the potential to generate a beneficial relationship between the community and the school. "These programs might provide benefits to the students, families and community members" (CDC, 2015, p. 14).

Family and Community Engagement. When parents and children are active together, both can experience health benefits (Lee et al., 2010). Coupling the school initiatives with family engagement has proven to be a successful strategy for promoting healthy behaviors in students. For example, it is more likely children will meet physical activity recommendations with increased family involvement and cohesion (Ornelas, Perreira, \& Ayala, 2007). Using the school as a recreational asset allows children, parents and community members to be involved in school physical activity promotions and events outside of school hours. "Community involvement allows maximum use of school and community resources and creates a connection between school and community-based physical activity opportunities. Community organizations might 
provide programs before or after school or establish joint-use or shared use agreements with schools" (CDC, 2015, p. 16).

\section{Health-related Public Policy}

Traditionally public health efforts to change behavior have focused on individual level interventions which encourage people engaging in a high-risk behavior (i.e. smoking) to take action to positively change the behavior (Culter, 2004). Individual level behavior interventions require the individual to be self-motivated and make an active decision to choose a healthy behavior change on their own (Schmid et al., 1995). Examples of are individualized interventions are smoking cessation programs, blood pressure monitoring and physical activity groups for chronic disease populations. Individualized approaches have been found to be difficult to sustain, time intensive and costly (Brownson, Haire-Joshu, \& Luke, 2006). Limited long-term success has been found when using traditional individual level interventions to increase adherence to physical activity (Mutrie \& Woods, 2003). The Institute of Medicine (IOM) has recognized the limited success of individual measures and redefined health, as not merely the result of clinical care, but the result of what we do as a society to create the condition in which people can be healthy (Institute of Medicine, 1988).

As a way to more effectively target population health, a shift in focus in public health has occurred away from individual level interventions and toward policy, systems, and environmental strategies (Institute of Medicine, 2001; Kohl et al., 2012; Lyn et al., 2013; Task Force on Community Preventive Services, 2002). Broadly, a policy is a statement of action to be carried out by government, an agency or an organization (Schmid, Pratt, \& Witmer, 2006). Policies can influence behavior at multiple levels (i.e. environmental, social). Policy gives structure and organization for collective action to achieve an intended goal in public health (Bull, 
Bellew, Schöppe, \& Bauman, 2004; Schmid et al., 2006). Successful implementation of state, regional, or local level policy has the potential to create a supportive environment to elicit change within the target population (Woods \& Mutrie, 2012). Some examples of supportive, health-related environmental policy changes are requiring housing projects to be built with recreational facilities (Schmid, Pratt, \& Howze, 1995), opening school recreational facilities for community use after hours (Evenson \& McGinn, 2004; Sallis et al., 2001; Young et al., 2014), and designing streets for all users who walk, drive, bicycle, or use public transportation (Smart Growth America, 2017).

In public health policy literature, two areas have emerged as the primary focus of policy change: nutrition and physical activity (Sacks et al., 2008). Previous individual interventions targeting nutrition and physical activity have been mostly ineffective (Lyn et al., 2013). Sacks, Swimburn \& Lawrence (2008) in a systematic review of public health population level environmental approaches across multiple sectors and levels of government identified targeted strategies that positively impacted food systems and physical activity environments. Policy areas that influence the food system change were community gardens, food safety, subsidies and taxes, marketing practice in schools and to children, and products sold in schools. Examples of physical activity environment-based strategies were identified as walking and cycling environments, physical education in schools, facilities for physical activity in schools, school travel policies, public liability, and general community access to school recreation and sports facilities. The strategies identified can provide a guide for how sectors and government can become involved, but are only the first step to understanding nutrition and physical activity policy action (Sacks et al., 2008). Further investigation is needed into stakeholder collaboration, knowledge building, and policy development, dissemination, implementation, and evaluation. 
Physical Activity Policy. As a public health priority, physical activity policies provide a foundation for schools and communities to increase physical activity levels of the population. Once a local, regional, or state policy has been developed and enacted, successful implementation has the potential to reach individuals within and across multiple settings (Kanters, Bocarro, Filardo et al., 2014; Spengler, Young, \& Linton, 2007; Woods \& Mutrie, 2012). Policy action plans provide those involved at the implementation level with support, guidance and consistency to achieve a set goal (WHO, 2010). Partnerships established at the onset of policy development and implementation can enhance collaboration and interaction across sectors (Woods \& Mutrie, 2012). Sectors can be categorized into "various groups that people within the larger community might be divided into for reasons of common social, political, economic, cultural or religious interests" (Center for Community Health and Development, 2017). Societal sectors (i.e. business/industry, education, healthcare, transportation) can and should work collaboratively to achieve and implement physical activity policy and action plans (National Physical Activity Plan Alliance, 2016). Sectors where public health is not necessarily the primary focus (i.e. business, education) have the potential for significant impact on population health and well-being (Bull et al., 2004). Having decision makers within each sector that view physical inactivity as a problem can help positively influence physical activity policy and awareness (Leyden, Reger-Nash, Bauman, \& Bias, 2008). Promoting physically active lifestyles can lead to increased awareness across multiple sectors and the formation of mutually beneficial partnerships (Burbage et al., 2014). For example, applying mixed land-use strategies to create school environments that promote physical activity during the school day for the students and after the school day for the community members relies on both environmental and education sectors for their expertise. 
Policy research targeting physical activity has increased over the last two decades (Dunton, Cousineau, \& Reynolds, 2010; Rütten, Abu-Omar, Gelius, \& Schow, 2013; Schmid et al., 2006). Physical activity policies a) outline physical activity as a priority area, b) identify specific population goals, and c) provide a framework or action plan to achieve goals (Bull et al., 2004). Bull and colleagues' (2004) review on policy development identified 11 criteria for successful physical activity policy and action plans: a) consulting with the principal stakeholders, b) using of multiple strategies (i.e. individual and environmental levels), c) utilizing layers of government or organizations (i.e. state, local), d) working across partnerships within a community, e) creating sustainability, f) marketing the policy (i.e. logo, communication plan, spokesperson), g) setting a timeframe, h) creating an evaluation plan, i) establishing surveillance measures, and k) including national physical activity guidelines. The focus of policy for physical activity promotion has been on a) selecting and funding physical activity resources, b) addressing regulations that prompt or inhibit physical activity, and c) examining the process involved in decision making which can include addressing the importance placed on physical activity or any undermining initiatives (Sallis et al., 2006). In a review of environmental and policy approaches to increase physical activity, Kahn et al. (2002) found through a correlational study that physical activity levels are associated with the availability of exercise opportunities. These findings provide strong support for the role policy and environmental changes can play in combatting physical inactivity within a community through the adoption of enhanced access measures.

A causal sequence model for how physical activity policy moves from creation to enactment was developed by Schmid et al., (2006). The model depicts how policy can have a direct or indirect effect on physical activity depending on the mechanism of action (i.e. policy, social, cultural or physical environment). To better conceptualize physical activity policy efforts, 
Schmid et al., (2006) proposes researchers address policy from three points of view: a) the critical component of policy (i.e. determinants, implementation, and outcomes); b) the sector setting where the policy is applied; and c) the scale (i.e. local, regional, state) at which the policy is applied. The CDC identified a physical activity policy priority as determining effective school policies and strategies. However, there is limited research on the impact of sector partnerships and policies on school facility use and physical activity (Beets et al., 2013; Kanters et al., 2014b). Expanded efforts to better understand physical activity policy implementation are needed.

To gain access to facilities, policy and environmental structures must be in place. The importance of policy in facilitating physical activity opportunities has been noted (Mowen \& Baker, 2009; Sallis, Bauman, \& Pratt, 1998). Limited evidence exists regarding the effectiveness of policies and practices to promote after-school physical activity (Beets, Beighle, Erwin, \& Huberty, 2009). In a meta-analysis by Beets et al.(2009), only 13 articles out of 797 described interventions with physical activity as a primary component. The finding suggests little support for after-school programs to improve children's physical activity levels.

By modifying environmental or contextual factors, policies can increase access to physical activity opportunities which may influence social factors like perceived barriers, social norms and stimulus control (Dunton et al., 2010). Greater access to physical activity resources can positively impact self-efficacy (Dishman et al., 2004) and enjoyment of participation (Anderson, Stodolska, \& Gobster, 2006). As the built environment plays a role in physical activity, positive effects are seen with increased access to facilities (Choy et al., 2008; Humpel, Owen, \& Leslie, 2002; Kanters, Bocarro, Moore, et al., 2014). In a review of 19 quantitative studies, accessibility, opportunities, and aesthetic qualities had significant associations with 
physical activity. In fact, sharing school recreational spaces has been recognized as a strategy and recommended on the national platform by the National Physical Activity Plan (National Physical Activity Plan Alliance, 2016), the American Heart Association (Young et al., 2014), the 2010 White House Task Force on Childhood Obesity, and is listed as an objective for Healthy People 2020 (USHHS, 2016). On the state level, the West Virginia Physical Activity Plan identifies maximizing physical activity opportunities before, during and after school and advocating for accessible, affordable physical activity facilities as priority tactics to promote physical activity (Bulger et al., 2015). Further investigations into context-specific strategies are needed to enhance the creation and implementation of initiatives to increase access to recreational facilities.

\section{Shared Use Agreements}

Leadership at the school and community level are beginning to recognize the critical role the built environment can play in influencing physical activity behaviors. One way to gain access to existing physical activity infrastructure is through a SUA. SUAs provide the community with access to school recreational facilities and grounds outside of school hours to increase physical activity levels and enhance the community's social environment (Lafleur et al., 2013). Shared use is a flexible term. It is also known as community use or joint use. There are numerous definitions for shared used. "Joint use is an agreement between a district and another public or private entity where facilities, land, utilities or other common elements are shared between two or more parties on sites" (Cooper \& Vincent, 2008, p. 3). Downer et al. (2016) stated shared use "refers to the concept of opening local buildings and grounds at a time when they are usually closed in order for residents to exercise and engage in other recreational activities" (p. 2). Additionally, Omura et al. (2016) defined shared use as agreements "that allow public use of 
school facilities during non-school hours" (p. 1). The common thread between the shared use definitions is that shared use allows access to designated spaces. In this case, the school is allowing access to its recreational spaces outside of school hours for community use.

Spengler et al. (2007) noted that shared use is not a novel concept. Shared use is documented as early as 1821 when a Salem Massachusetts school provided access to its recreational facilities for community use (Meyer \& Brightbill, 1964). In 1885 Dr. Marie Zakreweska built the first playground in the U.S. in Boston, MA. The playground movement took off, and in an effort to improve social conditions for urban dwellers, 21 playgrounds were constructed for community use in Boston by 1889 (Hanson, 2013). Soon following, the Division of Community Centers for Vacation Playgrounds was established by New York City's board of education which led to the development of multiple community centers throughout the city and surrounding area (Kraus, 1964). In an Educational Policies for Community Recreation bulletin, it was noted that sound educational policy requires public school properties to be opened to public use outside of school hours (United States Board of Education, n.d.). Meyer and Brightbill (1964) suggested that "where a community is unable to sustain both an education and a recreation system it is the obligation of the school to sponsor and operate a community recreation program" (p. 165). The recreational user policy that the school should aid in providing community recreation paved the way in the 1950 s and 1960 s to double the recreational programming offered in U.S. schools after hours (Kraus, 1964).

SUAs have seen a resurgence as researchers, practitioners and policy-makers have embraced ecological models to efficiently create opportunities for community physical activity engagement (Sallis et al., 2006). More recently, a number of states (i.e. California, Missouri, New York and Texas) have passed legislation to facilitate shared use between the school and 
community to provide physical activity programming and open access to school facilities for recreational use outside of school hours (Cal Ed Code $\$ 10900,2006$, NY CLS Ed §414, 2006, RS Mo $\$ 67.775,2006$, Texas Local Gov’t Code $§ 332.021,2005)$. West Virginia was added to the list of states that have a federal shared use policy. In 2015 West Virginia Legislature passed the Shared Use bill. The Shared Use bill provided schools with limited liability protection which will allow schools across the state of WV to open their doors and facilities to the public. Since 2015, 43 WV schools have created formal SUAs (THEHUBWV, 2016).

Shared use programming for community use can range from organized after-school and weekend physical activity events, to open public access to school grounds, to community gardens (Cooper \& Vincent, 2008). Typical facilities included within a SUA are gymnasiums, other athletic facilities, tracks, playgrounds and outdoor spaces (Downer et al., 2016). The primary objective of shared use is to utilize the existing built environment of a school to create more physical activity opportunities for a community. Schools opening their facilities for community use continue to provide good cases of well implemented SUAs. For example, in Springfield, MA, public school gyms are open in the evenings for basketball programming (Downer et al., 2016). In Honolulu, one urban high school opened its doors before and after school for various recreation classes offered free to the community (Choy et al., 2008). At Kenna Elementary School in Jackson County, WV the community has access to the rebuilt playground and walking track after school hours (Lynch, 2015).

A SUA can include community members' informal use for unstructured, unsupervised activity and for supervised, community-sponsored activity like supervised open gym hours (Young et al., 2014). Shared use can occur through two formats. The first format is a formal agreement. In a formal SUA, the agreement describes the responsibilities, obligations, and 
expectations of all parties involved (Downer et al., 2016). The second format is an informal arrangement like unlocking school playgrounds. However, advocates for shared use strongly encourage schools and communities to formalize any informal arrangements, so they are sustained long after the existing personal relationships that first formed the arrangement. Formalized SUAs also allow schools to qualify for grants or financial assistance designated for schools implementing shared use policies (THEHUBWV, 2016).

In 2012 the CDC conducted the School Health Policies and Practices Study (SHPPS). In an analysis of the SHPPS, Jones \& Wendel (2015) examined school district characteristics associated with having a formal SUA. Their findings indicated $61.6 \%$ of schools nationwide had a formal SUA. However, SUAs were more common in the West, and in large, urban school districts. SUAs were less common in rural areas which is in line with other research that has found rural, lower-income communities to lack opportunities for physical activity (Hansen et al., 2015; Umstattd Meyer et al., 2016). More than $80 \%$ of the formal SUA included use of both indoor and outdoor facilities (Jones \& Wendel, 2015).

Why Shared Use? "Physical activity is placed-based" (McKenzie, 2016, p. 334). The lack of access to places and facilities is a common barrier to engagement in physical activity. Increasing access can enhance physical activity participation and encourage community residents to live more healthy lives. Maximizing already existing physical activity resources can provide safe spaces to be active outside of school hours (Downer et al., 2016; Evenson, Wen, Lee, Heinrich, \& Eyler, 2010). In regards to shared use "public school facilities have emerged as an area of public health advocate attention because of their great availability in U.S. communities and their importance as a place for physical activity" (Young et al., 2014, p. 1584). Often schools are only utilized during school hours. Schools are a community resource equipped with indoor 
and outdoor facilities as well as open field space or tracks for physical activity opportunities, but many school grounds are left empty when the school the day ends (Cooper \& Vincent, 2008). Not utilizing shared use for mutually-beneficial community-school development is a missed opportunity.

Shared used works within the local context as many schools and school districts have a commitment to serve the community by providing some level of general, public use of their grounds or facilities. Four local factors impacting the demand for shared use of the public school are demographic patterns, housing, community character, and school district capital infrastructure. Student enrollment varies based on the local demographics, so every school has a unique challenge to meet the needs of not only the students but the community in which it is located. The physical location of the school, as well as the density of housing and the community, affect the need for the SUAs. Shared use makes sense for communities with schools in the center of densely populated neighborhoods as well as in schools districts with a wider spread population as resources may not be as abundant (Filardo et al., 2010). In areas where the community population is more spread out, the school may serve as the central hub for that community (Hansen et al., 2015; Kristjansson et al., 2015). Viewing the school and its recreational resources as a capital investment can reignite community partners, the local government, and the schools to work together to provide resources to the people of the community increasing collaboration and support (Filardo et al., 2010).

\section{Barriers and Facilitators to Shared Use Implementation.}

Barriers. While shared use can foster community collaboration and support, there are real and perceived barriers that the school and community must confront to allow access to school recreational facilities. One common barrier to the widespread implementation of SUAs include 
budgets constraints as extending a facility's hours beyond the normal school day can increase operations, maintenance, and staffing costs (Burbage et al., 2014; Filardo et al., 2010; Spengler et al., 2011; Young et al., 2014). However, in a cost-benefit assessment of 30 middle schools offering after-school physical activity programs found policies that permitted shared used for community-based physical activity programming increased participation without significant increases in operating costs (Kanters, Bocarro, Filardo, et al., 2014).

Liability is a major concern for school administrators (Public Health Law Center at William Mitchell College of Law, 2012; Spengler, Carroll, Connaughton, \& Evenson, 2010). Spengler et al. (2011) in a national survey of school administrators found $82.2 \%$ of respondents were concerned with liability. Even when there was an existing state law providing limited liability protection for schools, $75 \%$ of school administrators were still concerned with liability. Safety is another barrier. Poor risk management strategies make community member safety and building security a challenge that must be overcome (Burbage et al., 2014; Filardo et al., 2010; Young et al., 2014).

Still, other barriers address the policy, built, and social environments surrounding SUAs. In a review of physical activity related policy and environmental strategies, barriers to moving an initiative forward were community support and political will (Umstattd Meyer et al., 2016). Inadequate school, district or state level policies can lead to under-informed school leaders resulting in poor decision-making processes or unclear guidelines for shared use at the local level (Filardo et al., 2010; Spengler, 2012; Young et al., 2014). Establishing a chain of command and common language between all parties involved in the SUA process poses a challenge. The design of the school recreational space itself can be a barrier to the ease of use and the ability to accommodate different users in the space (Filardo et al., 2010; Young et al., 2014). 
Facilitators. There are more public school buildings than any other public facility in the U.S. (Filardo et al., 2010). As schools are publicly supported, they morph into local assets with recreational resources. Within a school-based SUA, community members are granted access to a safe, accessible and familiar place to be physically active outside of school hours. Shared use of recreational school spaces has been shown to increase physical activity levels in children and adults, help decrease obesity rates, and increase social activity among community members (Cooper \& Vincent, 2008; Downer et al., 2016). Poortinga (2006) in an analysis of the 2003 Health Survey found when community members had positive perceptions of their social environment (i.e. social activity facilitated through shared use) there was an association with increased physical activity and lower levels of reported poor health and obesity.

Not every community member has a school-aged child. According to the U.S. Census Bureau only $43.5 \%$ of households have children younger than 18 years (Vespa, Lewis, \& Kreider, 2013), so shared use may enhance taxpayer support for education facilities when community members see tangible evidence that tax revenues benefit households without children in the local public school systems (Jones \& Wendel, 2015). The prospect of community use helps secure support for tax increases required to repay the cost of construction for school facilities. This support is accompanied with the expectation that the enhanced or newly constructed school recreational spaces will be open for community use (Filardo et al., 2010). There is a cost saving benefit realized by both the school districts and local partners when shared use is employed. Opening the doors to school facilities helps to avoid duplication of other physical activity opportunities provided by tax-supported monies (Spengler et al., 2007).

Considerations throughout the Shared Use Process. Where does a community member or school administration start when wanting to put shared use into action? Creating a well- 
structured SUA can address concerns like liability, maintenance, staffing, security, and facilities accommodations and use (Jones \& Wendel, 2015). Downer et al. (2016) at the Center for Health Law \& Policy Innovation of Harvard developed The Massachusetts Community Use Toolkit to help guide community members on how to gain access to available community resources (i.e. school) to increase opportunities for physical activity. To take shared use from an idea to a sustainable agreement in action, the Toolkit outlines nine steps which are: a) developing a concept, b) choosing a location, c) identifying and approaching the key players, d) creating a budget and identifying sources of funding, e) managing risk, f) writing the community use agreement, g) planning for disagreement, h) publicizing the initiative, and i) developing a community use timeline and tracking progress.

When developing the concept for how the recreational space will be shared, the community need should be assessed. Epstein (1995) recommends going to the community to ask what they would like to have happen in a shared use space. This can be accomplished through town hall meetings, interviews or surveys. This open line of communication creates a whole community initiative, not just the interests of a few. The type of activities should also be considered in the needs assessment (Downer et al., 2016). Choy et al. (2008) piloted a joint use agreement with an urban Honolulu high school. The preferred type of physical activity offerings of the students, staff and community members were assessed to help guide the development of program offerings and space needed for each activity. As each community make-up is unique, some agreements take a more open form like an open playground or track during non-school hours while others are more structured and provide programming to meet a community need. While public schools are typically equipped with recreational facilities, for the SUA the location and included spaces (i.e. indoor vs. outdoor facilities) need to be decided. Downer et al. 
(2016) recommend that the shared space is familiar and accessible to the intended users. Cleanliness, lighting, and maintenance of the facilities should also be considered. The school space being shared should be easy to secure outside of school hours, so users are not accessing other areas of the school that could put them or others at risk. Along with security, safety is another concern to address as actions may need to be taken to increase the safety measures during shared use hours (Choy et al., 2008).

Downer et al. (2016) describe the next step in the SUA process as building a team of community stakeholders. With state-level policies in place and support from district and school administration, putting a community team together is a critical piece in the shared use process. The members of the team should be diverse to ensure all voices are heard (Epstein, 1995). The team should include at the very least school administration, a representative from the town, and a representative of the organization or community that wants to utilize the school space (Downer et al., 2016). Other stakeholders to be considered when constructing a team are town planners, school personnel including teachers and custodial staff, public health professionals, parents, students, and residents in the community (Downer et al., 2016; Hansen et al., 2015). The goal when forming a team should be that it is a community-school based team. When the communityschool team takes ownership, the SUA becomes sustainable and not based solely on one person moving an initiative forward (Epstein, 1995).

"Community use is about maximizing use of existing facilities at the lowest possible cost" (Downer et al., 2016, p. 20). While shared use can occur with little to no additional cost, the cost is still perceived as a barrier (Kanters, Bocarro, Filardo et al., 2014; Spengler et al., 2011). When moving forward with a SUA, creating a budget should be included as an action 
item. The cost of maintaining equipment and grounds, extra hours required for staffing, cost, and if needed, additional equipment should be discussed.

Liability is the "legal responsibility for something, such as someone else's injury or damage to property" (Downer et al., 2016, p. 20). Liability must be discussed in any communityschool access decision making. Spengler et al. (2010) found in a survey of school administrators in four U.S. communities liability was one of the top three perceived barriers. These findings were echoed in another study where $82.2 \%$ of surveyed school administrators in underserved communities indicated some level of concern about liability (Spengler et al., 2011). However, schools are required to carry insurance that provides liability coverage and a risk management strategy will be written in as a section in a formal SUA. In a review of recreational user statutes, Spengler et al. (2010) found WV had a recreational user statute from 1965 that could potentially limit liability for schools who choose to open their facilities to community members after school. More recently in WV, legislation passed the Shared Use Bill that states "in addition to the liability protection for organized use...county boards are not liable for any loss or injury arising from the use of school property made available for unorganized recreation" (S238, 2015). The WV Shared Use bill effectively removes liability for schools that allow community use of their facilities. While legislation supports shared use, steps should be taken by the school to maintain the safety of the grounds, facilities, and ensure the equipment is in good condition for community use (Downer et al., 2016).

Burbage, Gonzalez, Dunning, Simon, \& Kuo (2014) evaluated the legal clauses in SUAs within seven Los Angeles County school districts that were consider to be under-resourced with a high obesity prevalence. For each school district, a review of their physical activity related programming was conducted along with site observations to assess shared use implementation. A 
school and community partner survey was distributed to identify comparisons of legal issues across all SUAs. Three major legal categories (cost responsibility, sustainability, and scope) were identified and used to analyze the SUAs. Only eight of the 18 SUAs analyzed contained a majority the legal issues identified through the survey. The authors suggest when school legal concerns are addressed, the SUA is more comprehensive and is a promising, safe strategy for increasing access to physical activity opportunities.

After the space, cost, and liability have been discussed, the physical SUA document should be written. Downer et al. (2016) recommend a list of issues be discussed and included in the official SUA to create the most comprehensive agreement possible. One of the 22 items is defining the term of the agreement. Does the agreement have beginning and end dates or is there an automatic renewal of the agreement each year? Another discussion item is supervision. It must be decided who will be responsible for supervising the users of the school facilities or if supervision is necessary. For example, in a playground SUA for use after school hours, no supervision may be required; only a custodial staff member would be needed to close and lock the gate at the end of the night. For each issue, a description of the solution should be included and how that decision will be facilitated. See Appendix A for a full list of the agreement items and item descriptions.

Even with a comprehensive SUA, conflicts may arise. It is imperative to have a way to handle and resolve conflicts. Downer et al. (2016) recommend three strategies to utilize in the conflict resolution process. The first strategy is to maintain communication with regular checkins. This alerts the team to any unresolved issues quickly, ensuring each team member knows what is happening. The next strategy is to identify someone who can take the lead to resolve the conflict. Lastly, the team should decide on a course of action and put it in place without delay. 
This may mean the team will need to set aside time for additional meetings to reach a timely resolution.

The last two steps in the Toolkit are implementation and evaluation. A formal written SUA does not mean the community will use the newly opened space. The agreement must be publicized. Using the school's website or social media platform, as well as press releases, school announcements, newsletters and hosting a kick-off event are all ways to jump start shared use. After the community is aware of the shared use initiative, how is the success of the SUA being measured? Tracking the utilization of the space, the age group of the users and peak hours of use outside of school hours are a few measures that can be collected to evaluate shared use. For example, Schultz, Wilhelm Stanis, Sayers, Thombs, \& Thomas (2016) through direct observations using the System for Observing Play and Recreation in Communities (SOPARC) found community member park use increased over a three year span. Another study using SOPARC assessed whether SUAs increased community member use in 12 school facilities. The findings showed community member use was increased with the presence of a formal SUA, especially when physical activity programming was provided on site during non-school hours (Lafleur et al., 2013). These numbers can provide support for the shared use initiative, adapt programming to meet the community members' needs, and if the initiative is not as successful as the team had hoped, action can be taken to increase awareness (Cooper \& Vincent, 2008; Downer et al., 2016).

SUAs can look very different when practically applied based on the context of the setting in which the agreements are implemented. Choy et al. (2008) presented a case study of a pilot joint used agreement program in an urban Honolulu, HI high school. A needs assessment was conducted within the selected school and surrounding community to determine the types of 
physical activity opportunities to be offered. A partnership was formed between the Department of Public Recreation (DPR) and the school to formalize and implement a shared use agreement. The school offered recreational classes taught by certified instructors to the community before and after school hours. Additional physical activity classes were offered during the lunch hour to the school's students, faculty and staff. The main findings highlight the importance of when activities are offered as critical piece in increasing participation, the value of publicity and allowing word-of-mouth to spread, and the potential contribution of the formal relationship between the DPR and the school. Factors to be considered when forming a partnership are the ability of the partners to work well with each other and mutual respect.

In a joint report from Center for Cities \& Schools and Public Health Law and Policy, Cooper \& Vincent (2008) examined three shared use cases in urban/suburban California schools. For each case, shared use documents were reviewed and interviews were conducted with school district staff and a district partner. Within each case the facility, local context, program drivers, implementation, responsibilities, design features, administration operations, accomplishment and challenges were described. The authors suggest that liability concerns can be overcome with strategic and comprehensive planning. Shared use recommendations that arose from this multiple case study were: identify a local need for shared use, identify essential partners, ensure communication, and monitor implementation progress.

\section{Community-School Partnerships}

Although previous literature has defined the characteristics of a SUA and evaluated physical activity as a result of the SUA, there is gap to be examined between enacting shared use policy and implementing a SUA at the local level. A critical piece in keeping the shared use process moving forward is identifying the key stakeholders and forming a shared use team. 
These stakeholders and team members form a partnership. Partnerships are people and organizations from multiple societal sectors within a community who join forces and unite resources to reach a common goal. Recognized as a prominent public health strategy, partnerships work toward the improvement of community health and well-being (Roussos \& Fawcett, 2000). Within the local context, community means people located in the same geographical area, a rural school district or an urban neighborhood (Meyer \& Brightbill, 1964; Roussos \& Fawcett, 2000). Partnerships can improve community-level population health by creating sustainable environmental changes (McLeroy et al., 1988; Stokols, 1992). Partners within a community recognize each other needs and are united by common interests. They take mutual responsibility in achieving a shared vision and work together to enhance programming and opportunities for their organization and community as a whole (Epstein, 1995). This is seen in community-school partnerships when school administrators, teachers, parents and the community view each other as partners. A relationship begins to form and change starts to take shape.

A community-school partnership is defined by a set of distinctive relational characteristics built on the school's setting, community, and location (Bauch, 2001). It is the relational features that create the building blocks for a community-school partnership. Partnerships require connections to be forged. Partnerships bring key stakeholders to the table from the school and community to initiate policy, develop programmatic and environmental change, and increase access to resources and physical activity opportunities (Omura et al., 2016). Prior to the 1950 s, community stakeholder involvement within the school was common. Town hall meetings were held to allow community stakeholders to have a voice and advocate for individual and group interests. These town hall meetings began to dissolve as a representative 
democracy emerged in the form of educational school boards. School boards served as the governing school body in which educational board members elected by the community along with school administration made decisions for the community (Levin, 1999). However, there has been a resurgence in community involvement within the school structure. Community involvement is now being viewed as an asset, as building a broad range of relationships with stakeholders can promote political capital, establish coalitions, and facilitate change in the school environment (Bauman, 1996).

The community and school setting allow for multidisciplinary partnerships to develop to meet the unique needs of each place. In a lessons learned paper from 25 Active Living by Design (ALbD) communities, Bors et al. (2009) identified multi-level strategies to increase physical activity through policy, environmental and sociocultural changes within the communities. Creating multidisciplinary partnerships to bring people together with varied skills, knowledge, motivations, and feel for the local climate is essential. Peer to peer exchange that occurs within the partnership platform facilitates a powerful method for capacity building, advocacy, increased awareness, and shared learning. These multidisciplinary partnerships were instrumental in generating important health-related outcomes across the 25 communities involved in the ALbD initiative.

There are multiple benefits to partnerships. Collaborative community stakeholder efforts can improve the community-school climate, harness family support, increase skills and leadership within the community and forge stronger connections between families, the school and the greater community (Epstein, 1995). Filardo et al. (2010) refers to the role of communityschool partnerships in the provision of more resources to schools. These resources might include access to local government officials, financial means, or increased political capital to facilitate 
change. As schools serve as the center for many communities, various models and frameworks address the importance of involving the community to improve health. An example is the Whole School, Whole Community, Whole Child model. A major component of the model is actively engaging community resources and fostering partnerships. One particular way a communityschool partnership could contribute to the well-being of the community is to support efforts regarding shared use of school recreational facilities (Lewallen, Hunt, Potts-Datema, Zaza, \& Giles, 2015).

Cardon et al. (2012) stated community-school partnerships should be the recommended avenue for physical activity promotion. Using the built environment of a school's recreational facilities is a low-cost way to promote and increase physical activity. However, using the school's built environment is seen as a convenience, not the standard. In fact, common barriers to establishing formal SUAs include insufficient partnerships between the school districts and collaborating community stakeholders and organizations, and inadequate capacity to navigate the development of a SUA (Jones \& Wendel, 2015). To access the built environment well-formed community-school partnerships can aid in facilitating buy-in, participation, and collaboration from the community. Utilizing the skill set of the community members can assist in navigating barriers, and provide a diverse skill set and expertise in many areas: built environment, design, wellness, policy, and law. (Hansen et al., 2015). There is value in creating a formal SUA as it brings together vested members of the community and important decision makers at the school, district and local government levels. It promotes an environment where partners can get down to details and make a SUA actionable.

Partnership Characteristics. Every community-school partnership will vary with each school and community's individual climate, location, structure, and need. However, Epstein 
(1995) proposes that successful partnerships have commonalities. In a study Lucidarme, Marlier,

Cardon, De Bourdeaudhuij, \& Willem (2014) examined factors linked to successful policy implementation in 13 community partnerships. The characteristics found to be most influential were: having a written formal agreement, strong political support, vested partners, regular communication and dedicated, and supportive leadership. These findings imply that much consideration should be given to who makes up the partnership as the various members that form the partnerships are linked to the success of an initiative.

For partnerships to be forged and action to take place, there must be leadership or a community champion that can create some political momentum around the need for increased access to exercise opportunities. "A school-community partnership model requires a different kind of school leadership, a type of leadership that will let go of traditional and behavioral models and embrace those that are relational and can build on the school community's own sense of place” (Bauch, 2001, p. 205). Leadership is a critical factor in a successful partnership. In order to foster enduring sustainable partnerships, leaders must demonstrate ownership, flexibility, mentorship, and strive to create a culture of mutual accountability (Bors et al., 2009). Embracing a community health focused agenda can create a new partnership and increase the impact on multi-level change. There is a need for insight into the creation of partnerships with a community health and physical activity policy agenda.

\section{Theoretical Frameworks}

Social Ecological Model. An ecological approach allows for the consideration of multiple levels of influence: political, environmental, and social. Change throughout the multiple levels will lead to changes at the individual level within the target population (McLeroy et al., 1988). An increase in the interest of ecological models has been seen within health promotion 
research as ecological models are a guide to population-wide approaches to changing behavior (Brownson, Hopkins, \& Wakefield, 2002; Cochrane \& Davey, 2008; Richard, Gauvin, \& Raine, 2011; James F. Sallis et al., 2006). The ecological model provides the framework for the Healthy People 2020 national objectives (USHHS, 2016) and for the IOM reports on health behavior (Institute of Medicine, 2001).

Rudolph Moos (1980) introduced the social ecological perspective outlining four categories of environmental factors that can affect behavior: the physical setting, organization setting, sociocultural characteristics, and social climate. When applying the Social Ecological Model (SEM), policies and environments that support positive choices will lead to positive behavior change. Within the SEM it is assumed "appropriate changes in the social environment will produce changes in individuals, and that the support of individuals in the population is essential for implementing environmental changes" (McLeroy et al., 1988, p. 351). Based on the assumptions of the SEM, individual level involvement of school administrators and community partners are key agents in influencing change. The community-school partnership is formed and actions are taken to utilize policy to create a formal SUA. The SUA when implemented spurs environmental change through increased access to school recreational spaces, social change as familiar places for physical activity are now available, and ultimately individual level change through increases in physical activity levels. The combined effects of change at the SEM policy environment, and social levels may result in individual behavior change.

Four core principles guide the application of ecological models on individual health behavior (Stokols, 1992). First, health behavior is influenced by physical and social environments as well as personal attributes. Second, environments are multidimensional. Third, individuals influence their settings, and the change in the setting can have a positive or negative 
influence on the health behavior of the individual. Lastly, human-environment interactions vary across different levels (i.e. individual, family, culture, and the whole population). The goal of the SEM is to guide the development and implementation of an initiative to target change at multiple levels of influence. To adapt to the complexity of public health, policy and strategies utilized had to become multi-dimensional, incorporate multiple sectors, and recognize the importance of health promotion and sustainability (Bull et al., 2004).

The use of ecological models has become widely accepted as is evident in the review of national physical activity plans for six countries. Bornstein, Pate, \& Pratt (2009) found one of the essential components to a physical activity plan was to ensure implementation across multiple levels. Many studies have applied the SEM to investigate physical activity in the various environments including schools, parks, and community sidewalks (Gentile et al., 2009; Langille \& Rodgers, 2010; McNeill, Kreuter, \& Subramanian, 2006; Robertson-Wilson, Leatherdale, \& Wong, 2008). In the local context, ecological models have been used to guide community-based physical activity interventions. An ecological framework called the 5Ps (i.e. preparation, promotions, programs, policy, and physical projects) was implemented in 25 U.S. communities. Each community used the 5Ps to create community partnerships and environments that were supportive of active living (Bors et al., 2009).

In examining school-based physical activity efforts, Langille \& Rodgers (2010) used stakeholders perspectives to provide insight on how each level within a school can influence the environment and access to physical activity opportunities. The main conclusions suggest higher level policies do "trickle down," but the decisions made at school level guide how the implementation of physical activity strategies will occur. A case study of Action Schools! BC used an ecological approach to examine the local and provincial levels of influence on children's 
health within the school setting (Naylor, Macdonald, Reed, \& Mckay, 2006). The results of this study indicated health behaviors improved due to influencing factors of knowledge, political will, and public interest. However, these findings are limited as the focus was only at the school level.

The SEM represents behavior change as an interdependence between the policy, environmental, and social levels. To promote change, each level must offer supportive conditions to achieve the desired change. The individuals, community, environment and characteristics of the local context must be considered for an intervention to be effective. (Green et al., 1996; Stokols, 1996). If individuals within the county level administration, school level administration, or school board do not place importance on physical activity and access to physical activity opportunities, the creation and implementation of a formal SUA will be inhibited regardless of the buy-in from community leaders. The SEM informs this study by guiding the examination of local level characteristics (i.e. policy, built environment, community and school characteristics, and support structures) in the community-school setting that affect the development and implementation of SUA.

Contextual Interaction Theory. Policy is a people-dependent process. The characteristics of the individuals and partnerships involved in the process are the primary forces driving forward an initiative through each level of the SEM. Layering SEM with the Contextual Interaction Theory (CIT) offers a deductive, social process approach that considers several contextual constructs and the interaction between the implementers and the target population (O'Toole, 2004). The underlying assumption of the CIT is that the outcome of a policy depends on the implementers' characteristics carrying out the policy strategies, not just the policy development and decision-making (Bressers, 2004). 
CIT distinguishes four core constructs that jointly contribute to the implementation of policy like a SUA: motivation, knowledge, power, and interaction (Spratt, 2009). The motivation construct seeks to identify the level of importance an implementer places on a particular policy and if that policy aligns with one's own goals and interests (Boer \& Bressers, 2011). For example, an involved parent who highly values daily physical activity may be a key member in community-school partnership to implement shared use. The knowledge construct seeks to understand if the people involved have sufficient knowledge to carry out their tasks and implement the policy. Knowledge is not only the technical awareness of the policy, guidelines or procedure steps but also the relational knowledge of how to interact and communicate within a partnership setting (Spratt, 2009). For instance, do implementers understand the culture and processes of the other organizations working together? Does the local government understand how the education system operates? Does the community member understand what the local government can offer to aid the process? Who is responsible for coordinating the communication of information? How is information communicated? The construct of power addresses the relationship between power and resources. Who has been empowered to implement a policy and to what extent? Power can be thought of formally like rules, legal rights or other governing guidelines or informally like money, skills, time, and consensus (Boer \& Bressers, 2011). "In most interactive processes, informal sources of power may be highly important and, in many cases, can balance the more formal power of implementing authorities" (Spratt, 2009, p. 3). Interaction is the last construct. How the implementers interact determines the level the collaboration and cooperation which influences the quality of the policy implementation. The interaction between the implementers is a key step in the Massachusetts Community Use Toolkit 
and should be examined to understand how barriers to SUAs are overcome and facilitators are leveraged.

The constructs affecting collaborative implementation as in a community-school partnership are different from traditional policy implementation (Koontz \& Newig, 2014). By operationalizing an ecological framework integrated with the CIT, all levels that have the potential to influence behavior as well as the interaction between the individual and the context can be addressed. Haggis, Sims-Gould, Winters, Gutteridge, \& McKay (2013) recommended narrowing the focus to a few levels and utilizing relationships within those levels to target a change. The use of the SEM coupled with the CIT allows for the examination of the interplay of several constructs unique to the collaborative implementation of an SUA across multiple levels of policy, environment and sociocultural.

\section{Summary}

Health-related public policy research has begun to turn its focus to examine how the environment can be changed to target population level physical activity. Shared use has reemerged as a solution to increase physical activity levels by granting access to school recreational facilities outside of school hours. The existing shared use literature is primarily focused on the outcomes of a SUA related to physical activity levels and usage (Choy et al., 2008; Kanters, Bocarro, Filardo, et al., 2014; Spengler, 2012) or the barriers and facilitators to shared use (Burbage et al., 2014; Omura et al., 2016; Spengler et al., 2011; Umstattd Meyer et al., 2016). Little research exists that examines the process a school and community must complete to create and implement a SUA. In an American Heart Association (AHA) policy statement addressing shared use, Young et al. (2004) calls for future research to "identify best approaches through case studies examining characteristics of successful schools, school districts, 
and community groups" (p. 1587). Few resources exist to guide the shared use process (Filardo et al., 2010), creating a need for future research to identify common strategies utilized by community-school partnerships in the development and implementation of SUAs.

Since the Shared Use Bill passed in 2015, WV schools can more confidently open their recreational spaces for community use because of the bill's limited liability protection. However, how a school chooses to share their facility can vary greatly. The schools are free to develop their own shared use process, identify promising community partnerships, and create risk management and cost-saving strategies that will fit their context. Considering the characteristics of community-school partnerships, the shared use process provides an opportunity to examine successful features of the partnership that are common to the implementation of shared use policy in WV public schools to increase access to physical activity opportunities for schools and communities. 


\section{References}

American Dietetic Association. (2006). Position of the American Dietetic Association:

Individual-, Family-, School-, and Community-Based Interventions for Pediatric

Overweight. Journal of the American Dietetic Association, 106(6), 925-945.

http://doi.org/10.1016/j.jada.2006.03.001

Anderson, T. K., Stodolska, M., \& Gobster, P. (2006). Environmental Preferences and the Use of Natural Areas for Physical Activity among Hispanic Residents.

Anfara, V. A., J. (2008). Visual data displays. In L. M. Given (Ed.), The Sage encyclopedia of qualitative research methods (p. Vol. 2, pp. 930-934). Thousand Oaks, CA: SAGE.

Barbeau, P., Johnson, M. H., Howe, C. A., Allison, J., Davis, C. L., Gutin, B., \& Lemmon, C. R. (2007). Ten months of exercise improves general and visceral adiposity, bone, and fitness in black girls. Obesity, 15(8), 2077-2085. http://doi.org/10.1038/oby.2007.247

Bassett, D. R., Fitzhugh, E. C., Heath, G. W., Erwin, P. C., Frederick, G. M., Wolff, D. L., ... Stout, A. B. (2013). Estimated energy expenditures for school-based policies and active living. American Journal of Preventive Medicine, 44(2), 108-113. http://doi.org/10.1016/j.amepre.2012.10.017

Bauch, P. A. (2001). School-community partnerships in rural schools: Leadership, renewal and a sense of place. Peabody Journal of Education, 76(2), 204-221. http://doi.org/10.1207/S15327930pje7602

Bauman, P. C. (1996). Governing education: Public sector reform or privatization. Boston, MA: Allyn and Bacon.

Beets, M. W., Beighle, A., Erwin, H. E., \& Huberty, J. L. (2009). After-School Program Impact on Physical Activity and Fitness. A Meta-Analysis. American Journal of Preventive 
Medicine, 36(6), 527-537. http://doi.org/10.1016/j.amepre.2009.01.033

Beets W., M., Huberty, J., Beighle, A., Moore B., J., Webster, C., Ajja, R., \& Weaver, G. (2013). Impact of Policy Environment Characteristics on Physical Activity and Sedentary Behaviors of Children Attending Afterschool Programs. Health Education \& Behavior, 40(3), 296304. http://doi.org/10.1177/1090198112459051

Bezold, C. P., Konty, K. J., Day, S. E., Berger, M., Harr, L., Larkin, M., ... Stark, J. H. (2014). The effects of changes in physical fitness on academic performance among New York City youth. Journal of Adolescent Health, 55(6), 774-781. http://doi.org/10.1016/j.jadohealth.2014.06.006

Boer, C. D., \& Bressers, H. (2011). Contextual interaction theory as a conceptual lens on complex and dynamic implementation processes. Challenges of Making Public Administration and Complexity Theory Work, (2009), 1-39.

Bornstein, D. B., Pate, R. R., \& Pratt, M. (2009). A review of the national physical activity plans of six countries. Journal of Physical Activity and Health, 6(Suppl 2), S245-64. Retrieved from http://www.ncbi.nlm.nih.gov/pubmed/20120133

Bors, P., Dessauer, M., Bell, R., Wilkerson, R., Lee, J., \& Strunk, S. L. (2009). The active living by design national program: Community initiatives and lessons learned. American Journal of Preventive Medicine, 37(6 SUPPL. 2), S313-S321. http://doi.org/10.1016/j.amepre.2009.09.027

Braun, V., \& Clarke, V. (2006). Using thematic analysis in psychology. Qualitative Research in Psychology, 3(2), 77-101. http://doi.org/10.1191/1478088706qp063oa

Bressers, H. (2004). Implementing sustainable development: How to know what works, where, when and how. In W. M. Lafferty (Ed.), Governance for Sustainable Development: The 
Challenge of Adapting Form to Function (pp. 284-318). Northhampton, MA: Edward Elgar Publishing, Inc.

Brownson, R. C., Haire-Joshu, D., \& Luke, D. A. (2006). Shaping the context of health: A review of environmental and policy approaches in the prevention of chronic diseases. Annual Review of Public Health, 27(1), 341-370.

http://doi.org/10.1146/annurev.publhealth.27.021405.102137

Brownson, R. C., Hopkins, D. P., \& Wakefield, M. A. (2002). Effects of smoking restrictions in the workplace. Annual Review of Public Health, 23, 333-348. http://doi.org/10.1146/annurev.publhealth.23.100901.140551

Brownson, R. C., Kelly, C. M., Eyler, A. A, Carnoske, C., Grost, L., Handy, S. L., ... Schmid, T. L. (2008). Environmental and policy approaches for promoting physical activity in the United States: a research agenda. Journal of Physical Activity $\{\&\}$ Health, 5(4), 488-503.

Bryant, C. A., Courtney, A. H., McDermott, R. J., Alfonso, M. L., Baldwin, J. A., Nickelson, J., ... Zhu, Y. (2010). Promoting physical activity among youth through community-based prevention marketing. Journal of School Health, 80(5), 214-224.

Bulger, S. M., Elliott, E., Jones, E., Fitzpatrick, S., Jones, D., O’Hara Tompkins, N., \& Olfert, M. (2015). ActiveWV 2015 West Virginia Physical Activity Plan, 1-44.

Bull, F. C., Bellew, B., Schöppe, S., \& Bauman, A. E. (2004). Developments in National Physical Activity Policy: an international review and recommendations towards better practice. Journal of Science and Medicine in Sport, 7(1), 93-104. http://doi.org/10.1016/S1440-2440(04)80283-4

Burbage, L., Gonzalez, E., Dunning, L., Simon, P., \& Kuo, T. (2014). Building mutually beneficial partnerships to improve physical activity opportunities through shared-use efforts 
in under-resourced communities in Los Angeles County. Preventive Medicine, 67(S1), S4S9. http://doi.org/10.1016/j.ypmed.2014.01.001

Butt, M. (1993). What do superintendents do to turn vision inot action? A biography of pragmatic visionaries. University of La Verne, La Verne, CA.

Cal Ed Code 10900 (2006).

Cardon, G. M., Van Acker, R., Seghers, J., De Martelaer, K., Haerens, L. L., \& De Bourdeaudhuij, I. M. M. (2012). Physical activity promotion in schools: Which strategies do schools (not) implement and which socioecological factors are associated with implementation? Health Education Research, 27(3), 470-483. http://doi.org/10.1093/her/cys043

Carlton, T. A., Kanters, M. A., Bocarro, J. N., Floyd, M. F., Edwards, M. B., \& Suau, L. J. (2016). Shared use agreements and leisure time physical activity in North Carolina public schools. Preventive Medicine. http://doi.org/10.1016/j.ypmed.2016.08.037

Center for Community Health and Development. (2017). Using Community Sectors to Reach Targets and Agents of Change. Retrieved September 2, 2017, from http://ctb.ku.edu/en/table-of-contents/analyze/where-to-start/community-sectors/main

Centers for Disease Control and Prevention. (2014). State Indicator Report on Physical Activity. Centers for Disease Control and Prevention. (2015a). Comprehensive school physical activity programs : A guide for schools. Atlanta, GA.

Centers for Disease Control and Prevention. (2015b). Trends in the Prevalence of Physical Activity and Sedentary Behaviors National YRBS : 1991 - 2015.

Choy, L. B., McGurk, M. D., Tamashiro, R., Nett, B., \& Maddock, J. (2008). Increasing access to places for physical activity through a joint use agreement: a case study in urban 
Honolulu. Preventing Chronic Disease, 5(3), A91. http://doi.org/A91 [pii]

Cochrane, T., \& Davey, R. C. (2008). Increasing uptake of physical activity: a social ecological approach. Perspectives in Public Health, 128(1), 31-40. http://doi.org/http://dx.doi.org/10.1177/1466424007085223

Cooper, T., \& Vincent, J. M. (2008). Joint Use School Partnerships in California : Public Health Law and Policy ( PHLP ). Retrieved from http://citiesandschools.berkeley.edu/reports/CCS_PHLP_2008_joint_use.pdf

Dishman, R. K., Motl, R. W., Saunders, R., Felton, G., Ward, D. S., Dowda, M., \& Pate, R. R. (2004). Self-efficacy partially mediates the effect of a school-based physical-activity intervention among adolescent girls. Preventive Medicine, 38(5), 628-636. http://doi.org/10.1016/j.ypmed.2003.12.007

Donnelly, J. E., Hillman, C. H., Castelli, D., Etnier, J. L., Lee, S., Tomporowski, P., ... SzaboReed, A. N. (2016). Physical activity, fitness, cognitive function, and academic achievement in children: A systematic review. Medicine and Science in Sports and Exercise, 48(6), 1197-1222. http://doi.org/10.1249/MSS.0000000000000901

Downer, S., Fields, J., Rothman, Z., Lopinsky, T., Strochlic, B., Fishwick, L., \& Broad Leib, E. (2016). The Massachusetts Community Use Toolkit.

Dunton, G. F., Cousineau, M., \& Reynolds, K. D. (2010). The intersection of public policy and health behavior theory in the physical activity arena. Journal of Physical Activity \& Health, 7 Suppl 1(Suppl 1), S91-S98.

Epstein, J. L. (1995). Family-School-Community Partnerships. Phi Delta Kappan, 76(9), 701. Esteban-Cornejo, I., Tejero-González, C. M., Martinez-Gomez, D., Del-Campo, J., GonzálezGalo, A., Padilla-Moledo, C., ... Veiga, O. L. (2014). Independent and combined influence 
of the components of physical fitness on academic performance in youth. Journal of Pediatrics, 165(2). http://doi.org/10.1016/j.jpeds.2014.04.044

Evenson, K. R., \& McGinn, A. P. (2004). Availability of school physical activity facilities to the public in four U.S. communities. American Journal of Health Promotion, 18(3), 243-250. Retrieved from http://search.ebscohost.com/login.aspx?direct=true\&db=rzh\&AN=106747983\&site=ehostlive

Evenson, K. R., Wen, F., Lee, S. M., Heinrich, K. M., \& Eyler, A. (2010). National study of changes in community access to school physical activity facilities: The school health policies and programs study. Journal of Physical Activity and Health, 7(Suppl 1), S20-S30. Retrieved from http://www.embase.com/search/results?subaction=viewrecord\&from=export\&id=L3584242 08\%5Cnhttp://hk.humankinetics.com/eJournalMedia/pdfs/17895.pdf

Filardo, M., Vincent, J. M., Allen, M., \& Franklin, J. (2010). Joint use of public schools: A framework for a new social contract. Washington, DC.

Fox, K. R. (1999). The influence of physical activity on mental well-being. Public Health Nutrition, 2(3a), 411-418. http://doi.org/10.1017/S1368980099000567

Gentile, D. A., Welk, G., Eisenmann, J. C., Reimer, R. A., Walsh, D. A., Russell, D. W., ... Fritz, K. (2009). Evaluation of a multiple ecological level child obesity prevention program: Switch ${ }^{\circledR}$ what you Do, View, and Chew. BMC Medicine, 7(7). http://doi.org/10.1186/1741-7015-7-49

Geraghty, A. B., Seifert, W., Preston, T., Holm, C. V., Duarte, T. H., \& Farrar, S. M. (2009). Partnership moves community toward complete streets. American Journal of Preventive 
Medicine, 37(6 SUPPL. 2), S420-S427. http://doi.org/10.1016/j.amepre.2009.09.009

Green, L. W., Richard, L., \& Potvin, L. (1996). Ecological Foundations of Health Promotion. American Journal of Health Promotion, 10(4), 270-281.

Gutin, B., Yin, Z., Johnson, M., \& Barbeau, P. (2008). Preliminary findings of the effect of a 3year after-school physical activity intervention on fitness and body fat: the Medical College of Georgia Fitkid Project. International Journal of Pediatric Obesity : IJPO : An Official Journal of the International Association for the Study of Obesity, 3 Suppl 1, 3-9. http://doi.org/10.1080/17477160801896457

Haggis, C., Sims-Gould, J., Winters, M., Gutteridge, K., \& McKay, H. A. (2013). Sustained impact of community-based physical activity interventions: key elements for success. $B M C$ Public Health, 13(1), 892. http://doi.org/10.1186/1471-2458-13-892

Hansen, A. Y., Meyer, M. R., \& Lenardson, J. D. (2015). Built environments and active living in rural and remote areas: A review of the literature. Current Obesity Reports, 4(4), 484-493. http://doi.org/10.1007/s13679-015-0180-9

Hanson, J. (2013). Playground and recreation association of America (1925). The beginning of the recreation movement in the United States. Retrieved June 5, 2017, from http://socialwelfare.library.vcu.edu/youth/recreation-movement-in-the-united-states/

Haskell, W. L., Lee, I. M., Pate, R. R., Powell, K. E., \& Blair, S. N. (2007). Physical activity and public health: Updated recommendation for adults from the American college of sports medicine and the American heart association. Retrieved November 20, 2015, from http://scholarcommons.sc.edu/cgi/viewcontent.cgi?article=1117\&context=sph_physical_act ivity_public_health_facpub

Hillman, C. H., Erickson, K. I., \& Kramer, A. F. (2008). Be smart, exercise your heart: exercise 
effects on brain and cognition. Nature, 9, 58-65. http://doi.org/10.1038/nrn2298

Hillman, C., Motl, R., \& Pontifex, M. (2006). Physical activity and cognitive function in a crosssection of younger and older community-dwelling individuals. Health Psychology, 25, 678687.

Howie, E. K., Beets, M. W., \& Pate, R. R. (2014). Acute classroom exercise breaks improve ontask behavior in 4th and 5th grade students: A dose-response. Mental Health and Physical Activity, 7(2), 65-71. http://doi.org/10.1016/j.mhpa.2014.05.002

Huberty, J. L., Balluff, M., O’Dell, M., \& Peterson, K. (2010). From good ideas to actions: A model-driven community collaborative to prevent childhood obesity. Preventive Medicine, 50(SUPPL.), S36-S43. http://doi.org/10.1016/j.ypmed.2009.08.013

Humpel, N., Owen, N., \& Leslie, E. (2002). Environmental factors associated with adults' participation in physical activity A review. American Journal of Preventive Medicine, 22(3), 188-199. http://doi.org/10.1016/S0749-3797(01)00426-3

Institute of Medicine. (1988). The Future of Public Health. Institute of Medicine (US) (Vol. 33). Washington, DC: National Academy Press. http://doi.org/10.1093/pubmed/fdr063

Institute of Medicine. (2001). Health and Behavior: The Interplay of Biological, Behavioral, and Societal Influences. Washington, DC: National Academies Press. http://doi.org/10.17226/9838

Janssen, M., Chinapaw, M. J. M., Rauh, S. P., Toussaint, H. M., Van Mechelen, W., \& Verhagen, E. A. L. M. (2014). A short physical activity break from cognitive tasks increases selective attention in primary school children aged 10-11. Mental Health and Physical Activity, 7(3), 129-134. http://doi.org/10.1016/j.mhpa.2014.07.001

Jones, S. E., \& Wendel, A. M. (2015). Characteristics of joint use agreements in school districts 
in the United States: findings from the School Health Policies and Practices Study, 2012. Preventing Chronic Disease, 12, E50. http://doi.org/10.5888/pcd12.140560

Kahn, E., Ramsey, L., Brownson, R., Heath, G., Howze, E., Powell, K., ... Corso, P. (2002). The effectiveness of interventions to increase physical activity: A systematic review. American Journal of Preventive Medicine, 22(4), 73-107. http://doi.org/10.1016/S07493797(02)00434-8

Kanters, M. A., Bocarro, J. N., Filardo, M., Edwards, M. B., Mckenzie, T. L., \& Floyd, M. F. (2014). Shared use of school facilities with community organizations and afterschool physical activity program participation: A cost-benefit assessment. Journal of School Health, 84(5), 302-309. http://doi.org/10.1111/josh.12148

Kanters, M. A., Bocarro, J. N., Moore, R., Floyd, M. F., \& Carlton, T. A. (2014). Afterschool shared use of public school facilities for physical activity in North Carolina. Preventive Medicine, 69(S), S44-S48. http://doi.org/10.1016/j.ypmed.2014.10.003

Kohl, H. W. (2001). Physical activity and cardiovascular disease: evidence for a dose response. Medicine and Science in Sports and Exercise, 33, S472-S483.

Kohl, H. W., Craig, C. L., Lambert, E. V., Inoue, S., Alkandari, J. R., Leetongin, G., \& Kahlmeier, S. (2012). The pandemic of physical inactivity: global action for public health. The Lancet, 380(9838), 294-305. http://doi.org/10.1016/S0140-6736(12)60898-8

Koontz, T. M., \& Newig, J. (2014). From Planning to Implementation: Top-Down and BottomUp Approaches for Collaborative Watershed Management. Policy Studies Journal, 42(3), 416-442. http://doi.org/10.1111/psj.12067

Kramer, A., Hahn, S., \& McAuley, E. (2001). Exercise, aging and cognition: Healthy body, healthy mind? (A. D. Fisk \& W. Rogers, Eds.), Human Factors Interventions for the Health 
Care of Older Adults. Hillsdale, NJ: Erlbaum.

Kraus, R. G. (1964). Recreation and the Schools: Guides to Effective Practices in Leisure Education and Community Recreation Sponsorship. New York City, New York: MacMillan Co.

Kristjansson, A. L., Elliott, E., Bulger, S., Jones, E., Taliaferro, A. R., \& Neal, W. (2015). Needs assessment of school and community physical activity opportunities in rural West Virginia: the McDowell CHOICES planning effort. BMC Public Health, 15(315), 1-10. http://doi.org/10.1186/s12889-015-1702-9

Krueger, R. A., \& Casey, M. A. (2009). Participants in a Focus Group. Focus Groups: A Practical Guide for Applied Research, 63-84. Retrieved from https://www.sagepub.com/sites/default/files/upm-binaries/24056_Chapter4.pdf

Lafleur, M., Gonzalez, E., Schwarte, L., Banthia, R., Kuo, T., Verderber, J., \& Simon, P. (2013). Increasing physical activity in under-resourced communities through school-based, jointuse agreements, Los Angeles County, 2010-2012. Preventing Chronic Disease, 10(6), E89. http://doi.org/10.5888/pcd10.120270

Langille, J. L., \& Rodgers, W. M. (2010). Exploring the influence of a social ecological model on school-based physical activity. Health Education \& Behavior, 37(6), 879-894. http://doi.org/10.1177/1090198110367877

Lee, I. M., Hsieh, C., \& Paffenbarger JR, R. (1995). Exercise intensity and longevigty in men: The Harvard alumni health study. The Journal of the American Medical Association, 273(15), 1179-1184.

Lee, I., \& Paffenbarger, R. (2000). Associations of light, moderate, and vigorous intensity physical activity with longevity The Harvard Alumni Health Study. American Journal of 
Epidemiology, 151(3), 293-299.

Lee, S. M., Nihiser, A., Strouse, D., Das, B., Michael, S., \& Huhman, M. (2010). Correlates of Children and Parents Being Physically Active Together. Journal of Physical Activity and Health, 7, 776-783.

Levin, H. M. (1999). The Public-Private Nexus in Education. American Behavioral Scientist, 43(1), 124-137. http://doi.org/10.1177/00027649921955191

Lewallen, T. C., Hunt, H., Potts-Datema, W., Zaza, S., \& Giles, W. (2015). The Whole School, Whole Community, Whole Child Model: A New Approach for Improving Educational Attainment and Healthy Development for Students. Journal of School Health, 85(11), 729739. http://doi.org/10.1111/josh.12310

Leyden, K. M., Reger-Nash, B., Bauman, A., \& Bias, T. (2008). Changing the hearts and minds of policy makers: An exploratory study associated with the West Virginia Walks campaign. American Journal of Health Promotion, 22(3), 204-207. http://doi.org/10.4278/ajhp.22.3.204

Lucidarme, S., Marlier, M., Cardon, G., De Bourdeaudhuij, I., \& Willem, A. (2014). Critical success factors for physical activity promotion through community partnerships. International Journal of Public Health, 59(1), 51-60. http://doi.org/10.1007/s00038-013$0527-5$

Lyn, R., Aytur, S., Davis, T. A., Eyler, A. A., Evenson, K. R., Chriqui, J. F., .. Brownson, R. C. (2013). Policy, systems, and environmental approaches for obesity prevention: A framework to inform local and state action. Journal of Public Health Management and Practice, 19(3 Suppl 1), S23-S33. http://doi.org/10.1097/PHH.0b013e3182841709

Lynch, J. (2015). Sharing: Is one simple idea the solution to our physical activity dilemma? 
Retrieved June 5, 2017, from http://wvhub.org/sharing-is-one-simple-idea-the-solution-toour-physical-activity-dilemma/

Mâsse, L. C., McKay, H., Valente, M., Brant, R., \& Naylor, P. J. (2012). Physical activity implementation in schools: A 4-year follow-up. American Journal of Preventive Medicine, 43(4), 369-377. http://doi.org/10.1016/j.amepre.2012.06.010

McKenzie, T. L. (2016). Context Matters: Systematic Observation of Place-Based Physical Activity. Research Quarterly for Exercise and Sport, 1367(October), 1-8. http://doi.org/10.1080/02701367.2016.1234302

McLeroy, K. R., Bibeau, D., Steckler, A., \& Glanz, K. (1988). Ecological Perspective on Promotion Programs. Health Education Quarterly, 15(4), 351-377. http://doi.org/10.1177/109019818801500401

McNeill, L. H., Kreuter, M. W., \& Subramanian, S. V. (2006). Social Environment and Physical activity: A review of concepts and evidence. Social Science and Medicine, 63(4), 10111022. http://doi.org/10.1016/j.socscimed.2006.03.012

Merriam, S. B. (2009). Qualitative Research A Guide to Design and Implementation (1st ed.). San Francisco: CA: Jossey-Bass.

Meyer, H. D., \& Brightbill, C. K. (1964). Community Recreation: A Guide to Its Organization, Third Edit, 1892-1974.

Moore, L. L., Gao, D., Bradlee, M. L., Cupples, L. A., Sundarajan-Ramamurti, A., Proctor, M. H., ... Ellison, R. C. (2003). Does early physical activity predict body fat change throughout childhood? Preventive Medicine, 37(1), 10-17. http://doi.org/10.1016/S00917435(03)00048-3

Moos, R. H. (1980). Social-ecological perspectives on health. In G. C. Stone, F. Cohen, \& N. E. 
Adler (Eds.), Health Psychology: A Handbook. San Francisco: CA: Jossey-Bass.

Mowen, A. J., \& Baker, B. L. (2009). Park, recreation, fitness, and sport sector recommendations for a more physically active america: a white paper for the United States national physical activity plan. Journal of Physical Activity \& Health, 6 Suppl 2(Suppl 2), S236-S244.

Mutrie, N., \& Woods, C. B. (2003). How can we get people to become more active? A problem waiting to be resolved. In J. McKenna \& C. Riddoch (Eds.), Perspectives on Health and Exercise (1st ed., pp. 129-152). Basingstoke, UK: Palgrave Macmillam.

Nasmith, L., Cote, B., Cox, J., Inkell, D., Rubenstein, H., Jimenez, V., ... Contandriopoulus, A.P. (2004). The challenge of promoting integration: conceptualization, implementation, and assessment of a pilot care delivery model for patients with Type 2 Diabetes. Family Medicine, 36, 40-45.

National Physical Activity Plan Alliance. (2016). U.S. National Physical Activity Plan. Columbia, SC.

Naylor, P. J., Macdonald, H., Reed, K., \& Mckay, H. (2006). Action Schools! BC: A Socioecological Approach to Modifying Chronic Disease Risk Factors in Elementary School Children. Preventing Chronic Disease, 3(2).

NY CLS Ed 414 (2006).

O'Hara Tompkins, N., Zizzi, S., Zedosky, L., Wright, J., \& Vitullo, E. (2004). School-based opportunities for physical activity in West Virginia public schools. Preventive Medicine, 39(4), 834-840. http://doi.org/10.1016/j.ypmed.2004.03.014

Oguma, Y., \& Sesso, H. (2002). Physical activity and all cause mortality in women: a review of the evidence. British Journal of Sports ....

Omura, J. D., Carlson, S. A., Paul, P., Sliwa, S., Onufrak, S. J., \& Fulton, J. E. (2016). Shared 
use agreements between municipalities and public schools in the United States, 2014. Preventive Medicine. http://doi.org/10.1016/j.ypmed.2016.09.026

Ornelas, I. J., Perreira, K. M., \& Ayala, G. X. (2007). Parental influences on adolescent physical activity : a longitudinal study, 10, 1-10. http://doi.org/10.1186/1479-5868-4-3

Paluska, S. A., \& Schwenk, T. L. (2000). Physical Activity and Mental Health Current Concepts. Sports Medicine, 29(3), 167-180.

Poortinga, W. (2006). Perceptions of the environment, physical activity, and obesity. Social Science \& Medicine, 63(11), 2835-2846. http://doi.org/10.1016/j.socscimed.2006.07.018

Public Health Law Center at William Mitchell College of Law. (2012). Eliminating barriers for community recreational use of school property: Policy guidance on liability and shared use.

Reiner, M., Niermann, C., Jekauc, D., \& Woll, A. (2013). Long-term health benefits of physical activity - a systematic review of longitudinal studies, 1-9. http://doi.org/10.1186/14712458-13-813

Richard, L., Gauvin, L., \& Raine, K. (2011). Ecological models revisited: their uses and evolution in health promotion over two decades. Annual Review of Public Health, 32, 307326. http://doi.org/10.1146/annurev-publhealth-031210-101141

Robertson-Wilson, J. E., Leatherdale, S. T., \& Wong, S. L. (2008). Social-Ecological Correlates of Active Commuting to School Among High School Students. Journal of Adolescent Health, 42(5), 486-495. http://doi.org/10.1016/j.jadohealth.2007.10.006

Roussos, S. T., \& Fawcett, S. B. (2000). A review of collaborative partnerships a strategy for improving community healh. Annual Review of Public Health, 21(2), 369-402.

RS Mo 67.775 (2006).

Rütten, A., Abu-Omar, K., Gelius, P., Dinan-Young, S., Frandin, K., Hopman-Rock, M., \& 
Young, A. (2012). Policy assessment and policy development for physical activity promotion: results of an exploratory intervention study in 15 European Nations. Retrieved November 19, 2015, from http://www.health-policy-systems.com/content/pdf/1478-450510-14.pdf

Rütten, A., Abu-Omar, K., Gelius, P., \& Schow, D. (2013). Physical inactivity as a policy problem: applying a concept from policy analysis to a public health issue. Health Research Policy and Systems, 11(9), 1-9. http://doi.org/10.1186/1478-4505-11-9

S238. (2015). Assemb. Reg. Sess. (W.V. 2015).

Sacks, G., Swinburn, B. A., Lawrence, M. A., Seidell, J., Swinburn, B., Egger, G., ... Owen, N. (2008). A systematic policy approach to changing the food system and physical activity environments to prevent obesity. Australia and New Zealand Health Policy, 5(1), 13. http://doi.org/10.1186/1743-8462-5-13

Saldana, J. (2016). The coding manual for qualitative researchers. (J. Seaman, Ed.) (Third). Thousand Oaks, CA: SAGE Publications, Inc.

Sallis, J., Bauman, A., \& Pratt, M. (1998). Environmental and policy interventions to promote physical activity. American Journal of Preventive Medicine, 15(4), 379-397. http://doi.org/10.1016/S0749-3797(98)00076-2

Sallis, J. F., Cervero, R. B., Ascher, W., Henderson, K. A., Kraft, M. K., \& Kerr, J. (2006). an Ecological Approach To Creating Active Living Communities. Annual Review of Public Health, 27(1), 297-322. http://doi.org/10.1146/annurev.publhealth.27.021405.102100

Sallis, J. F., Conway, T. L., Prochaska, J. J., McKenzie, T. L., Marshall, S. J., \& Brown, M. (2001). The association of school environments with youth physical activity. American Journal of Public Health, 91(4), 618-620. http://doi.org/10.2105/ajph.91.4.618 
Schmid, T. L., Pratt, M., \& Howze, E. (1995). Policy as intervention: environmental and policy approaches to the prevention of cardiovascular disease. American Journal of Public Health, 85(9), 1207-1211. http://doi.org/10.2105/AJPH.85.9.1207

Schmid, T. L., Pratt, M., \& Witmer, L. (2006). A Framework for Physical Activity Policy Research. Journal of Physical Activity and Health, 3, 20-29.

Schultz, C. L., Wilhelm Stanis, S. A., Sayers, S. P., Thombs, L. A., \& Thomas, I. M. (2016). A longitudinal examination of improved access on park use and physical activity in a lowincome and majority African American neighborhood park. Preventive Medicine, 6-11. http://doi.org/10.1016/j.ypmed.2016.08.036

Simon, M. K., \& Goes, J. (2013). Scope of the study. Dissertation and Scholarly Research: Recipes for Success. http://doi.org/10.1080/02681309009414645

Smart Growth America. (2017). National Complete Streets Coalition. Retrieved March 13, 2017, from https://smartgrowthamerica.org/program/national-complete-streets-coalition/

Sothern, M. S., Loftin, M., Suskind, R. M., \& Udall, J. N. (1999). The health bene ${ }^{\circledR}$ ts of physical activity in children and adolescents : implications for chronic disease prevention. European Journal Pediatric, 158, 271-274. http://doi.org/10.1007/s004310051070

Spengler, J. O. (2012). Promoting Physical Activity through the Shared Use of School and Community Recreational Resources. Journal of Physical Activity and Health, 8208(352), 19.

Spengler, J. O., Carroll, M. S., Connaughton, D. P., \& Evenson, K. R. (2010). Policies to Promote the Community Use of Schools. A Review of State Recreational User Statutes. American Journal of Preventive Medicine, 39(1), 81-88. http://doi.org/10.1016/j.amepre.2010.02.019 
Spengler, J. O., Connaughton, D. P., \& Maddock, J. E. (2011). Liability concerns and shared use of school recreational facilities in underserved communities. American Journal of Preventive Medicine, 41(4), 415-420. http://doi.org/10.1016/j.amepre.2011.06.031

Spengler, J. O., Young, S. J., \& Linton, L. S. (2007). Schools as a community resource for physical activity: Legal considerations for decision makers. American Journal of Health Promotion, 21(4 SUPPL.), 390-396. http://doi.org/10.4278/0890-1171-21.4s.390

Spratt, K. (2009). Policy Implementation Barriers Analysis : Conceptual Framework and Pilot Test in Three Countries. Health Policy Initiative Task Order I, (October), 48.

Stein, A., Baldyga, W., Hilgendorf, A., Walker, J. G., Hewson, D., Rhew, L., \& Uskali, A. (2015). Challenges in Promoting Joint Use Agreements: Experiences From Community Transformation Grant Awardees in North Carolina, Illinois, and Wisconsin, 2011-2014. Preventing Chronic Disease, 12, 140457. http://doi.org/10.5888/pcd12.140457

Stillman, F. A., Hartman, A. M., Graubard, B. I., Gilpin, E. A., Murray, D. M., \& Gibson, J. T. (2003). Evaluation of the American Stop Smoking Study (ASSIST): A Report of Outcomes. Journal of the National Cancer Institute, 95(22), 1681-1691. http://doi.org/https://doi.org/10.1093/jnci/djg098

Stokols, D. (1992). Establishing and maintaining healthy environments. Toward a social ecology of health promotion. The American Psychologist, 47(1), 6-22. http://doi.org/10.1037/0003066X.47.1.6

Stokols, D. (1996). Translating social ecological theory into guidelines for community health promotion. Am J Health Promot, 10, 282-298. http://doi.org/10.4278/0890-1171-10.4.282 Task Force on Community Preventive Services. (2002). Recommendations to Increase Physical Activity in Communitites. American Journal of Preventive Medicine, 22(\$S), 67-72. 
http://doi.org/10.1016/S0749-3797(02)00433-6

Testa, K. C. (2000). Development of joint-use educational facility agreements between California public school districts and community entities: A cross-case analysis of strategic practices, barriers and supportive elements. University of La Verne.

Texas Local Gov’t Code 332.021 (2005).

THEHUBWV. (2016). Growth of Shared Use Agreements in West Virginia's Schools | S.O.C. Retrieved January 26, 2017, from https://stateofourcommunities.org/2016/09/14/growth-ofshared-use-agreements-in-west-virginias-schools/

Troiano, R. P., Berrigan, D., Dodd, K. W., Mâsse, L. C., Tilert, T., \& Mcdowell, M. (2008). Physical activity in the United States measured by accelerometer. Medicine and Science in Sports and Exercise, 40(1), 181-188. http://doi.org/10.1249/mss.0b013e31815a51b3

Tucker, S., Lanningham-Foster, L., Murphy, J., Olsen, G., Orth, K., Voss, J., ... Lohse, C. (2011). A school based community partnership for promoting healthy habits for life. Journal of Community Health, 36(3), 414-422. http://doi.org/10.1007/s10900-010-9323-9

Umstattd Meyer, M. R., Perry, C. K., Sumrall, J. C., Patterson, M. S., Walsh, S. M., Clendennen, S. C., ... Valko, C. (2016). Physical Activity-Related Policy and Environmental Strategies to Prevent Obesity in Rural Communities: A Systematic Review of the Literature, 20022013 . Preventing Chronic Disease, 13, E03. http://doi.org/10.5888/pcd13.150406 [doi] United States Board of Education. (n.d.). The Schools and Recreation Services. Washington, DC. United States Department of Health and Human Services. (2008). 2008 Physical Activity. Health (San Francisco).

United States Department of Health \& Human Services. (2016). Healthy People 2020 [Internet]. Retrieved March 8, 2017, from https://www.healthypeople.gov/2020/topics-objectives 
University of Wisconsion Population Health Institute. (2017). County Health Ranking \& Roadmaps. Retrieved March 21, 2017, from http://www.countyhealthrankings.org/

Vanhelst, J., Béghin, L., Duhamel, A., Manios, Y., Molnar, D., De Henauw, S., ... Gómez Lorente, J. J. (2016). Physical activity is associated with attention capacity in adolescents. Journal of Pediatrics, 168, 126-131. http://doi.org/10.1016/j.jpeds.2015.09.029

Vespa, J., Lewis, J. M., \& Kreider, R. M. (2013). America's Families and Living Arrangements : 2012 Population Characteristics. Retrieved from http://www.census.gov/prod/2013pubs/p20-570.pdf

Warburton, D. E. R., Nicol, C. W., \& Bredin, S. S. D. (2006). Health benefits of physical activity: the evidence. CMAJ : Canadian Medical Association Journal = Journal de l'Association Medicale Canadienne, 174(6), 801-809. http://doi.org/10.1503/cmaj.051351

Wofford, L. G. (2008). Systematic Review of Childhood Obesity Prevention. Journal of Pediatric Nursing, 23(1), 5-19. http://doi.org/10.1016/j.pedn.2007.07.006

Woods, C. B., \& Mutrie, N. (2012). Putting Physical Activity on the Policy Agenda. Quest, 64(2). http://doi.org/10.1080/00336297.2012.669318

World Health Organization (2010). Global recommendations on physical activity for health. Geneva: Switzerland. Retrieved from http://medcontent.metapress.com/index/A65RM03P4874243N.pdf\%5Cnhttp://scholar.googl e.com/scholar?hl=en\&btnG=Search\&q=intitle:Global+Recomendations+on+physical+activ ity+for+health\#0

Yin, R. K. (2014). Case Study Research Design and Methods (5th ed.). Thousand Oaks, CA: SAGE Publications, Inc.

Yin, Z., Gutin, B., Johnson, M. H., Hanes, J., Moore, J. B., Cavnar, M., ... Barbeau, P. (2005). 
An environmental approach to obesity prevention in children: Medical College of Georgia FitKid Project year 1 results. Obesity Research, 13(12), 2153-2161.

http://doi.org/10.1038/oby.2005.267

Young, D. R., Spengler, J. O., Frost, N., Evenson, K. R., Vincent, J. M., \& Whitsel, L. (2014).

Promoting physical activity through the shared use of school recreational spaces: A policy statement from the American heart association. American Journal of Public Health, 104(9), 1583-1588. http://doi.org/10.2105/AJPH.2013.301461 